University of South Florida

DIGITAL COMMONS

Digital Commons @ University of

@ UNIVERSITY OF SOUTH FLORIDA

South Florida

Marine Science Faculty Publications

College of Marine Science

1991

\title{
Tectonic Evolution of the Easter Microplate
}

David F. Naar

University of Hawaii, naar@usf.edu

R. N. Hey

Follow this and additional works at: https://digitalcommons.usf.edu/msc_facpub

Part of the Life Sciences Commons

\section{Scholar Commons Citation}

Naar, David F. and Hey, R. N., "Tectonic Evolution of the Easter Microplate" (1991). Marine Science Faculty Publications. 2239.

https://digitalcommons.usf.edu/msc_facpub/2239

This Article is brought to you for free and open access by the College of Marine Science at Digital Commons @ University of South Florida. It has been accepted for inclusion in Marine Science Faculty Publications by an authorized administrator of Digital Commons @ University of South Florida. For more information, please contact digitalcommons@usf.edu. 


\title{
Tectonic Evolution of the Easter Microplate
}

\author{
DAVID F. NAAR ${ }^{1}$ \\ Department of Marine Science, University of South Florida, St. Petersburg
}

\author{
R. N. HEY \\ School of Ocean and Earth Science and Technology, University of Hawaii, Honolulu
}

\begin{abstract}
The plate tectonic history of the Easter microplate has been reconstructed by "closing" the microplate in a series of steps using the Pacific-Nazca magnetic anomalies north and south of the microplate and the NUVEL 1 global plate motion model. After each step, the Easter microplate was rotated rigidly to match the Nazca and Pacific anomalies. Gaps and overlaps formed by this kinematic treatment indicate compressional and tensional deformation, respectively, and show that rigid plate motions are insufficient to explain the complete tectonic evolution. Analysis of the magnetic anomaly data was guided by contoured SeaMARC II, Sea Beam, and 3.5$\mathrm{kHz}$ bathymetry data and a lineament map derived from SeaMARC II side scan and Sea Beam bathymetry data The patterns of lineaments and bathymetric structures suggest that rotational deformation of the Nazca plate is the general mechanism that accommodates the space problems arising from transfer of the Nazca plate to the microplate and rapid rotation of the microplate against the Nazca plate. Similar but smaller amounts of deformation are predicted along the southem boundary of the microplate. Prior to the origin of the microplate, the East Pacific Rise (EPR) was offset in at least two places according to the older magnetic anomalies, yet there is no evidence of linear fracture zones within the sparse data set except for occasional small consistent changes in regional depth across these age offsets. The magnetic, bathymetry, and satellite altimetry data indicate that the microplate initially formed at (or perhaps southeast of) Easter Island near a left-lateral offset of the EPR sometime between anomaly 3 and 3'. The East Rift started propagating north from the present location of Easter Island at $\sim 4.5 \mathrm{Ma}$, which is $\sim 1.5 \mathrm{~m}$.y. earlier than previously proposed. However, the magnetic data that support this interpretation are sparse and complicated by recent volcanic flows and associated rough bathymetry west of Easter Island. The geometry of the microplate changes very rapidly during its evolution. At the initial stages of development, the microplate resembles a large propagating rift system, suggesting that deformation may have been occurring throughout most of its interior up to about $2.47 \mathrm{Ma}$. At this time, the length to width of overlap ratio of the two rifts reaches a value of 3 , the northward propagation slows down, the curved opening of the Southwest Rift becomes well established, and rigid rotation of the previously deformed transferred lithosphere probably starts to predominate. At this time, the offset distance between the two overlapped rifts starts to increase. Some time after $2.47 \mathrm{Ma}$ and before $1 \mathrm{Ma}$, the East Rift starts propagating northwestward, probably in response to the microplate rotation, and continues up until present. Also during this time period, the East Rift breaks into a series of northward propagating rifts, each propagating into the microplate interior, thereby transferning lithosphere from the microplate to the Nazca plate and reducing the total growth rate of the microplate.
\end{abstract}

\section{INTRODUCTION}

The Easter microplate is located along the very fast spreading Pacific-Nazca plate boundary where a large-scale reorganization is presently occurring (Figure 1). The Easter microplate is probably the best modern analog of how large-scale spreading center jumps occur. The microplate is located in a broad shallow region of the East Pacific Rise (EPR) just to the north of the fastest seafloor spreading currently in existence. There are broad chains of young seamounts extending east and west of the microplate making up the Easter/Sala y Gomez Seamount Chain and the Tuamotu Chain. Below this general broad shallow region, there are anomalously slow surface and shear wave velocities in the upper mantle [Woodhouse and Dziewonski, 1984] and a 0.6-s slowness minimum of $P K P$ travel times at the core-mantle

\footnotetext{
${ }^{1}$ Previously at School of Ocean and Earth Science and Technology University of Hawaii, Honolulu, and Scripps Institution of Oceanography, University of California, San Diego.

Copyright 1991 by the American Geophysical Union.
}

Paper number $90 \mathrm{JB} 02398$

0148-0227/91/90JB-02398\$05.00 boundary [Creager and Jordan, 1986], suggesting intensive mantle convection [Hey et al., 1985]. The summit of the East Rift of the microplate is the shallowest seafloor spreading axis along the entire EPR $(-2050 \mathrm{~m})$. Rocks from this area have anomalously high $\mathrm{He}(3 / 4), \mathrm{Sr}(87 / 86), \mathrm{La} / \mathrm{Sm}, \mathrm{Pb}(206 / 204$, 207/204, 208/204), and $\mathrm{Ra} / \mathrm{Th}(226 / 230)$ ratios, and low Nd (143/144) and Th (230/232) ratios [Craig et al., 1984; Macdougall and Tanzer, 1984; Schilling et al., 1985; Fontignie et al., 1986a, b; White et al., 1987; Poreda et al., 1988; Hanan and Schilling, 1989]. These geochemical ratios indicate a mantle component mixing with the normal mid-ocean ridge basalt (MORB). The source of this primitive enriched source has been attributed to a hotspot located somewhere east of the East Rift [Craig et al., 1984; Schilling et al., 1985; Poreda et al., 1988; Hanan and Schilling, 1989].

A plate is defined as a rigid piece of lithosphere surrounded by active boundaries. We use the word microplate to signify a smaller plate, while acknowledging the possibility of internal deformation and that the microplate may only exist during the time of the large-scale rift jump. Thus, the overlap region, the area within the active boundaries of the microplate, is not necessarily a small plate. Presently, it appears that the Easter microplate consists of rigid lithosphere formed by the 


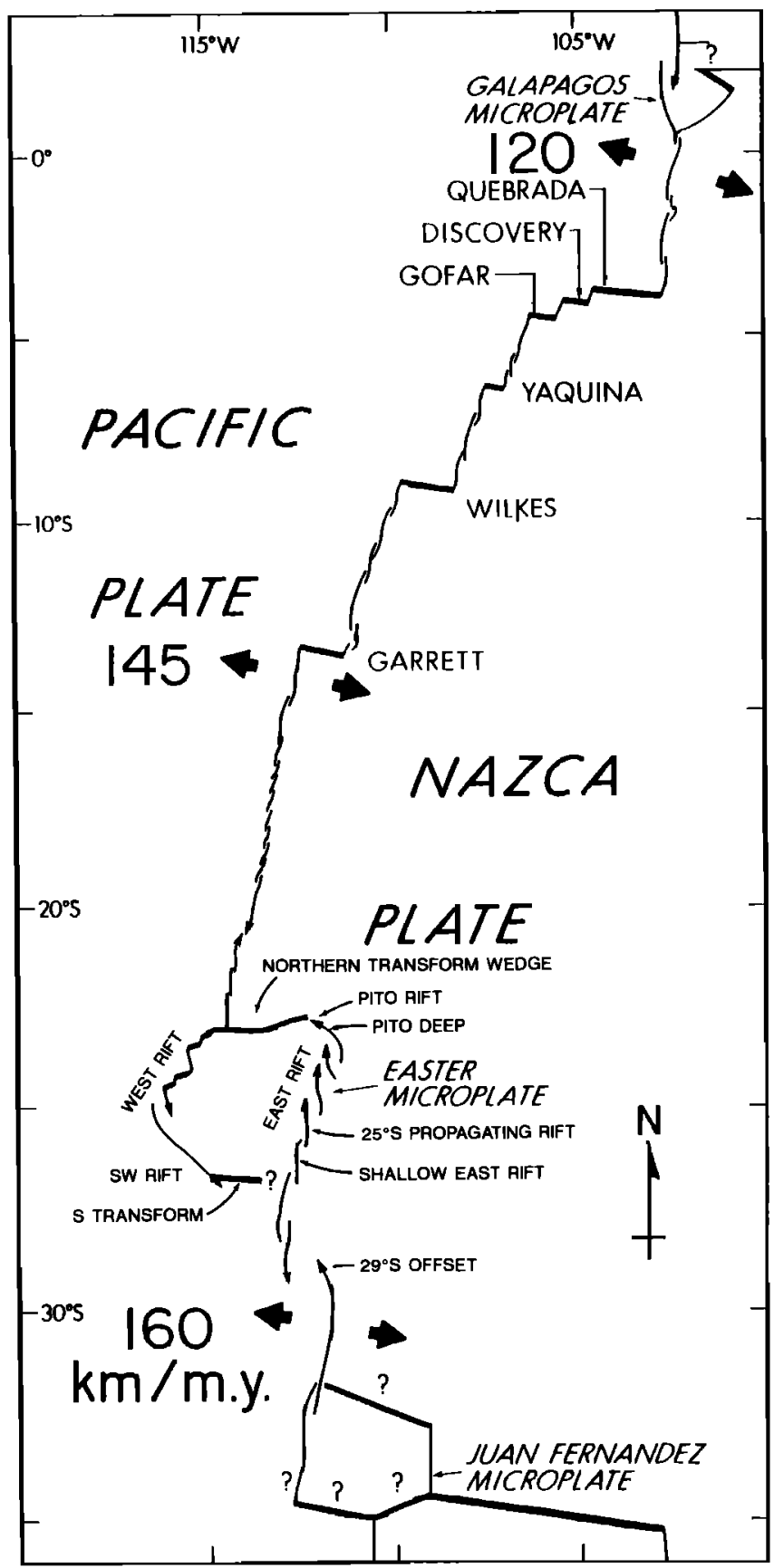

Fig. 1. Geometry of the Pacific-Nazca plate boundary and the location of the Easter microplate. Thick lines are transform faults and thin lines are spreading axes. Solid arrows along spreading axes indicate rifts which appear to be currently propagating. Bold numbers at paired arrows are full spreading rates in $\mathbf{k m} / \mathbf{m} . \mathbf{y}$. from the relative motion model of Naar and Hey $[1989 b]$. The Cocos and Antarctica plates are north and south, respectively, of the Nazca plate. Figure modified from Naar and Hey $[1989 b]$.

microplate's divergent boundaries and rigid Nazca lithosphere that was deformed when it was transferred to the Easter microplate [Naar and Hey, 1989b].

Discoveries of active and inactive oceanic microplates are becoming increasingly more abundant [Herron, 1972a, $b$; Forsyth, 1972; Anderson et al., 1974; LaBrecque and Hayes, 1979; Mammerickx et al., 1980; Handschumacher et al., 1981; Klitgord and Mammerickx, 1982; Craig et al., 1983; Rea and
Dixon, 1983; Engeln and Stein, 1984; Hey et al., 1985; Anderson-Fontana et al., 1986; Madsen et al., 1986; Mammerickx and Sandwell, 1986; Strong and Engeln, 1986; Taylor et al., 1987; Francheteau et al., 1987, 1988; Sager et al., 1988; Tamaki and Larson, 1988; Mammerickx and Sharman, 1988; Lonsdale, 1988; Mammerickx et al., 1988; Engeln et al., 1988]. What proportion of the total area of the major plates is composed of previously active microplates remains uncertain. It appears that they do add up to a small proportion of the total surface area of the larger plates (Figure 2), unless, of course, the larger plates originally grew from microplates [see Hilde et al., 1977].

The difference between small-scale and large-scale rift jumps is the distance between the offset ridge axes. Although there is probably a continuum, we define small-scale rift jumps to have a ridge offset $<10 \mathrm{~km}$ and large-scale rift jumps to have a ridge offset $>100 \mathrm{~km}$. Small-scale nontransform offsets are suspected to be nucleation points where large-scale ridge reorganizations begin [Phipps Morgan and Parmentier, 1985; Macdonald et al., 1987]. The tectonic evolution of the Easter microplate and of the Juan de Fuca area [Wilson, 1988] suggests that most large-scale rift jumps originate as small-scale rift jumps and the ridge offset grows with time. The major differences between the two scales are the general geometry of the ridge axes, the geomorphology of the propagating rift tips, and how the transform shear between the two larger plates is accommodated across the overlap zone.

There are several general models for microplate formation and instantaneous microplate motions [Hilde et al., 1977; Hey et al., 1980; Engeln and Stein, 1984; Hey et al., 1985; McKenzie, 1986; Engeln et al., 1988; Mammerickx et al., 1988; Naar and Hey, $1989 b$; Schouten et al., 1988]. Continuous rift propagation with some finite broad transform zone in conjunction with rapid angular rotation of the microplate about a pole near its center is the preferred evolutionary model for the formation of the Easter microplate. Sorting out which of these two mechanisms is active at any given time is difficult because there are not enough data to constrain whether the oblique lineaments within the interior were sheared or rotated or to determine when the reorientation took place. The preference for this model is largely a result of this work and previous work [Naar and Hey, 1989b; Searle et al., 1989].

During October-November 1987, we conducted an investigation of the Easter microplate using the SeaMARC II survey system on the R/V Moana Wave (MW8711). The major objectives of the expedition were to investigate the origin and evolution of this anomalous area, to what extent is it behaving as a separate rigid plate, and to what extent is it deforming. The general results from our expedition; new bathymetry, lineament, and magnetic maps; rigid plate tectonic reconstructions; and a schematic evolutionary model for the area are presented.

\section{DATA}

\section{Earthquakes}

The teleseismically recorded earthquakes from 1963 to 1986 are shown with Euler vectors for the Pacific, Easter, and Nazca plates and the linear motion vectors predicted by the Euler vectors (Figure 3). The pattern of earthquakes clearly delineates a "ringshaped" pattern, as initially noted by Herron [1972a], surrounding the interior of the Easter microplate, suggesting that during this recent "snapshot" of geological time the interior of the microplate has been behaving rigidly at least with respect to teleseisms. There are a few small intraplate earthquakes which are probably 


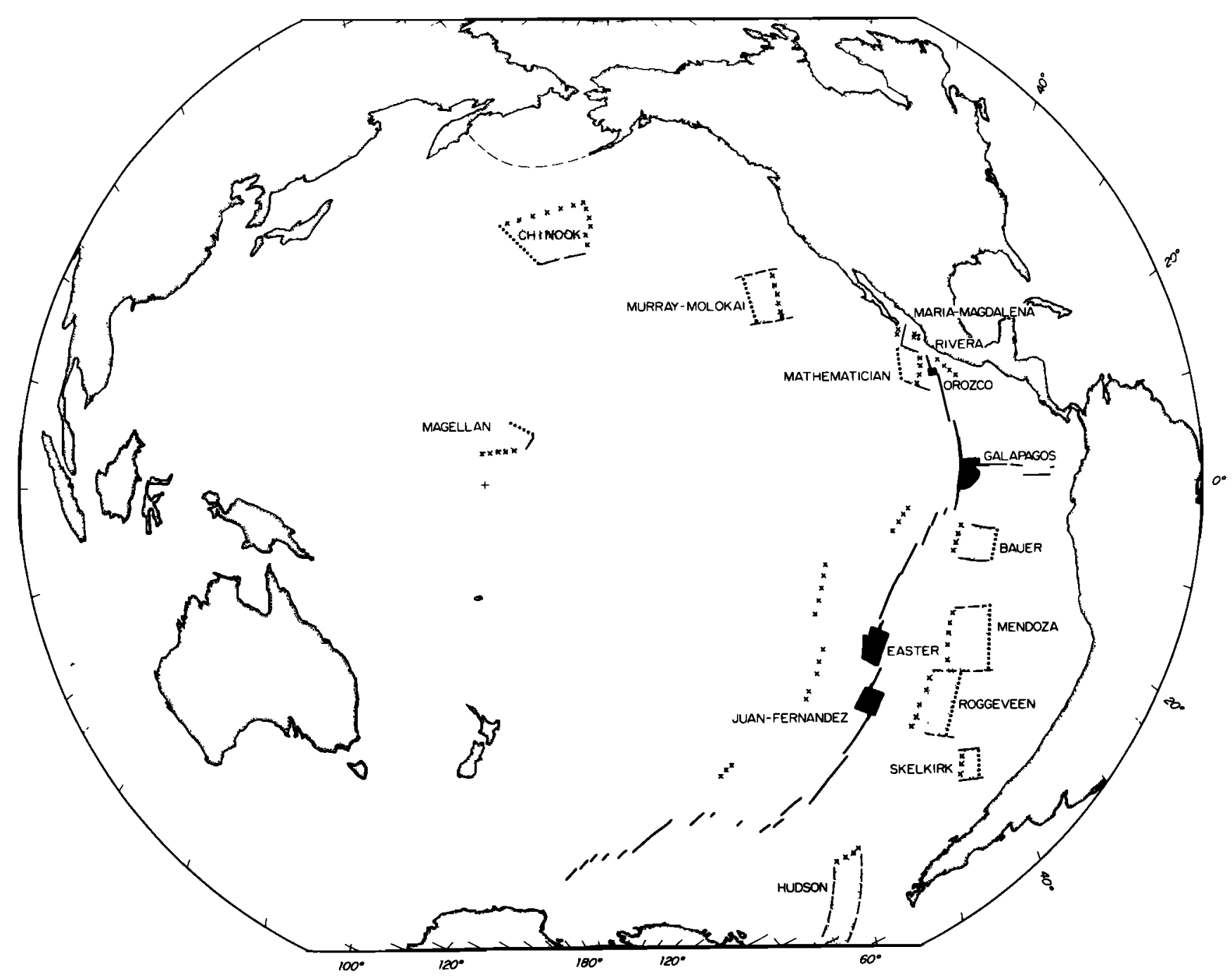

Fig. 2. Map showing active and previously active microplates within the Pacific basin. Shaded areas are active and stippled areas are inactive. Dotted lines are abandoned spreading ridges; crosses are pseudofaults. Figure modified from Mammerickx et al. [1988].

mislocated and do not appear to correlate with any major structures shown in Figure $\mathbf{4}$ and Plate 1 nor with GLORIA data which cover the majority of the microplate interior [Rusby et al., 1988; Searle et al., 1989]. The earthquake epicenter pattern was used in conjunction with the other data to define the active boundaries of the microplate. The northern boundary has a diffuse epicentral pattern with strike-slip and compressive fault plane solutions [Engeln and Stein, 1984]. The southern boundary also has a diffuse pattern of earthquakes. Within this pattern there are closely grouped earthquakes which tend to occur as swarms [Walker, 1988]. The predominant fault plane solutions from the south are tensional and strike-slip [Engeln and Stein, 1984]. Figure 3 extends farther north than the other figures to show the the microplate's spatial relationship with the $20^{\circ} 40^{\prime} \mathrm{S}$ dueling propagators [Macdonald et al., 1988; Rea, 1978].

\section{SeaMARC Il Side Scan}

The SeaMARC II (Sea Mapping And Remote Characterization) seafloor mapping system generates coregistered side scan and bathymetry images, as described elsewhere [Blackington et al., 1983; Hussong and Fryer, 1983]. The system is generally towed at about 8 knots $(15 \mathrm{~km} / \mathrm{h})$ at a depth of about $100 \mathrm{~m}$ and uses a long-range 12- and 11-kHz acoustic signal (starboard and port) which generates $10-\mathrm{km}$-wide slant range corrected side scan images and a bathymetry image with a width about 3.4 times the water depth. Beyond this distance, the bottom multiple interferes with the incoming signal. The sonars consist of two lines of parallel transducers on both the port and starboard sides of the towfish. The phase difference between the acoustic energy received by the parallel transducers is measured as well as the total travel time and the amplitude of the echo. These three numbers are recorded for each reflector. The bathymetry can be calculated using the first two numbers and assumptions about acoustic travel paths within the ocean.

Lineaments (Figure 4) from the shipboard SeaMARC II side scan mosaics are shown with the Sea Beam lineaments from the Pascua expedition legs 2, 3, and 4 aboard the R/V Thomas Washington [Hey et al., 1985; Francheteau et al., 1987], the Sea Rise expedition aboard the R/V Jean Charcot (J. Francheteau, unpublished data, 1987), and a few select transits from the Rapa Nui expedition aboard the R/V Jean Charcot [Francheteau et al., 1988; J. Francheteau, unpublished data, 1987]. The swath widths are drawn to represent the true area covered. Single lines on 


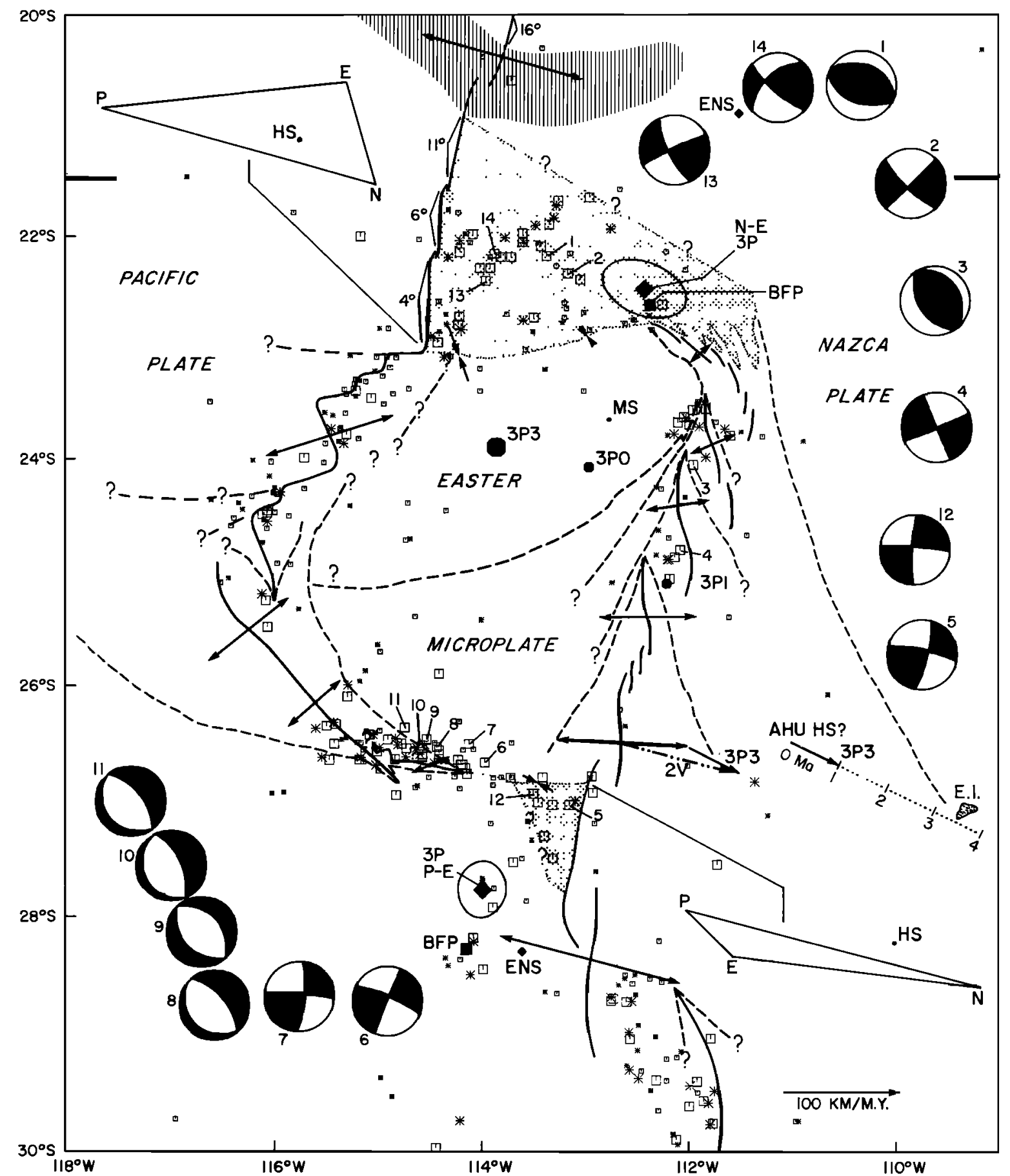

Fig. 3. Tectonic boundaries, relative and absolute Euler poles, plate motion vectors, and two triple junction velocity triangles for the Easter microplate, with two types of earthquake epicenters and fault plane mechanisms [Engeln and Stein, 1984]. Large (Mb> 5) and small open squares represent National Geophysical Data Center earthquakes from 1963 to 1986 . Large $(M b>5)$ and small asterisks represent International Seismological Centre earthquakes from 1972 to 1984 . All solid lines between plates represent divergent boundaries except for transforms along the West Rift (where solid lines are parallel to the relative motion vectors). Short-dashed lines represent pseudofaults. Long-dashed lines represent fracture zones. The northern and southemmost relative motion vectors are predicted from the 3P Nazca-Pacific Euler vector [Naar and Hey, 1989b]. The other vectors on the West Rift and East Rift are also predicted from the 3P Pacific-Easter and Nazca-Easter Euler vectors (3P P-E and 3P N-E). Error ellipse about the 3P poles represents $95 \%$ confidence level ( 2 sigma). Best fitting poles (BFP) for the respective plate pairs and the preferred Engeln and Stein [1984] Euler poles (ENS) are shown as solid squares and diamonds. Preferred hotspot-Easter Euler pole (3P3) is shown as a large solid octagon. The other hotspot-Easter Euler poles are small solid octagons. MS represents the pole of second-order motion [Schouten et al., 1988] of the Easter microplate located 3.5 times closer to the Nazca-Easter than the PacificEaster pole. Vertical line stipple near $21^{\circ} \mathrm{S}$ represents disturbed area of Rea [1978]. Large area of stipple represents deforming wedge of Nazca plate and the northem boundary of the Easter microplate. Its boundaries are based on earthquake epicentral pattem, bathymetry, magnetics, SeaMARC II side scan, and orientation of the EPR $\left(004^{\circ}, 006^{\circ}, 011^{\circ}\right)$ in an area where it is predicted to be $016^{\circ}$. The southem stipple represent the uncertain location of the southern triple junction. HS represents the hotspot frame of reference for each velocity triangle. $2 \mathrm{~V}$ vector marks the migration of the shallow East Rift summit with respect to the hotspot frame. The line extending from the Ahu hotspot predicts age of hotspot volcanism, which predicts that Easter Island was initially formed about $3.5 \mathrm{Ma}$. Two short thick horizontal ticks on the vertical borders of the figure at $21.5^{\circ} \mathrm{S}$ represent the northermmost limit of the other data figures. Lower right vector represents velocity magnitude scale. Figure modified from Naar and Hey [1989b]. 


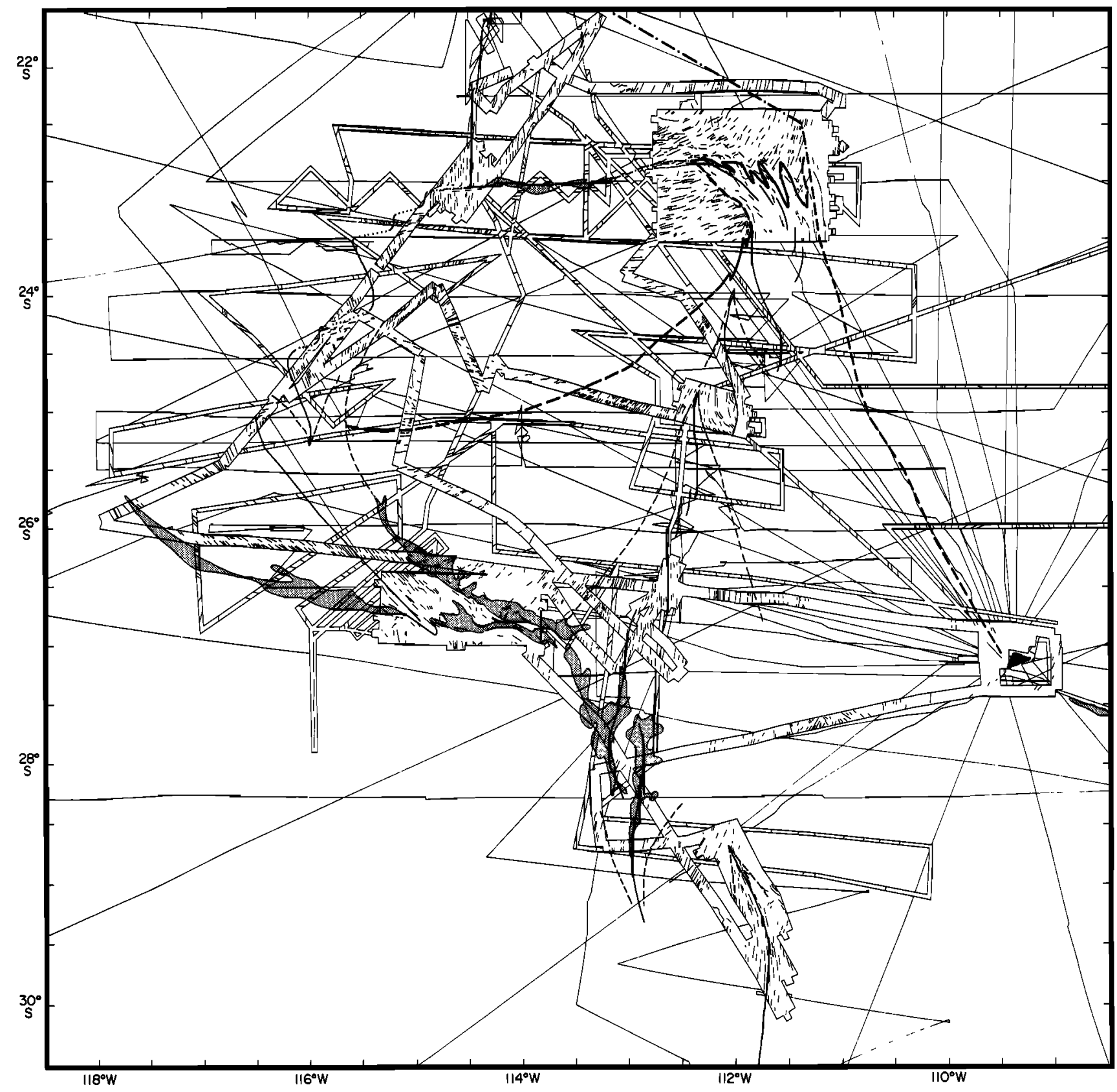

Fig. 4. Lineament and ship track map. All single lines represent 3.5- or 12-kHz data. SeaMARC II coverage is shown by large envelopes (with no exaggeration) that designate the side scan coverage, which is $10 \mathrm{~km}$ along single transit tracks. The very narrow envelopes represent Sea Beam coverage (with no exaggeration). Lineaments observed in the SeaMARC side scan data and scarps observed in the Sea Beam data are shown within the envelopes. Solid triangle is Easter Island (Rapa Nui). Stipple pattern represents areas of shallow bathymetry $(<2400 \mathrm{~m})$ that coincide with the pseudofaults of the Southwest Rift, the southem boundary of the microplate, the southern EPR, the shallow east-west northern (transform?) boundary, and a long shallow ridge radiating ESE from Easter Island, which may be a continuation of the major outer pseudofault of the East Rift, a volcanic ridge, or a fracture zone. Boundaries are the same as in Figure 3, except that dotted lines represent active transform faults and thick-dashed lines represent major pseudofaults formed by the initial formation of the microplate. Thick-dashed/dotted line represents the northernmost limit of the microplate's interaction with the Nazca plate. Thin-dashed lines represent pseudofaults formed by local small-scale propagators. Thin-dashed/dotted line represents the southern boundary of the northem transform zone wedge.

Figure 4 show the remaining data used in conjunction with the SeaMARC II and Sea Beam data to generate the hand-contoured bathymetry contour map (Plate 1). The advantage of the SeaMARC II system is that it allows the imaging of long lineaments (even those with small relief) which would be otherwise undetected in Sea Beam or 3.5-kHz data. In addition, the backscatter amplitudes provide useful information on the bottom roughness and character after all the parameters responsible for backscatter are accounted for, such as the topography of the seafloor and the location of the towfish. Detailed analysis of the SeaMARC II side scan and bathymetry mosaics can be found elsewhere [Hagen et al., 1990; Klaus et al., 


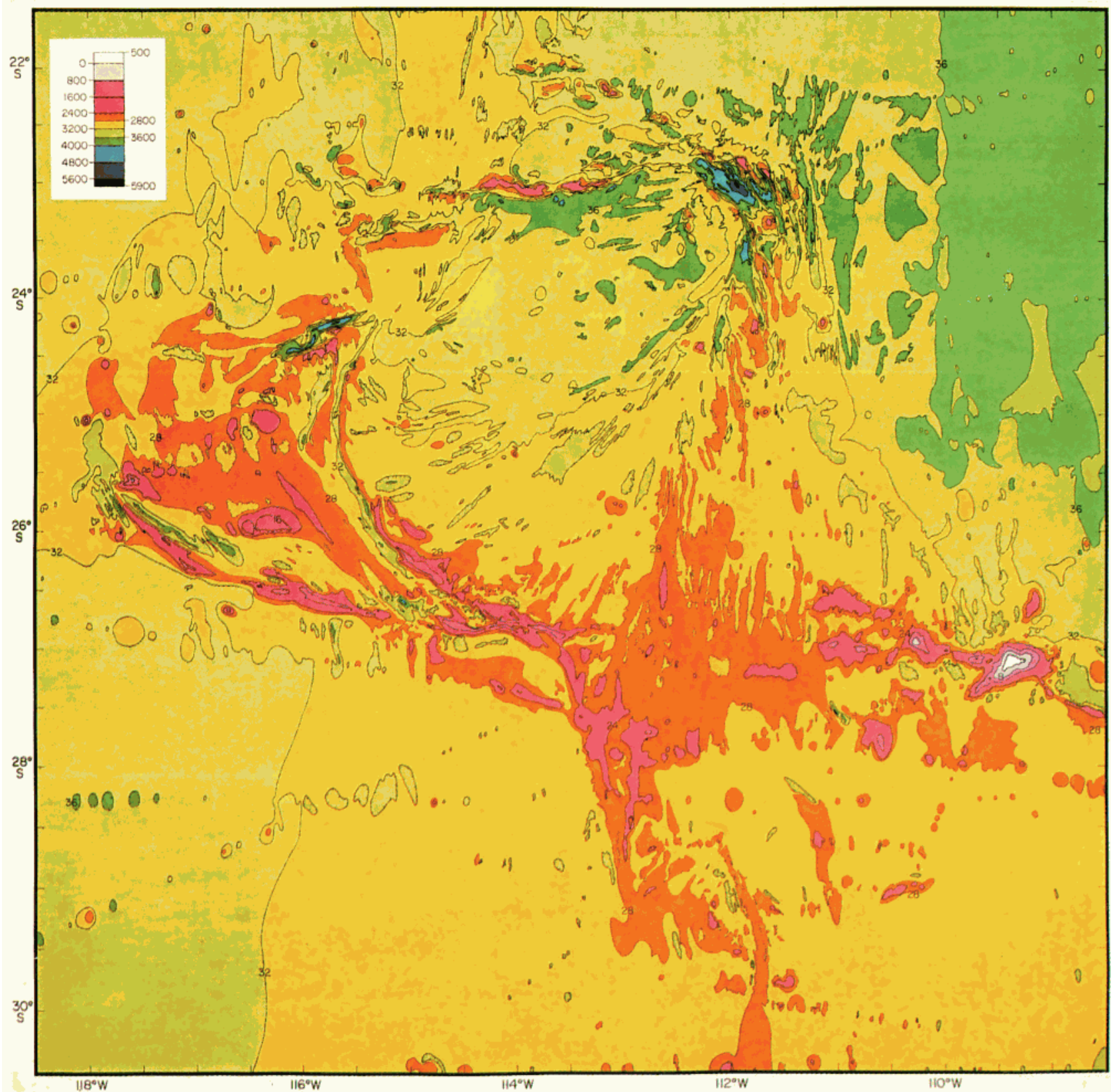

Plate 1. Bathymetric contour map of the Easter microplate area. Microplate boundaries are not shown on the color version (Plate la) to prevent obscuring data but are shown on the black-and-white version (Plate $1 b$ ) following the scheme in Figure 4 . Contour interval is shown in key. Data sources are listed in text.

1991; D. F. Naar et al., Pito Rift: How a large-offset ridge propagates, submitted to Marine Geophysical Researches; F. Martinez et al., Three-dimensional SeaMARC II, gravity, and magnetics study of large-offset rift propagation at the Pito Rift, Easter microplate, submitted to Marine Geophysical Researches]. The digitized lineaments (Figure 4) from the shipboard mosaics are used to help guide the hand-contouring of the bathymetry data and to help constrain structural boundaries such as spreading axes, transform faults, fracture zones, transform faults, and pseudofaults [Hey, 1977]. These digitized boundaries are shown in all the data figures, and a simplified version of these boundaries is shown in the reconstruction figures.

\section{SeaMARC II, Sea Beam, and Conventional Bathymetry}

Over 80 mosaics and transits, representing more than 4 weeks of virtually continuous SeaMARC II bathymetry data, were contoured by hand using a 100 -m contour interval at standard Mercator projection scales that matched a map scale of 1:94488.24 (transverse Mercator projection, using the World Geodetic System 1972 ellipsoid constants). Contouring by hand was necessary to smooth minor noise and to interpolate across gaps formed underneath the towfish and between parallel tracks. These 80 maps were photographically reduced to a map scale of 16 inches per degree of longitude (standard Mercator map 


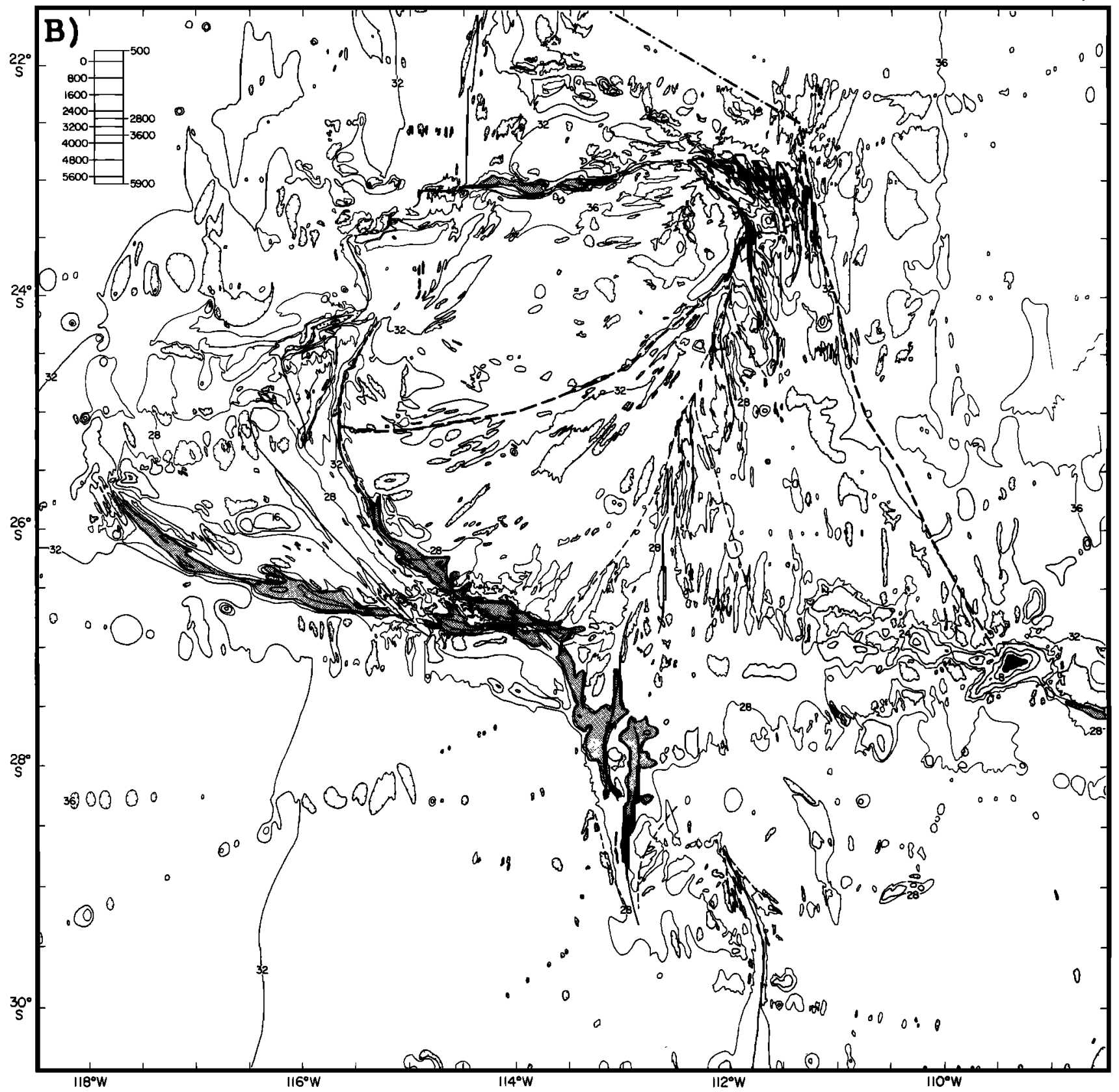

Plate 1. (continued)

projection) and contoured using 20 sheets of Sea Beam bathymetry maps from the Pascua expeditions, 10 sheets from the German Geometep expeditions [Marchig et al., 1987], a few transit trảcks from the Rapa Nui expedition, and 42 sheets of all the available 3.5- and $12-\mathrm{kHz}$ data from the National Geophysical Data Center (NGDC) plus data that were digitized from the handwritten data logs of the EN113 cruise aboard the R/N Endeavor (J.-G. Schilling, University of Rhode Island). The 42 base maps, which cover an area from $120^{\circ} \mathrm{W}$ to $105^{\circ} \mathrm{W}$ and $21^{\circ} \mathrm{S}$ to $31^{\circ} \mathrm{S}$, were contoured using a 200 -m contour interval at a map scale of 16 inches per degree of longitude. These 42 base maps, which are available for future recompilations, were photographically reduced to a map scale of 4 inches per degree and were redrafted at a 400-m contour interval, except for shallow and deep bathymetry which were redrafted at an $800-\mathrm{m}$ contour interval (Plate 1).
All available conventional wide-beam echo soundings from the NGDC and the EN113 expedition, plus the vertical beam profiles from Pascua legs $2-4$ and $3.5-\mathrm{kHz}$ data collected during our SeaMARC II . survey (MW8711) that cross the major tectonic structures,- are shown superimposed with the tectonic interpretations (Figure 5). The bathymetry profiles which are very oblique to structures (Figure 4) are not shown but have been contoured.

\section{Magnetics}

All the available magnetic anomaly profile data from the NGDC, the MW8711 expedition, the Pascua expedition, the Rapa Nui expedition, and the EN113 expedition are shown in Figure 6. Although there appears to be a large amount of magnetic data, more data are needed to resolve the complex magnetic pattems 


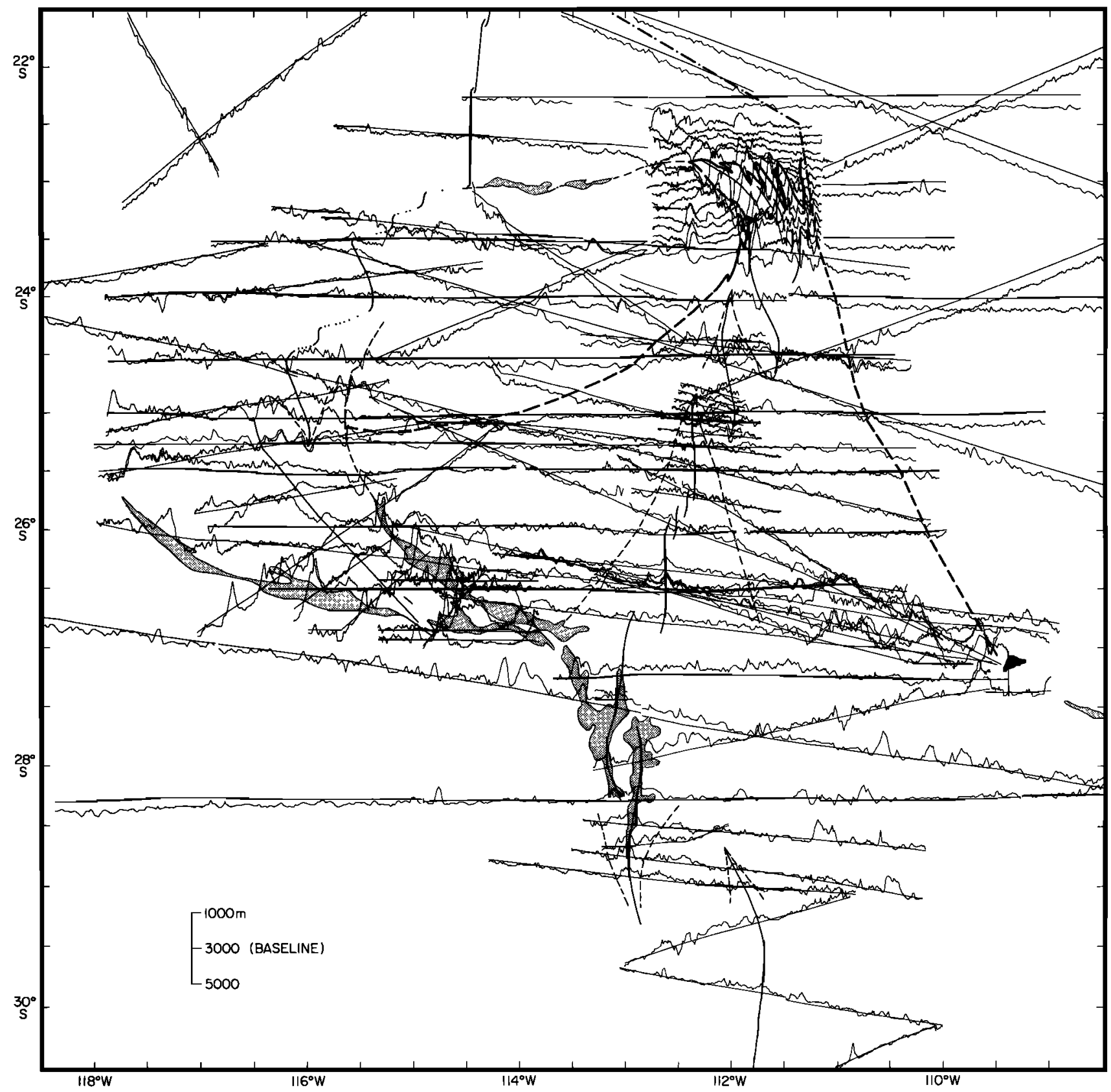

Fig. 5. Bathymetric profile data projected north-south from ship track. Ship track represents the 3000 -m baseline. Ship tracks are not plotted in the densely surveyed area of Pito Deep, tip of the East Rift. Tectonic boundaries are from Figure 4.

resulting from the multiple episodes of rift propagation along the divergent boundaries of the microplate. For this reason and to prevent cluttering Figure 6 with question marks, only magnetic anomaly correlations and identifications with a high degree of certainty are shown. The magnetic isochron identifications are constrained by the two-dimensional magnetic models shown in Figure 7 and published elsewhere [Naar and Hey, 1989b]. Most of the identifications are in general agreement with identifications of Handschumacher et al. [1981], except for the detailed geometry of the Brunhes on the East Rift and the location of some of the tectonic boundaries, which are minor, considering all the additional data collected in this area over the past decade. The only magnetic profile data not incorporated into Figure 6 are from the GLORIA cruise. Incorporating new data along with any aeromagnetic data that may exist would be of great help for the middle of the West Rift, the interior of the microplate, and to the west and east of the microplate where there are large data gaps or small-scale spreading system reorganizations.

\section{DATA DESCRIPTION}

\section{Overview}

The general results from our SeaMARC II expedition and kinematic analyses [Engeln and Stein, 1984; Hey et al., 1985; $\mathrm{Naar}$ and Hey, 1989b] indicate that the majority of the microplate is currently behaving as a rigid body. Its fast $\sim 15^{\circ} \% \mathrm{~m}$.y. relative and absolute rotation velocities predict rapid convergence along the northern boundary (increasing from $0 \mathrm{~km} / \mathrm{m}$.y. in the east to $-50 \mathrm{~km} / \mathrm{m}$.y. in the west). This rapid $\sim$ north-south convergence 


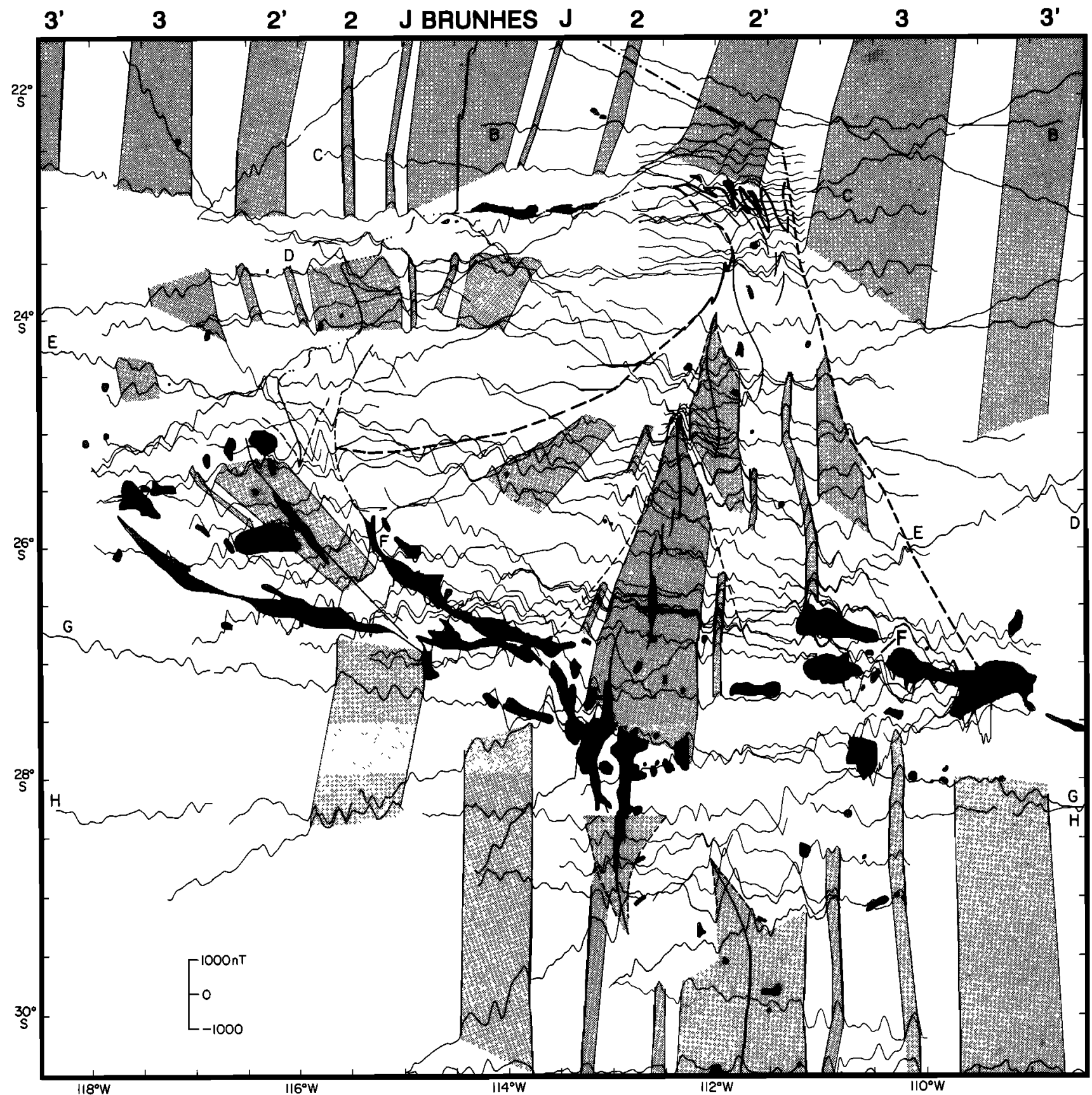

Fig. 6. Magnetic profile data projected north-south. Isochron identifications with a high degree of certainty are shown in light stipple. The dark stipple represents all bathymetry shallower than $2400 \mathrm{~m}$. Note the broad belt of shallow bathymetry radiating in a westerly direction from the vicinity of Easter Island. Profiles that are modeled in Figure 7 are indexed here as single capital letters, except for profile A which crosses the EPR at $21.39^{\circ} \mathrm{S}, 114.27^{\circ} \mathrm{W}$. Tectonic boundaries are from Figure 4.

may be accommodated over a large wedge-shaped zone of deformation north of the microplate. It is characterized by a pattern of en echelon scarps with an overall $\sim$ NW-SE trend (Plate 1) that disrupts the regional north-south seafloor fabric and by a diffuse distribution of earthquakes (large area of stipple in Figure 3). At the Pito Rift area (near $23^{\circ} \mathrm{S}, 112^{\circ} \mathrm{W}$ ), the tip of the northernmost East Rift is breaking into $\sim 3 \mathrm{Ma}$ Nazca lithosphere (Figure 3 and 6) [Francheteau et al., 1988]. The southernmost West Rift, also known as the Southwest Rift, is propagating toward the southeast within an envelope of curving pseudofaults (concave to the northeast) that converge toward the southeast (Figures 3 and Plate 1) [also see Searle et al., 1989]. The microplate interior is characterized by seafloor fabric with a complex pattern of orientations (Figure 4) [Searle et al., 1989]. More detailed descriptions of the data from the various parts of the microplate are given below in a counterclockwise manner around the microplate, starting with the Pito Rift area.

\section{Pito Rift Area}

The Pito Rift area is roughly 150 by $150 \mathrm{~km}$, centered near $23^{\circ} \mathrm{S}, 112^{\circ} \mathrm{W}$. The extent of the SeaMARC II data coverage in this area is shown in Figure 4. The greatest depth of the area, Pito Deep, was recorded by the SeaMARC II system at $-6100 \mathrm{~m}$, 

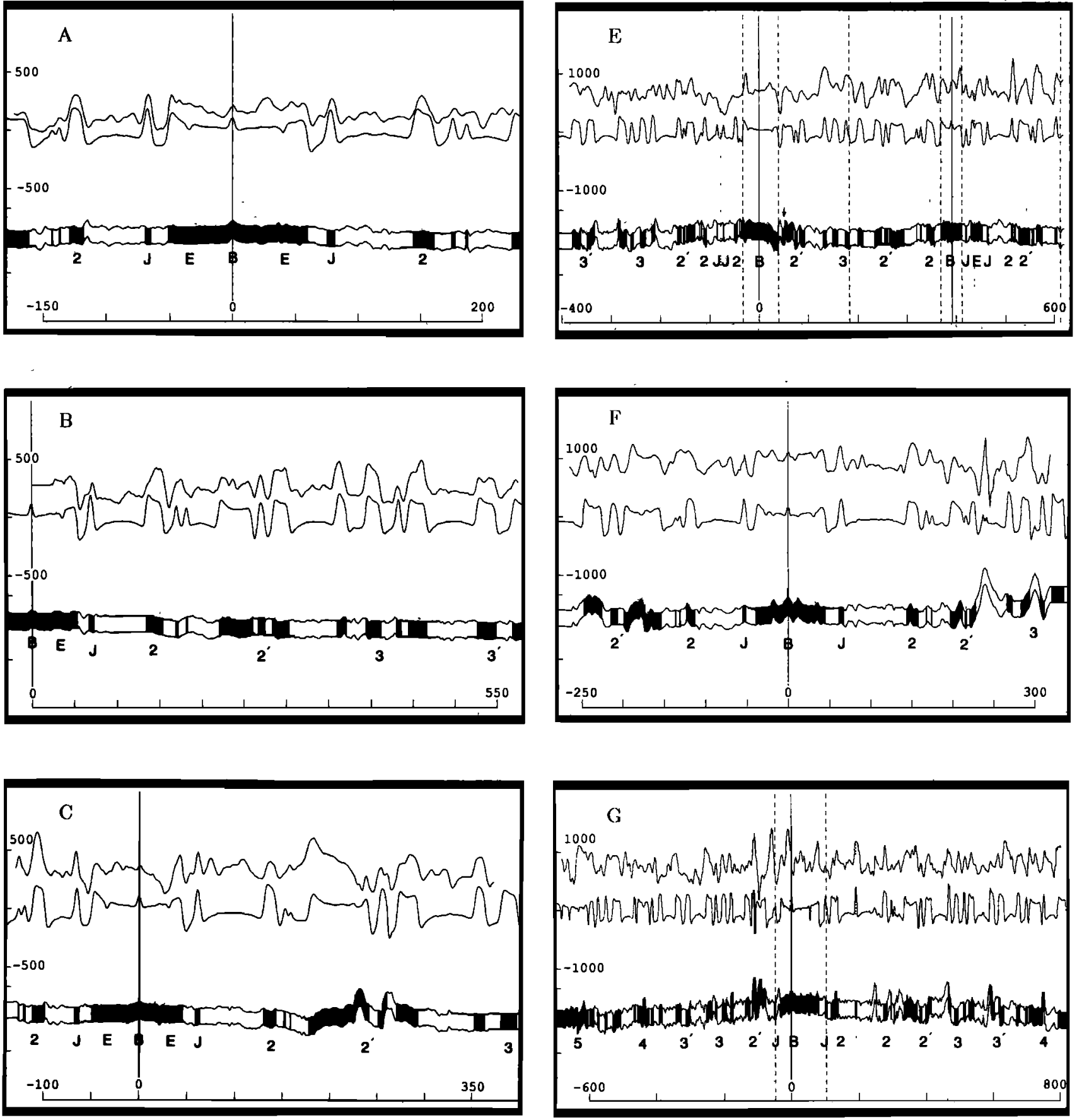

G

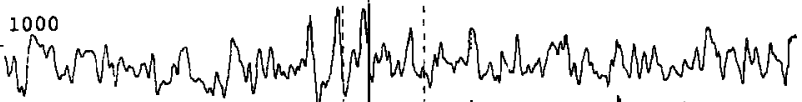

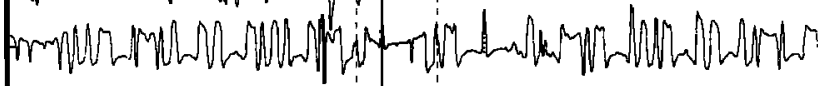
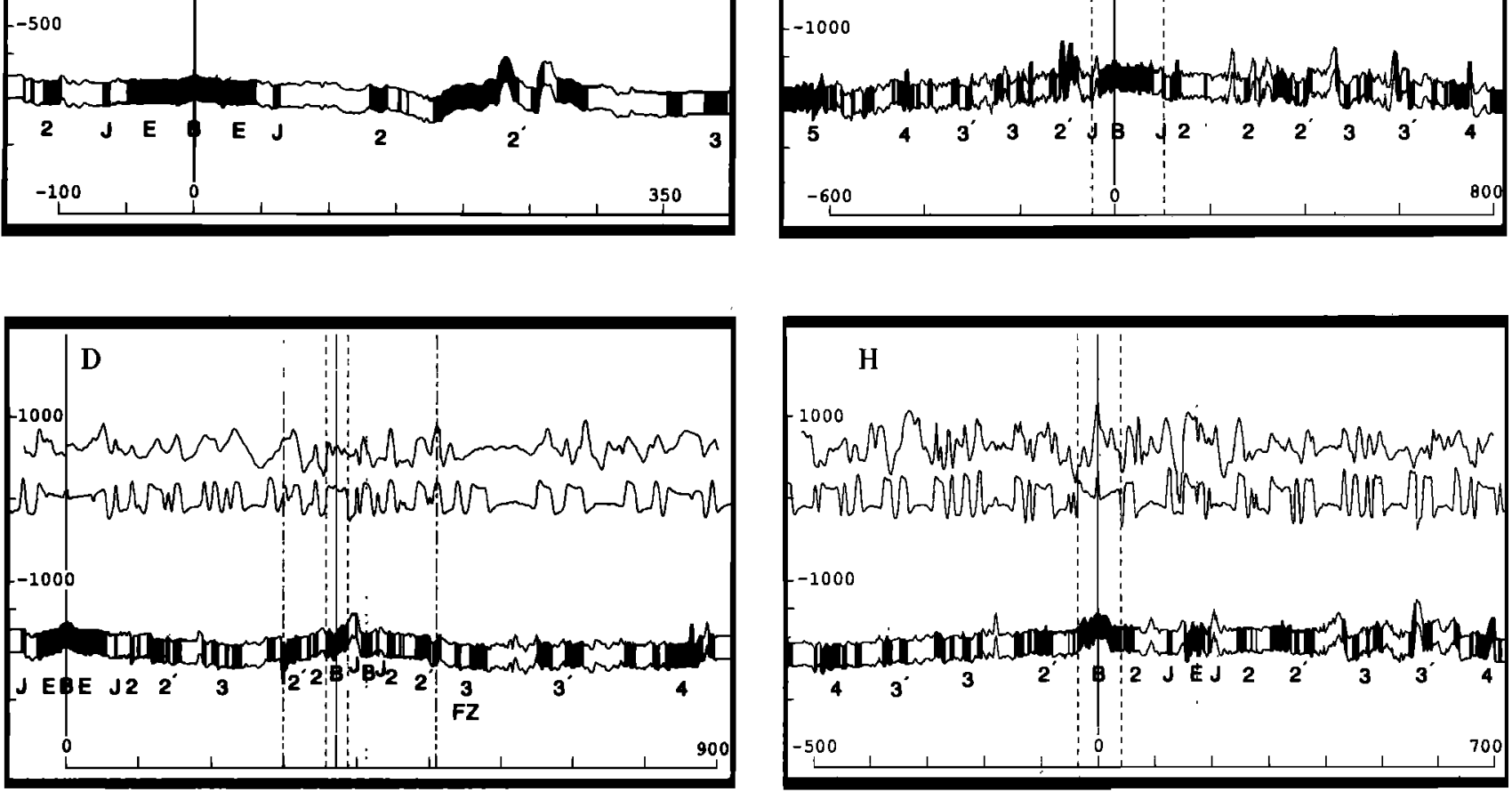

$\mathrm{H}$

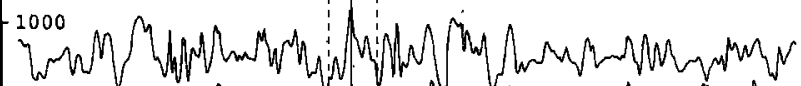

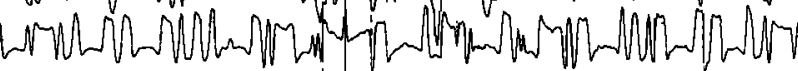

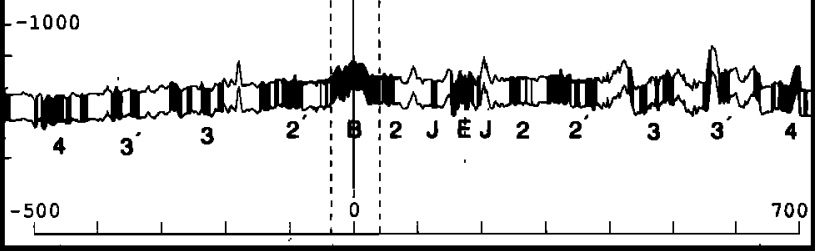


about $200 \mathrm{~m}$ deeper than the 5890-m depth recorded by Sea Beam [Francheteau et al., 1988]. This deep, as defined by the $5.6-\mathrm{km}$ isobath, lies within an approximately 2 by $5 \mathrm{~km}$ wide graben oriented NW-SE [Francheteau et al., 1988]. The entire area is extensively faulted by NW-SE oriented scarps frequently $1000 \mathrm{~m}$ high and forming $4000 \mathrm{~m}$ of relief [Francheteau et al., 1988]. These scarps appear to be normal faults that cut across the local NE-SW abyssal hill fabric [D. F. Naar et al., submitted manuscript, 1991; F. Martinez et al., submitted manuscript, 1991]. Photographs from the Pito Deep area show talus and sediment probably redeposited during rifting [Hey and Naar, 1987]. There are only gross similarities between the $95.5^{\circ} \mathrm{W}$ Galapagos propagating rift tip [Hey et al., 1986] and the Pito Rift area. One similarity is that they are both anomalously deep and "curve" toward the doomed rift, although the method of curvature at the Pito Rift area is much more discontinuous and en echelon. Second, it appears that distributed rifting (tectonic extension by normal faulting over several half grabens) also occurs prior to the formation of an active well-developed spreading center but is much more widespread [Martinez et al., 1989; D. F. Naar et al., submitted manuscript, 1991; F. Martinez et al., submitted manuscript, 1991] than observed at the Galapagos propagator [Kleinrock, 1988; Kleinrock and Hey, 1989a].

\section{Northern Transform Wedge}

The northern boundary of the Easter microplate has been described as a broad diffuse east-west transform/compressive boundary [Engeln and Stein, 1984; Hey et al., 1985] and as a narrow transform ridge [Francheteau et al., 1988]. Figures 3 and 4 and Plate 1 indicate that the northern boundary covers a larger area than previously thought and has more than one ridge extending westward from the Pito Deep area, although the one described by Francheteau et al. [1988] is the largest and most continuous. This area has a few transit/reconnaissance SeaMARC II and Sea Beam crossings (Figure 4), which show anomalous abyssal hill orientations, patterns of disrupted bathymetry, and scissorlike faulting. Subsequent GLORIA data show that this area is composed of mostly normal abyssal hill fabric that is disrupted by several east-west trending structures [Rusby et al., 1988; Searle et al., 1989]. Comparisons between the identified structures and predicted plate motions [Engeln and Stein, 1984; Naar and Hey, $1989 b$ ] show that the long shallow east-west ridge cannot be one long continuous transform fault. The current morphology and geometry of the ridge (Figure 4) are more consistent with both compressive and strike-slip plate motions.

\footnotetext{
Fig. 7. Magnetic anomaly data and synthetic models arranged from north to south for profiles indexed $(\mathrm{A}-\mathrm{H})$ in Figure 6 . The full spreading rates used to match the $0.73 \mathrm{Ma}$ Brunhes/Matuyama reversal are listed in Table 1. For each set, the top profile is the data (nT), the middle profile is the model (nT), the lower profile is bathymetry $(\mathrm{m})$, the darkened blocks within the 1-km magnetic layer shown following the bathymetry are blocks of normal magnetic polarity, lower scale is distance $(\mathrm{km})$, and the vertical scale bars are for the magnetics (upper tick is the positive value of the value shown at the lower tick) and bathymetry $(2-6 \mathrm{~km})$. Labels underneath model represent Brunhes, Emperor, Jaramillo, and magnetic anomalies numbers. Vertical solid lines represent seafloor spreading centers. Vertical dashed lines represent pseudofaults. Vertical dotted lines represent failed rifts. Profiles were analyzed and modeled at magnified scales as needed. All profiles have a double intensity spike for $0.00-0.02$ $\mathrm{Ma}$ at the ridge axis except for profiles $\mathrm{G}, \mathrm{H}$, and the East Rift of profile E, which all have a 2.2 intensity spike for $0.00-0.03 \mathrm{Ma}$. Small arrow in profile E shows location of the Southwest Rift inner pseudofault shown in the other figures. Each model is generated by a forward modeling program [Hey et al., 1986] which uses the polarity, bathymetry, ridge orientation, and intensity spike. See Table 1 for parameters for the individual profiles.
}

It seems unlikely that this northern transform wedge is a separate plate, because the northern area is teleseismically active throughout most of its interior and has very little activity near the shallow east-west ridge where more activity would be expected if the ridge were a transform fault (Figure 3). The earthquake mechanisms of the larger earthquakes in this region (earthquakes $13,14,1$, and 2) have mostly north-south compressional axes and strike-slip fault planes [Engeln and Stein, 1984] in general agreement with the predicted plate motions. Furthermore, spreading rates just north of the triple junction (at $23^{\circ} 03^{\prime} \mathrm{S}$, $\left.114^{\circ} 32^{\prime} \mathrm{W}\right)$ are slow $(-140 \mathrm{~km} / \mathrm{m} . \mathrm{y}$.) compared to predicted Pacific-Nazca rates $(\sim 160 \mathrm{~km} / \mathrm{m} . \mathrm{y}$.$) . The curvature of the EPR at$ the triple junction (concave toward the west) suggests the dominant stress felt is the Easter-Pacific shear couple. The orientation of the EPR segment north of the $20^{\circ} 40^{\prime} \mathrm{S}$ ridge offset is $016^{\circ}$, which is perpendicular to the predicted $106^{\circ}$ spreading direction over the past $0.73 \mathrm{~m} . \mathrm{y}$. [Naar and Hey, 1989b] and nearly perpendicular to the predicted spreading directions from global plate motion models: $103^{\circ}$ [DeMets et al., 1990] and $104^{\circ}$ [Minster and Jordan, 1978]. South of the $20^{\circ} 40^{\prime}$ 'S ridge offset, the EPR is offset by two small overlapping spreading centers (Figure 3). The orientation of each EPR segment becomes progressively more north-south as one nears the microplate. The azimuths of these segments $\left(011^{\circ}, 006^{\circ}, 004^{\circ}\right)$ are significantly different from the orthogonal orientations predicted by the plate motion models, which predict a range of $014^{\circ}-016^{\circ}$.

Spreading rates predicted from the three relative motion Euler vectors of Naar and Hey [1989b] are compared along the EPR north and south of the microplate to see where the spreading rates predicted by the microplate Euler vectors equal the rates predicted by the Pacific-Nazca Euler vector. The location of this theoretical intersection of equal rates is herein called an equal rate point. These equal rate points are found by trial and error using the digitized tectonic boundaries and the Euler vector for each plate pair as input into a computer program that returns the given latitude and longitude pairs with their corresponding spreading rate and direction. The equal rate point south of the microplate will be discussed later in the southern triple junction section.

The spreading directions predicted from the two Euler vectors (at the equal rate points) are $106.1^{\circ}$ for the Pacific-Nazca direction and $96.3^{\circ}$ for the Pacific-Easter direction. To compensate for this $19.8^{\circ}$ deviation in spreading direction, the predicted Pacific-Nazca rates are compared to the predicted Pacific-Easter rates multiplied by the cosine of $19.8^{\circ}$. This projects the Pacific-Easter vector onto the Pacific-Nazca vector so that their magnitudes can be compared properly. The northern equal rate point is at $21^{\circ} 59^{\prime} \mathrm{S}$, $114^{\circ} 24^{\prime} \mathrm{W}$. It has a Pacific-Nazca rate of $154.4 \mathrm{~km} / \mathrm{m}$.y. and a Pacific-Easter rate of $164.1 \mathrm{~km} / \mathrm{m}$.y. which multiplied by the cosine of $19.8^{\circ}$ gives a projected rate of $154.4 \mathrm{~km} / \mathrm{m} . \mathrm{y}$.

This equal rate point is approximately in the middle of the EPR segment that bounds the western edge of the northern transform zone shown by the stipple in Figure 3 and is just to the north of the majority of the earthquakes in the transform zone. In addition, the geochemical pattem observed from dredged basalts along the EPR that bounds the western edge of the northem transform zone shows a trend that suggests that this portion of the EPR is in the process of failing (J. Sinton, personal communication, 1989). The pattern observed is a limited degree of fractionation (e.g., high $\mathbf{M g}$ values). The northern limit of failing predicted by this geochemical pattern is not well constrained but is roughly located somewhere near $22.25^{\circ} \mathrm{S}$ along the EPR. This northem limit is only $-30 \mathrm{~km}$ south of the northern equal rate point, which suggests a possible relationship. 
It is not surprising that the predicted fast convergence rate in this area $(-50 \mathrm{~km} / \mathrm{m}$.y.) does not form a trench because the ages of the two juxtaposed plates are quite young $(<-2 \mathrm{Ma})$ and the age contrast is low $(<-1 \mathrm{Ma})$. There are other places where predicted convergence rates are somewhat less and a trench is not formed. For example, the northeastern boundary of the Caroline plate does not have a trench and has a convergence rate estimated at about 15 $\mathrm{km} / \mathrm{m} . \mathrm{y}$. (with an uncertainty of a factor of 2) [Weissel and Anderson, 1978]. The Azores-Gibraltar plate boundary in the North Atlantic has a convergence rate estimated at $10-15 \mathrm{~km} / \mathrm{m}$.y. and there is evidence of overthrusting of the Gorringe Bank [Purdy, 1975].

\section{Northern Triple Junction}

We mapped the previously proposed northern triple junction interpreted to be a ridge-fault-fault (RFF) triple junction [Hey et al., 1985; Francheteau et al., 1988], where the "ridge" is the EPR, which curves strongly to the west as it approaches the microplate. There is shallow bathymetry south of the triple junction and two nearly collinear faults. Velocity triangle analysis of the triple junction (Figure 3) indicates that the triple junction is unstable as RFF because the predicted Easter-Nazca plate motion is not parallel to Easter-Nazca limb of the triple junction. The triple junction could be kinematically stable as a ridge-trench-fault (RTF) triple junction if the Easter-Nazca limb was a convergent boundary fixed to the Easter plate because it is nearly collinear with the Pacific-Easter transform fault.

The orientation and structure of the western limb of the triple junction (Figures 4 and Plate 1) are more compatible with the predicted plate motions [Naar and Hey, 1989b], although there is a $7^{\circ}$ discrepancy between its orientation $\left(089^{\circ}\right)$ and the predicted direction of slip $\left(082^{\circ}\right)$, which suggests a small amount of divergence across the transform fault. This small amount of divergence could explain the observed deep bathymetry along the western transform limb at $23^{\circ} 21^{\prime} \mathrm{S}, 115^{\circ} 13^{\prime} \mathrm{W}$ that appears to contain a transform relay zone or pull-apart basin (Plate 1). However, the origin of the shallow bathymetry just to the south of the westem limb of the triple junction is unclear. The eastern limb of the triple junction, the shallow ridge flanked with a steep south dipping scarp with over a kilometer of relief and a gently north dipping slope, is compatible with the predicted convergence in this area (Figure 5).

As discussed earlier, deformation is probably occurring in the northern transform wedge, and thus triple junction stability analysis is done as an exercise with the understanding that a real triple junction may not exist on a local scale and instead is distributed over a large area.

\section{West Rift}

In contrast to the entire East Rift, which is characterized by northward propagating rifts and a lack of transform faults (except perhaps the eastern part of the northern transform zone), the West Rift (see Figure 1 for location) is offset by transform faults. This difference could be a result of propagating versus stationary ridge tips, where hotspot or forced asthenospheric upwelling interactions with the East Rift may cause rift tips to propagate [Hey et al., 1980; Phipps Morgan and Parmentier, 1985], thereby preventing a transform fault from developing along the East Rift. However, on the West Rift, where hotspot interactions appear to be subdued or nonexistent, ridge tips do not propagate as much, thereby allowing transform faults to develop.
The generally broad shallow area surrounding the West Rift, roughly triangular in shape, was used as the basis for the geometry shown in Figure 8 (see light stipple in Figure 8 and compare to Plate 1). The light stippled area in Figure 8 represents seafloor formed at a rate slower than the full Pacific-Nazca spreading rate. It is outlined by the overlap traces that surround the overlapped rift (the West Rift). The full Pacific-Nazca rate is still maintained because of the new spreading on the East Rift. The lithosphere formed by the West Rift narrows to the north because the East Rift has been progressively propagating northward and has been sharing spreading for less time in the north than in the south. The geometry of this wedge is complicated because of the southeastward propagation of the Southwest Rift. The precise location of the western edge of the overlap wedge is not well constrained because there are few data west of the microplate (Figure 4).

The overlap trace also represents where seafloor spreading started to slow down so it probably will not be a well-defined structural boundary, especially compared to the pseudofault structures observed near the northern part of the East Rift where old lithosphere had to be broken up before seafloor spreading could start. However, there is a change of lineament trends observed in some places along the overlap traces indicating that the spreading direction as well as the spreading rate changed at the time of overlap (Figure 4 and Searle et al. [1989]). If the

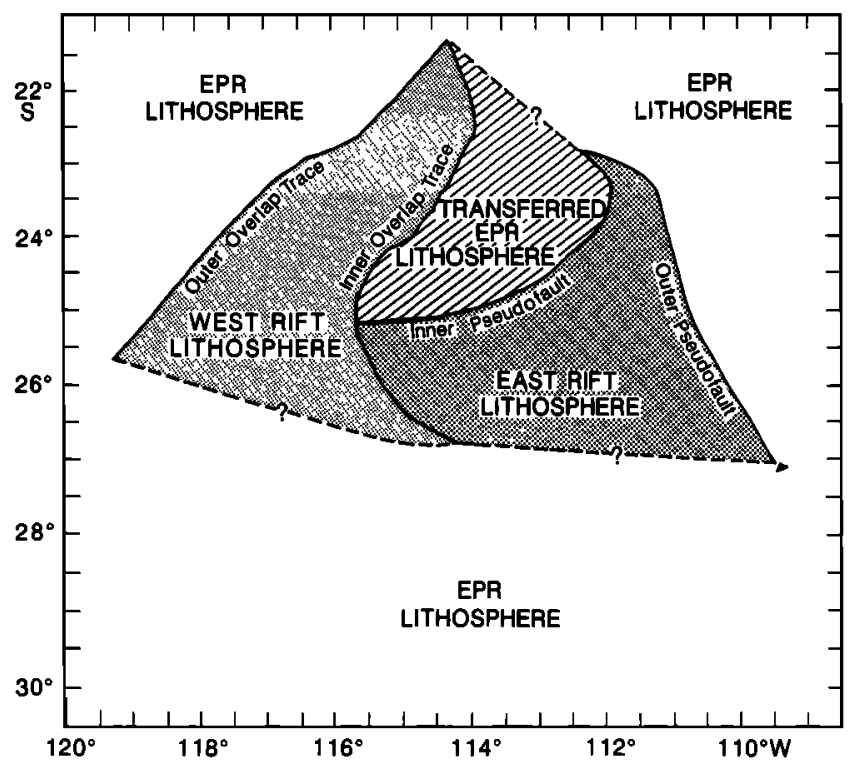

Fig. 8. Schematic representation of lithosphere formed by the EPR (clear), by the overlapped West Rift (light stipple) which was the EPR but has slowed down, and by the East Rift (dark stipple) which has propagated northward. Solid triangle represents Easter Island. Surrounding the West Rift lithosphere are overlap traces which mark when the seafloor spreading along the EPR slowed down to share spreading with the East Rift (and thus become the West Rift). Pseudofaults surround the East Rift lithosphere. Dashed lines bounding the dark stipple represent the uncertain southem limit of lithosphere formed by the East Rift. The dashed line bounding the light stipple represents the more certain southern limit of the West Rift lithosphere. The diagonal hachure represents lithosphere formed at the full Pacific-Nazca spreading rate and transferred to the Easter microplate. The dashed line at the top of this transferred lithosphere connects the East Rift tip with the northernmost point of the overlapped rift. This point is located where the southward increase of observed spreading rates along the Pacific-Nazca plate boundary is reversed and rates are observed to decrease as one approaches the microplate. The envelopes are estimated from the data presented in Figures 4-6 and Plate 1. 
slowing down of the West Rift was more abrupt, one would also expect to see a change from smooth to rough bathymetry [Menard, 1967]. An overlap trace is identical to the failing stiffening boundary, a term used by McKenzie [1986] to mark when and where the spreading rate of a failing rift becomes less than the full spreading rate. An overlap trace is also similar to a triple junction trace except in this case the triple junction would be migrating northward along the EPR as the East Rift propagated northward.

\section{Southwest Rift}

The enveloping scarps of the Southwest Rift are more visible than the spreading segments themselves (Plate 1). The patterns observed in the side scan within this area suggest it is very tectonically and volcanically active, which could explain the frequent teleseismic events from this area. The bathymetry along the axis deepens toward the tip of the propagating Southwest Rift where it appears to be breaking across the southwestern pseudofault ridge (near $26^{\circ} 45^{\prime} \mathrm{S}, 115^{\circ} \mathrm{W}$; Plate 1) [also see Searle et al., 1989]. It appears that a recent episode of propagation replacing the small grabens to the east (interpreted to be spreading axes [Francheteau et al., 1988]) is responsible for this morphology according to GLORIA data interpretation [Searle et al., 1989]. There are some large shallow $(<1600 \mathrm{~m})$ seamounts west of the shallowest portion of the West Rift near $26^{\circ} \mathrm{S}$, $116^{\circ} 30^{\prime} \mathrm{W}$ (Plate 1). It is not clear whether this broad east-west band of shallow seamounts (dense stipple along $26^{\circ} \mathrm{S}$, just west of $116^{\circ} \mathrm{W}$ in Figure 6) is related to channeled flow from the Easter hotspot or from another hotspot.

The shallow ridges associated with the pseudofaults along the Southwest Rift coalesce at an east-west saddle (at $26^{\circ} 47^{\prime} \mathrm{S}$, $\left.114^{\circ} 06^{\prime} \mathrm{W}\right)$, the probable location of the southern transform fault (Plate 1). This location is $-70 \mathrm{~km}$ east of the westernmost expression of a transform fault at $26^{\circ} 46^{\prime} \mathrm{S}, 114^{\circ} 50^{\prime} \mathrm{W}$ [Francheteau et al., 1988]. To the east of this saddle area, the ridges quickly deepen to the surrounding regional depth, suggesting that the shallow ridges are currently being formed by convergence of the microplate and the Pacific plate and/or by volcanic activity.

\section{Southern Transform Zone}

The cluster of teleseismic earthquakes and their fault plane mechanisms along the southern boundary (east of the Southwest Rift tip) indicate very active transcurrent and tensional tectonics. The southern boundary of the microplate appears to be dominated by mostly transcurrent tectonics with very shallow ridges $(<1000$ $m$ in some places) trending easterly toward the East Rift and then curving toward the southeast. The lack of compressional mechanisms (Figure 3) is difficult to comprehend if the large shallow ridges along the pseudofaults of the Southwest Rift were indeed formed by compressional tectonics. If convergent plate motions are not responsible for the formation of the shallow ridges, then an extensive amount of active constructional volcanism must have occurred, especially near where the two ridges coalesce into the east-west topographic saddle mentioned earlier, or else the shallow ridges and saddle are related to some kind of exaggerated uplift due to rifting.

Where the southern boundary continues east of the saddle is not clear. There is a strong southward curving ridge (Plate 1) that appears to be a continuation of the transform fault. This ridge follows the general shape of a small circle about the Pacific-Easter
Euler pole [Naar and Hey, 1989b] as noted by Zukin and Francheteau [1990]. However, transit crossings by SeaMARC II and GLORIA data [Hey and Naar, 1987; Rusby et al., 1988; Searle et al., 1989] indicate that this area is volcanically active and thus may be a new spreading axis overlapping with the axis to the east (Plate 1).

Another enigma in this area is the pattern of earthquakes in the southwest, near the Pacific-Easter Euler poles $\left(-28^{\circ} \mathrm{S}, 114^{\circ} \mathrm{W}\right.$; Figure 3). The origin of these earthquakes is not clear because of the large data gaps in this area (Figure 4). One speculation is that they are related to some kind of deformation to the south of the microplate in the same manner as observed in the northern transform wedge. This analogy to the northern wedge is weak, however, because the geometry of the southern boundary is very different. Another speculation is that there may be very active midplate volcanism in this area. This latter speculation is favored because of the shallow bathymetry directly to the east near the EPR (Figure 5).

\section{Southern Triple Junction}

The southern triple junction area appears to be an RRF triple junction with an overlapped ridge geometry, corroborating the interpretation of Francheteau et al. [1988] and Zukin and Francheteau [1990]. However, this area has a very complicated pattern of bathymetric structures and the southern triple junction may be more diffuse.

Two possible locations for the hypothetical triple junction based on equal predicted rates (see northern transform wedge section) exist south of the microplate at $27^{\circ} 57^{\prime} \mathrm{S}, 113^{\circ} 11^{\prime} \mathrm{W}$ and at $28^{\circ} 1^{\prime} \mathrm{S}, 112^{\circ} 53^{\prime} \mathrm{W}$. There are two points (instead of one) because there appear to be active overlapping spreading axes at this latitude (Figure 3 and Plate 1). The first equal rate point is at the westernmost axis and has a Pacific-Nazca spreading rate of 158.5 $\mathrm{km} / \mathrm{m}$.y. at a direction of $104.7^{\circ}$. The second equal rate point, on the easternmost axis, has the same rate at a direction of $104.9^{\circ}$. The Easter-Nazca spreading rates and directions at these two points are $159.8 \mathrm{~km} / \mathrm{m} . \mathrm{y}$. at $97.5^{\circ}$ and $161.0 \mathrm{~km} / \mathrm{m} . \mathrm{y}$. at $94.5^{\circ}$. When the two Easter-Nazca rates are multiplied by the cosine of $7.4^{\circ}$ and $10.2^{\circ}$, respectively, rates of $158.5 \mathrm{~km} / \mathrm{m} . \mathrm{y}$. are obtained, which match the Pacific-Nazca predicted rates.

The two equal rate points are just to the north of where the two overlapping spreading axes appear to merge into one ridge near $28.5^{\circ} \mathrm{S}$ (Plate 1), suggesting a possible relationship between this area of equal rates and where the EPR appears to divide into a long dual ridge system from $28.5^{\circ} \mathrm{S}$ to $27.5^{\circ} \mathrm{S}$. However, the Pacific-Easter Euler vector predicts approximately north-south convergence at this location (Figure 3) which is not compatible with a ridge-ridge-ridge triple junction configuration unless the Pacific-Easter Euler vector is much farther to the southeast or the relative motion predicted by the Pacific-Easter Euler vector is not applicable in this area (i.e., local nonrigid behavior).

\section{Hotspot/Microplate Interactions}

The shallowest part of the East Rift is located near $26^{\circ} 29^{\prime} \mathrm{S}$, $112^{\circ} 38^{\prime} \mathrm{W}$ at a depth of about $2050 \mathrm{~m}$. The depth of the East Rift increases to a maximum of $5890 \mathrm{~m}$ recorded by the Sea Beam system at $23^{\circ} \mathrm{S}, 111^{\circ} 56.5^{\prime} \mathrm{W}$ [Francheteau et al., 1988]. Thus, along $400 \mathrm{~km}$ of the East Rift, the shallowest and the deepest depths of the entire EPR are observed. There may be a shallower spreading axis along the EPR near $28^{\circ} \mathrm{S}$ (Plate 1), but it is difficult to determine if the bathymetry, which is shallower than $2000 \mathrm{~m}$, is 
actually part of the divergent boundary or is an independent volcanic edifice (Plate 1).

The major outer pseudofault appears to extend from the eastern edge of the Pito Rift area all the way to Easter Island as a continuous structure as indicated by the data shown here and in the GLORIA data [Rusby et al., 1988; Searle et al., 1989]. The significance of this observation is discussed in the reconstruction section. The shallow bathymetry $-190 \mathrm{~km}$ WNW of Easter Island is the Ahu volcanic field, which appears to have been recently active [Hagen et al., 1990] and is also discussed in the reconstruction section.

\section{East Rift and the Microplate Interior}

The seafloor formed by the East Rift is characterized by a wide shallow triangular-shaped area of bathymetry (Figure 8) outlined mostly by the $3200-\mathrm{m}$ contour shown as the yellow-green contour in Plate 1 and by several northward propagating rifts with variable amounts of overlap with the failing rift segments to the east (Figure 6). The amount of overlap shown for all the rift axes in Plate 1 is based on how far the rift grabens curve toward each other. Thus, the amount of volcanic activity along the overlapped ridges is not well constrained.

The propagating rifts are always propagating to the west of the propagating rifts that they are replacing and appear to follow the previously formed pseudofault, explaining why the changes in lineament trends (Figure 4) across the western pseudofaults of the East Rift (except for the major pseudofault) are observed to be subtle in the GLORIA data [Searle et al., 1989]. These subtle changes make it difficult to locate the pseudofaults formed by small-offset propagating rifts in the data (Figures 4 and 7 and Plate 1). The pseudofaults have not been drawn as far as they may extend, especially the ones formed by the propagating rifts in the north, because the slower spreading rates and the rough topography make the magnetic anomaly data difficult to identify. The morphology of the East Rift spreading axes changes as one moves from south to north, from shallow robust ridges to deep, wide rift grabens (Figure 5).

The propagating rift that has currently propagated north of $25^{\circ} \mathrm{S}$ [Naar and Hey, 1986; Sempere et al., 1989] shows bathymetric and SeaMARC II side scan patterns similar to the Galapagos $95.5^{\circ} \mathrm{W}$ propagator. Specifically, curved lineaments between the propagating and failing rifts are observed near $25^{\circ} \mathrm{S}, 112^{\circ} 15^{\prime} \mathrm{W}$ (Figure 4) as expected by the pervasive simple shear model [Hey et al., 1980, 1986] or by changes in propagation and/or spreading rates that are similar to those proposed for the Galapagos propagator [Acton et al., 1988]. This suggests that the curved lineament pattem in both areas was either fortuitously formed by nearly the same changes of spreading and propagation rates [Acton et al., 1988] or by pervasive simple shear [Hey et al., 1986; McKenzie, 1986]. The latter interpretation is preferred because the former interpretation is unlikely.

The zone of transferred lithosphere on the interior of the microplate consists of mostly east-west structures (Figure 4) and is somewhat deeper than the surrounding material (Plate 1). There are other trends in the interior that are visible (Figure 4) [Searle et al., 1989]. East-west profiles of magnetic anomaly data over this area of east-west fabric show very smooth longwavelength variations clearly different from those observed near the West Rift, the East Rift, and the EPR (Figure 6).

The transition between the -east-west trending structures observed on the interior of the microplate from the north-south oriented Nazca abyssal hill fabric is complicated and occurs over a broad area north and west of the Pito Deep area [D. F. Naar et al., submitted manuscript, 1991]. The southern portion of the microplate between the major inner pseudofault and the East Rift exhibits a general fanning of the lineament pattern which is clearly evident in the virtually complete coverage of the GLORIA data [Searle et al., 1989], although this pattern also contains subtle expressions of pseudofaults that have very little change in lineament orientations across them [Searle et al., 1989]. The corresponding lineament pattern on the Nazca plate (Figure 4) does not show the same fanning pattern and instead shows a more ridge-parallel fabric [Hey et al., 1985; Naar and Hey, 1986; Searle et al., 1989]. This inconsistency appears to be related to multiple episodes of northern rift propagation [Hey et al., 1985], but the details of this process are unclear. All the data suggest that the East Rift is a complex, rapidly evolving boundary [Naar and Hey, 1989b; Searle et al., 1989] that has been formed by continuous rift propagation with a nearby pole which was then followed by waves of northward propagating rifts complicating the bathymetric and magnetic patterns along the East Rift.

\section{MAGNETIC MODELING}

\section{Methods}

Lack of information indicating flow lines through the microplate (paleospreading directions) prevents accurate rate estimates for most of the microplate that has probably undergone complex and rapidly changing plate motions and episodes of deformation [Naar and Hey, 1989b; Searle et al., 1989]. In addition, the spreading rates used in the models (Figure 7) must account for the actual spreading rate plus any active or previous deformation of the seafloor, the two of which are inseparable with respect to the magnetic modeling program. Thus the rates in Table 1 do not necessarily represent true spreading velocities. Profiles $\mathrm{D}$ and $\mathrm{E}$ are modeled using an average spreading direction and separate spreading rates for the West Rift and East Rift (WR and ER in Table 1) and then are physically combined. Rates prior to the formation of the microplate (old Pacific-Nazca rates) are also included as WR rates in Table 1. In other words, the WR rates are for the entire profile except for the part across the triangular wedge of lithosphere formed by the new East Rift (Figure 8). To generate synthetic profiles out beyond the last identified magnetic anomaly, an arbitrary age of $15 \mathrm{Ma}$ was occasionally used in Table 1.

Extremely rugged bathymetry and the suspected slow spreading rates in the northeast area of the microplate (north of $25^{\circ} \mathrm{S}$ ) make the magnetic anomaly pattern complex. Only the magnetic anomalies that have been identified with confidence in this section are shown in Figure 6. Extrapolations to the north and south of the microplate follow previous interpretations of the data by others [Rea, 1981; Handschumacher et al., 1981]. Seven long profiles across the area, used to help decipher the older magnetic anomalies, are shown in Figure 7 and indexed in Figure 6 as profiles $B$ through $H$. An eighth east-west profile, profile $A$, is just $12 \mathrm{~km}$ north of the northem limit of Figure 6 and crosses the EPR at $21.39^{\circ} \mathrm{S}, 114.27^{\circ} \mathrm{W}$. There are many shorter magnetic profiles and models not shown in Figure 7 because they have been published elsewhere [Naar and Hey, 1989b]. All the parameters used to generate the magnetic anomalies are described in the caption for Figure 7 and listed in Table 1.

The magnetic anomaly data were modeled by generating a synthetic magnetic anomaly using the observed bathymetry, the orientation of magnetic stripes, and the magnetic polarity time 
TABLE 1. Magnetic Model Parameters

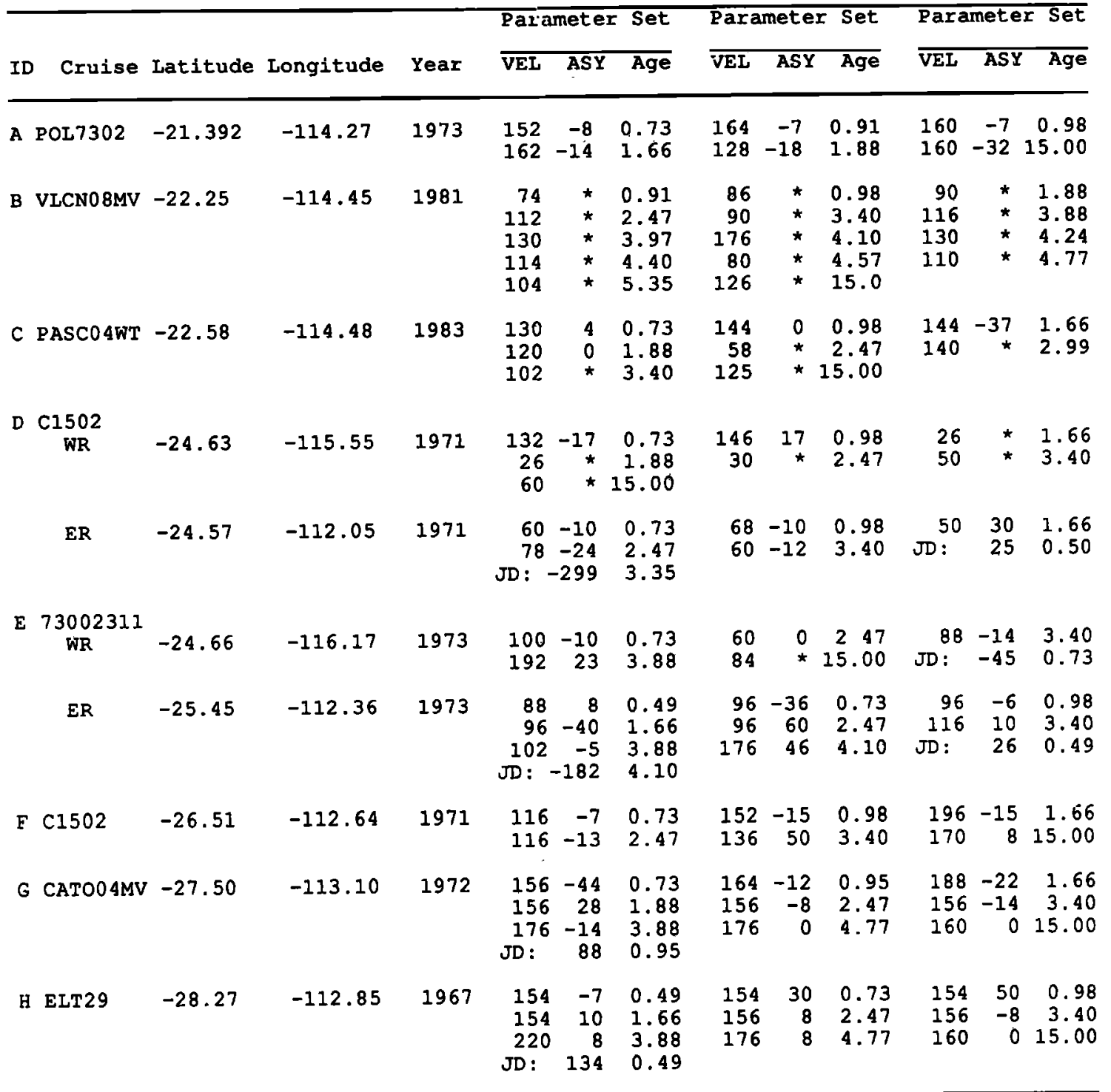

ID, profile label; VEL, spreading full rate (mm/yr), except when there

is an asterisk in the ASY column which means the rate is only a half rate;

ASY, spreading asymetry (percent added to the west from the east); Age,

(Ma) the time when parameter goes into effect: WR, parameters for West Rift;

ER, parameters for East Rift; JD, distance of rift jump at the time of the

rift jump (km, Ma). Note that JD is in the VEI column, the actual jump

distance is in the ASY column, and the jump time is in the Age column.

*Indicates there is no asymmetry given because only one spreading half rate was available.

scale of Kent and Gradstein [1986] modified to include the Emperor reversed event [Ryan, 1972; Champion et al., 1981] which Wilson and Hey [1981] date at 0.49-0.50 Ma based on modeling magnetic anomalies along the Cocos-Nazca spreading axis. The $X$ and $W$ normal events within the Gauss at 2.01-2.04 $\mathrm{Ma}$ and at 2.12-2.14 Ma were also added [Rea and Blakely, 1975]. The spreading axis is located by bathymetry and, if observed, by the high-amplitude axial magnetic anomaly which appears to exist along most spreading axes [Rea and Blakely, 1975; Wilson and Hey, 1981]. The skewness of some axial magnetic anomalies is an additional independent check on the orientation of the magnetic isochrons.

\section{Results}

The magnetic anomaly data in profile A (Figure 7) are well matched by the magnetic model using rates in general agreement with plate motion models for this area [Near and Hey, 1989b; Gordon et al., 1988; DeMets et al., 1990]. Profile A exhibits asymmetric spreading faster to the east or asymmetric accretion adding more material to the east (via repeated events of rift propagation that would leave failed rifts and transferred lithosphere to the east). Profile B, farther to the south, shows more seafloor to the east of the EPR than profile A, although without the western half of profile $B$, asymmetry cannot be 
measured properly. Profile $\mathrm{C}$, which passes through the northern deformation zone of the microplate, shows evidence of a disrupted magnetic pattern. The eastern edge of the Brunhes and the eastern Jaramillo display an unusual shape with respect to the model. Anomaly 2' has a very fast half rate and may be related to the rotational deformation (as defined by Means [1976, pp. 145-148]) indicated in the lineament data (Figure 4) and predicted in the reconstruction section. The sum of the fast half rates needed to model the older anomalies of profile $\mathrm{C}$ and the slower rates measured on the westem flank (Figure 6) gives the approximate whole rate expected [Gordon et al., 1988; DeMets et al., 1990].

Profile D shows a reasonable fit for the anomalies surrounding the West Rift out to anomaly 2'. The model is not meant to match data on the microplate interior where the lineament pattern (Figure 4) clearly shows an east-west trend which is parallel to the magnetic profile orientation. The anomalies across the East Rift are well identified except for the anomalies near the shallow bathymetry (Figure 7) where a recent propagation event has complicated the Brunhes and Jaramillo magnetic anomaly pattern. To the east of the major outer pseudofault of the East Rift, the model unsuccessfully attempts to match the older anomalies using the identifications from the continuous relatively undisturbed anomalies from the north (Figure 6). The reconstruction section shows there is an offset in the magnetic anomalies in this region which is predicted from a clear offset of magnetic anomalies on the Pacific plate during the time span of the older anomalies (Figure 6). If this offset of the magnetic anomaly data was accommodated by a long-term history of dueling propagating rifts, the magnetic anomaly pattern would be confused. The lack of east-west magnetic profile data to the north and south of Easter Island makes modeling this area difficult. Clearly, more east-west magnetic data in the vicinity of Easter Island would constrain the geometry of the Pacific-Nazca plate boundary prior to the formation of the Easter microplate.

Profile E starts from the major outer pseudofault of the East Rift and extends a great deal farther west than profile D. Profile E has a reasonable match for the anomalies across the East Rift and anomalies 1 and 2' across the West Rift (Figure 7 and Table 1). There are many magnetic anomaly wiggles west of the West Rift that cannot be explained by one stationary ridge, suggesting that this profile crosses a zone of old dueling propagation or some other tectonic complexity. There is an expected poor fit to the anomalies on the microplate interior between the major inner pseudofault of the East Rift and the inner pseudofault formed by the initial propagation of the Southwest Rift because of the probable rotation and deformation of the microplate core. Because of this poor fit, the magnetic anomalies of the microplate interior (Figure 9) are predicted from the plate reconstructions described in the next section.

Profile $\mathrm{F}$ shows a reasonable fit of the model to the data across the East Rift out to anomaly 2. Beyond that, things break down, mostly because of the disrupted bathymetry just to the west of Easter Island and the complicated short-wavelength magnetic anomaly pattern on the microplate interior.

Profiles $\mathrm{G}$ and $\mathrm{H}$ are to the south of the microplate across the hypothesized large-offset southward propagating rift [Naar and Hey, 1986] that currently appears to be dueling with a recently northward propagating rift from the failing portion of the EPR [Hey et al., 1988; Klaus et al., 1991]. Both profiles show reasonable correlations out to anomaly 3 in the areas unaffected by anomalous bathymetry and by the propagation history. Beyond that, the disrupted bathymetry in the east and the irregular magnetic anomaly pattern in the west, which does not correlate between profiles $G$ and $H$, clearly show an unusual tectonic history which gives support to a nontransform offset existing during this time. This type of nontransform offset is consistent with the speed limit hypothesis for transform faults [Naar and Hey, 1989a].

\section{TECTONIC RECONSTRUCTION}

\section{Methods}

The caption of Figure 9 describes the reconstruction method. The dashed isochrons (Figure 9) were predicted after reconstructions by assuming unidentified lithosphere must match identified lithosphere across a divergent boundary. When minimizing all the overlaps and gaps around the microplate for each reconstruction, the pseudofault tips do not always come to a point as expected if the microplate were behaving as a rigid body. In some instances, rigid rotation can bring the pseudofault tips back together but very large gaps and overlaps around the microplate result. Thus, in the reconstructions for 1.66 and 2.47 Ma (Figures $9 d$ and $9 e$ ) the pseudofault tips are not coincident.

If the magnetic anomaly identifications shown in Figure 9 are correct, then gaps in the reconstructions imply that compression occurred and the material needs to be stretched back to its previous configuration. Conversely, overlaps indicate that extension occurred and that compression of the lithosphere is needed to obtain its original shape. The overlaps and gaps shown in each reconstruction represent the total amount of deformation of lithosphere older than the time of the reconstruction. The gaps, overlaps, and slight mismatch of pseudofault tips in these (rigid) reconstructions indicate that plate deformation is required to some extent during the evolution of the microplate. Unfortunately, it is not clear how this deformation is accommodated. In addition, data uncertainties are difficult to estimate and thus the amounts of deformation may be in part related to these uncertainties.

The detailed reconstructions (Figure 9) are simplified in Figure 10 to show how the active plate boundaries evolve depending on the microplate's size and shape. The simplified reconstructions are based on the detailed reconstructions and are positioned relative to the spreading axes to the north and south of the microplate to enable a "flip book" of the evolution to be constructed in a manner similar to the Juan de Fuca reconstruction [Hey and Wilson, 1982].

\section{Detailed Reconstructions}

For the initial starting configuration, the previous tectonic boundaries (see Figures 4, 5, and 6 and Plate 1) have been simplified; for example, the geometry of the Pito Rift area has been shown as a narrow triangular wedge to approximate the more complicated horst and graben structures observed (Plate 1 and Figure 6). This triangular shape, however, is probably more representative of the amount of extension within the Pito Rift area (Figure 8). The minor simplifications of the boundaries were made to facilitate the reconstructions, especially in complex areas such as the Pito Rift area and along the midportion of the West Rift. For example, the orientation of the fracture zone shown to extend west from the middle of the West Rift near $25^{\circ} \mathrm{S}$ (Figure 9) is not well constrained and is only suggested to exist by a disrupted bathymetric pattern (Plate 1). The (incomplete) GLORIA data [Searle et al., 1989] in this area suggest that the fracture zone extends almost to the outer pseudofault but does not connect directly to the active transform fault (Figure 9a). These types of discrepancies are minor compared to other complications 

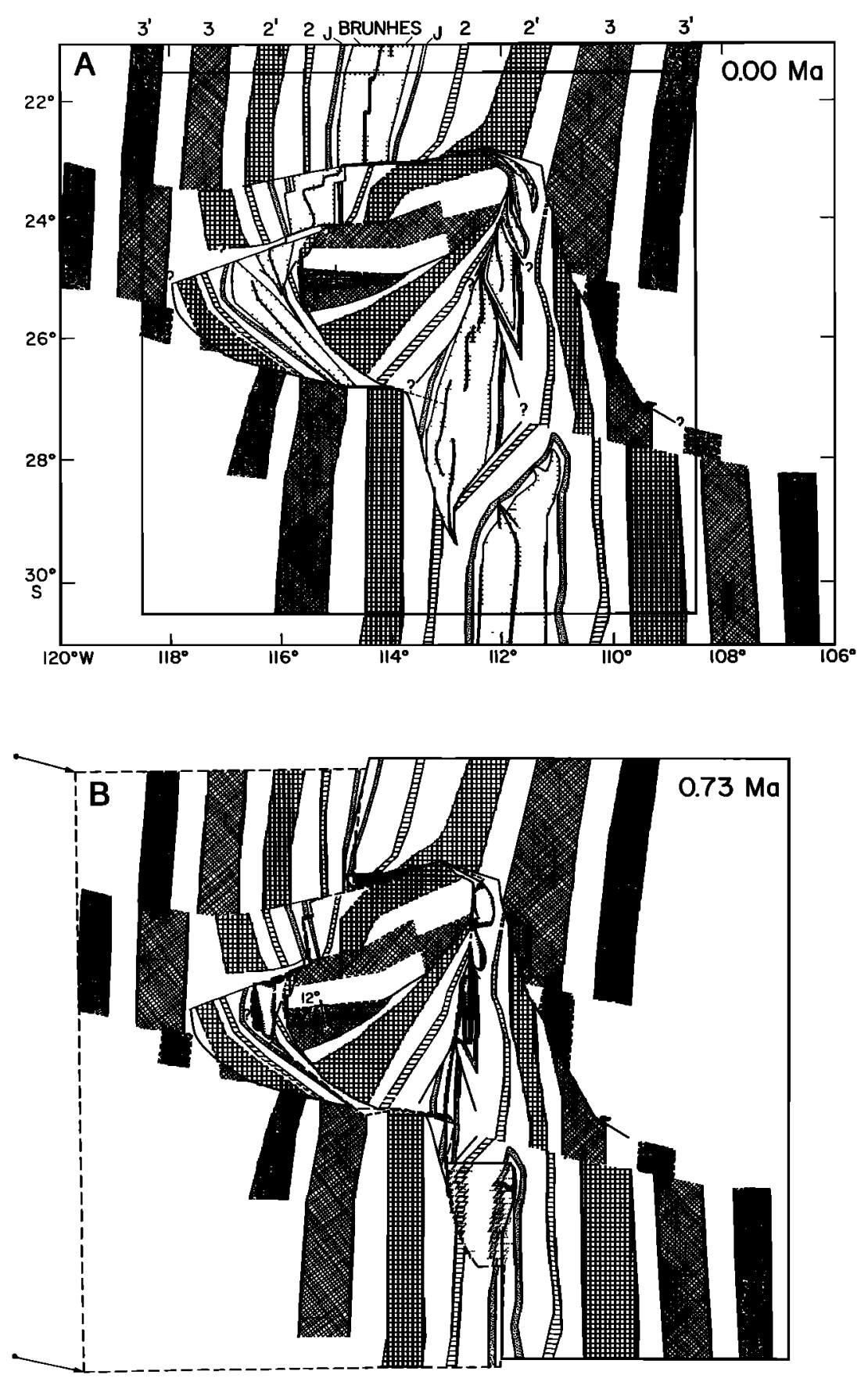

Fig. 9. Detailed reconstructions of the Easter microplate using rigid plate assumptions. Tectonic boundaries are simplified from Figure 4. The time of each reconstruction is indicated at upper right corner. There is a total of 10 time periods (Figures $9 a-9 j$ ). (a) The rectangle represents the size of the data figures, and the labels at top identify the magnetic anomalies. Identifications made outside of the rectangle were based on other data and previous interpretations [Handschumacher et al., 1981; Rea, 1981]. Magnetic anomaly identifications within the rectangle were extrapolated from those of Figure 6 using the bathymetry (Plate 1 and Figure 5) and lineament pattern (Figure 4) as constraints. The dashed isochrons are predicted by the reconstructions and are not always observed in the available magnetic data. $(b)-(j)$ The reconstructions were created by cutting and removing magnetic anomalies of a certain age and moving the Pacific plate to match the "fixed" Nazca isochrons north and south of the microplate using the NUVEL 1 global plate motion model [Gordon et al., 1988; DeMets et al., 1990] as a directional guide. In all the reconstructions (Figures $9 b-9 j$ ), the Nazca plate is outlined by a solid line. The Pacific plate is outlined by a long-dashed line. The Easter plate is outlined by a short-dashed line. Relative motion of the Pacific plate with respect to the Nazca plate during one time interval is shown by a heavy solid arrow pointing at the two western "corners" of the Pacific plate. The previous PacificNazca relative motion is shown by a heavy dotted line (see Figure $9 c$ ). The Easter microplate was then rotated to fit within the interior of the microplate to minimize all the cumulative gaps and overlaps, similar to the method of Bullard et al. [1965]. Gaps are shown as solid black. Overlaps are shown by having isochrons disappear in a systematic way so that the Easter plate always blocks out the Nazca and Pacific isochrons and the Nazca plate always blocks out the Pacific isochrons. Gaps indicate that too much material was removed and compression probably occurred. Overlaps indicate that not enough material was removed and extension probably occurred. The "corners" of the Pacific, Nazca, and Easter plates that used to meet at a triple junction do not always line up in the reconstructions. Arrows are drawn showing how some of the "comers" could be brought back together (see Figures $9 b-9 f$. In places where there were small-offset propagating rifts, the material that was transferred was cut into strips parallel to relative motion (outlined by dotted lines) to simulate simple shear. Previously active spreading axes are always on the Nazca side of these simulated shear zones except on the West Rift, which has the previously active axis on the Pacific side of the simulated shear zone. Large cross and number of degrees on the microplate interior give the cumulative rotation of the microplate interior backward in time. 

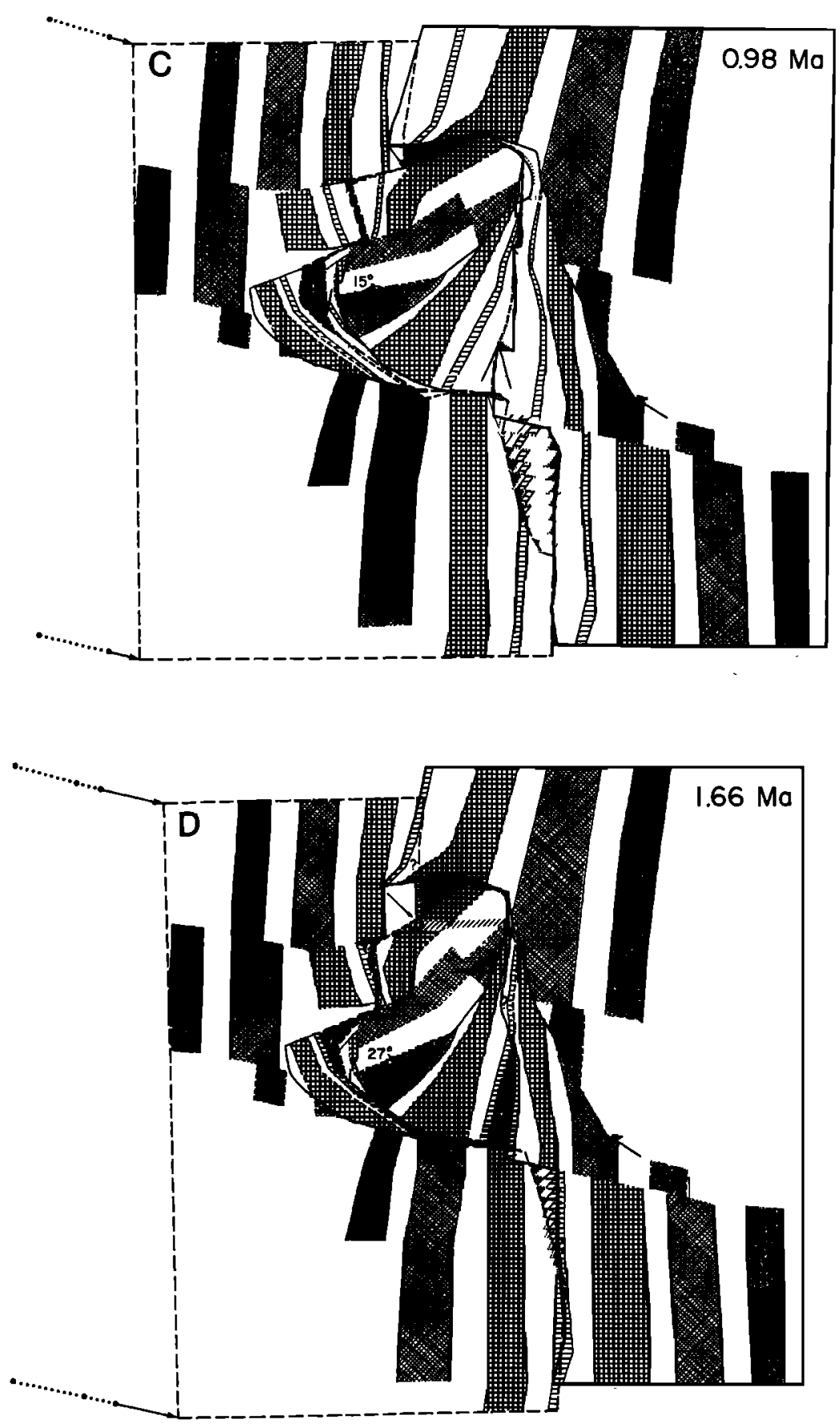

Fig. 9. (continued)

that arise during the reconstructions and will not be addressed here unless they are related to the general plate tectonic evolution of the microplate. Other aspects of the current geometry and tectonics of the microplate are discussed in detail in the data description section and elsewhere [Naar and Hey, 1989b; Searle et al., 1989].

0.00 to $0.73 \mathrm{Ma}$. At $0.73 \mathrm{Ma}$, the geometry of the microplate boundaries is similar to the present geometry. There is a gap and overlap formed at the northern transform wedge indicating that there was north-south compression and east-west extension, assuming the magnetic anomalies are correctly identified, which for this time interval is a safe assumption [Naar and Hey, 1989b]. The east-west shallow ridge, flanked by a steeply dipping scarp to the south and a gradual rise on the north, has shallow summit depths of about $1700 \mathrm{~m}$ [Francheteau et al., 1988] and is clearly shallower than the 2400-m contour (Plate 1). In addition, the southern scarp of the ridge has a total offset greater than $1200 \mathrm{~m}$ whereas the northern relief is about 800 meters or less. The morphologic characteristics suggest that there is some degree of compression, with the younger northern edge overriding or folding up with respect to the older southern edge which gently dips northward toward the deep east-west trough outlined by the 3600 -m contour (Plate 1). It is possible that transform motion may be contemporaneous with the suspected compression or was active in the past because there is a furrow along the crest of this east-west trending ridge observed in the Sea Beam data suspected 

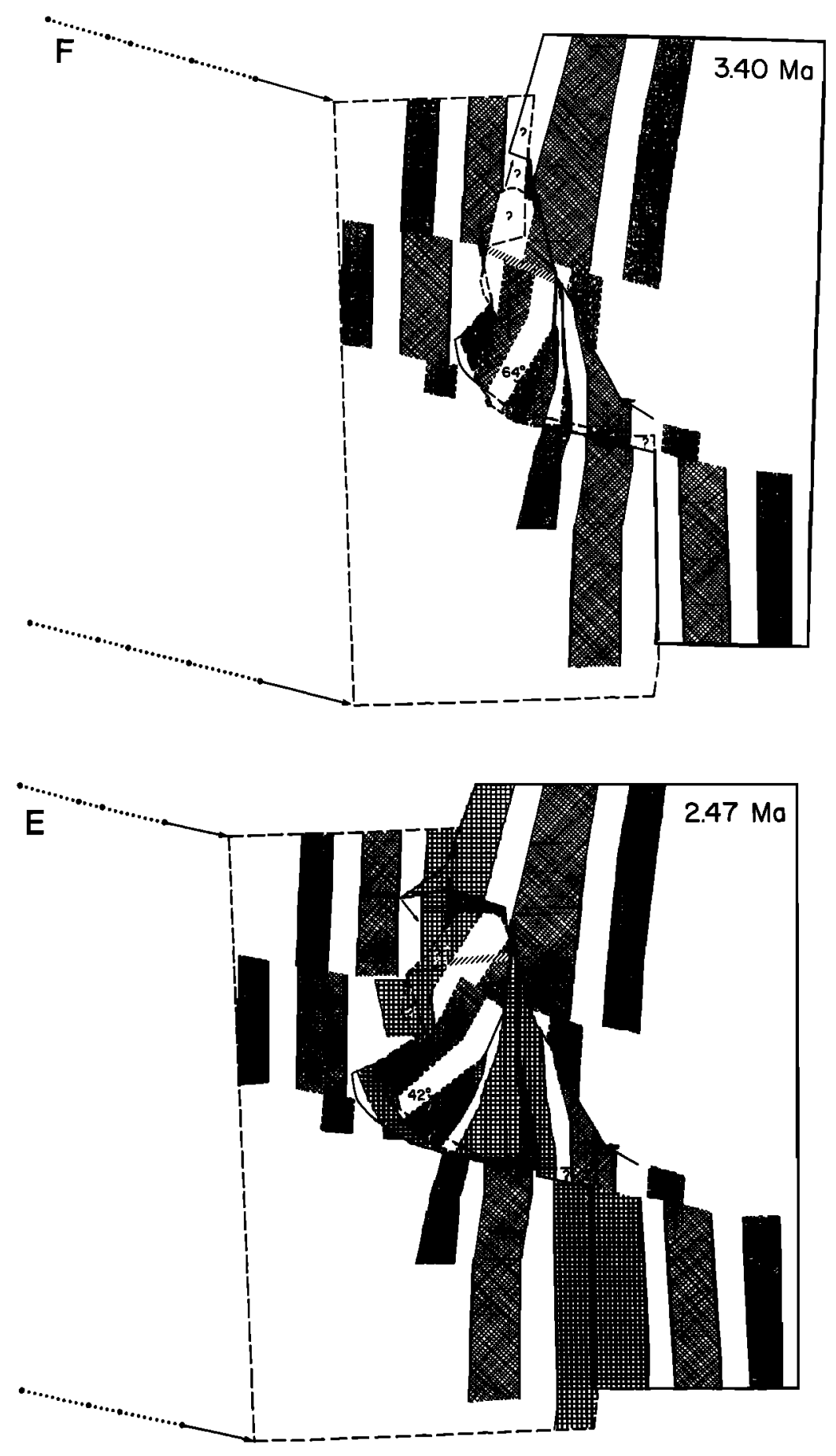

Fig. 9. (continued)

to have been formed by strike-slip faulting [Francheteau et al., 1988].

Both the compression and extension could be accommodated by simple shear within a triangular wedge north of the microplate in a direction parallel to the arrow pointing from the Nazca plate "comer" of the northern triple junction to the Pacific plate "comer" of the northern triple junction (Figure $9 b$ ). Oblique and progressively rotated magnetic anomaly isochrons (Figure 6) and lineaments observed in the SeaMARC II side scan and Sea Beam lineaments (Figure 4) and the GLORIA side scan lineaments
[Rusby et al., 1988; Searle et al., 1989] are observed in the eastern half of the northern wedge. However, the western half of the wedge has a more north-south and east-west seafloor fabric, suggesting that the actual mechanism of deformation is complex and not homogeneous throughout the northern transform wedge. The "bookshelf mechanism" [Kleinrock and Hey, 1989b] appears consistent with the structural fabric observed in the eastem half of the northem wedge but not for the western half. See Kleinrock and Hey [1989b] for a review of some possible mechanisms of rotational deformation that are consistent with simple shear. 

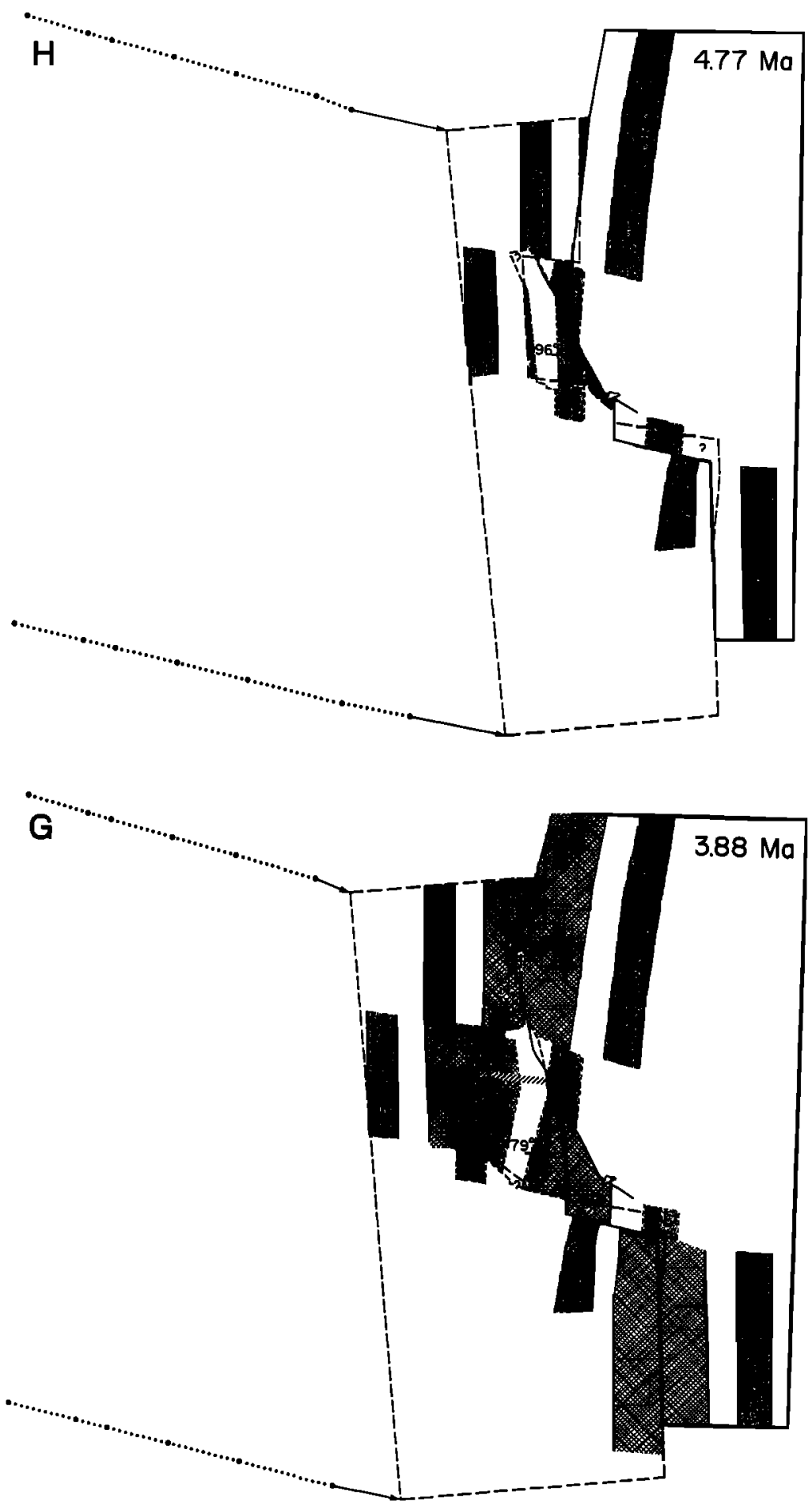

Fig. 9. (continued)

A similar geometry of coupled compression and extension is observed within a similar triangular wedge south of the microplate at the $0.73 \mathrm{Ma}$ reconstruction stage (Figure $9 \mathrm{~b}$ ). This space problem can also be accommodated in a similar manner as described for the northern area, although the structural data indicate that the mode of deformation is much more complex. An arrow connecting the Pacific plate "comer" of the southern triple junction with the Nazca plate "comer" of the southern triple junction is shown in Figure $9 b$ to show how the two "comers" should be together after the reconstruction. In addition, there is overlap along the western part of the southern boundary indicating that either extension occurred, there was diffuse spreading, the southern boundary geometry reorganized rapidly, and/or the western part of the southern boundary was oriented more NW-SE than assumed here.

The above possibilities cannot be investigated because the area is extremely tectonized and the previous plate boundary could have been easily overprinted by more recent activity. In addition, this area is characterized by extremely rough bathymetry and recent volcanic activity (as suggested by the high backscatter 

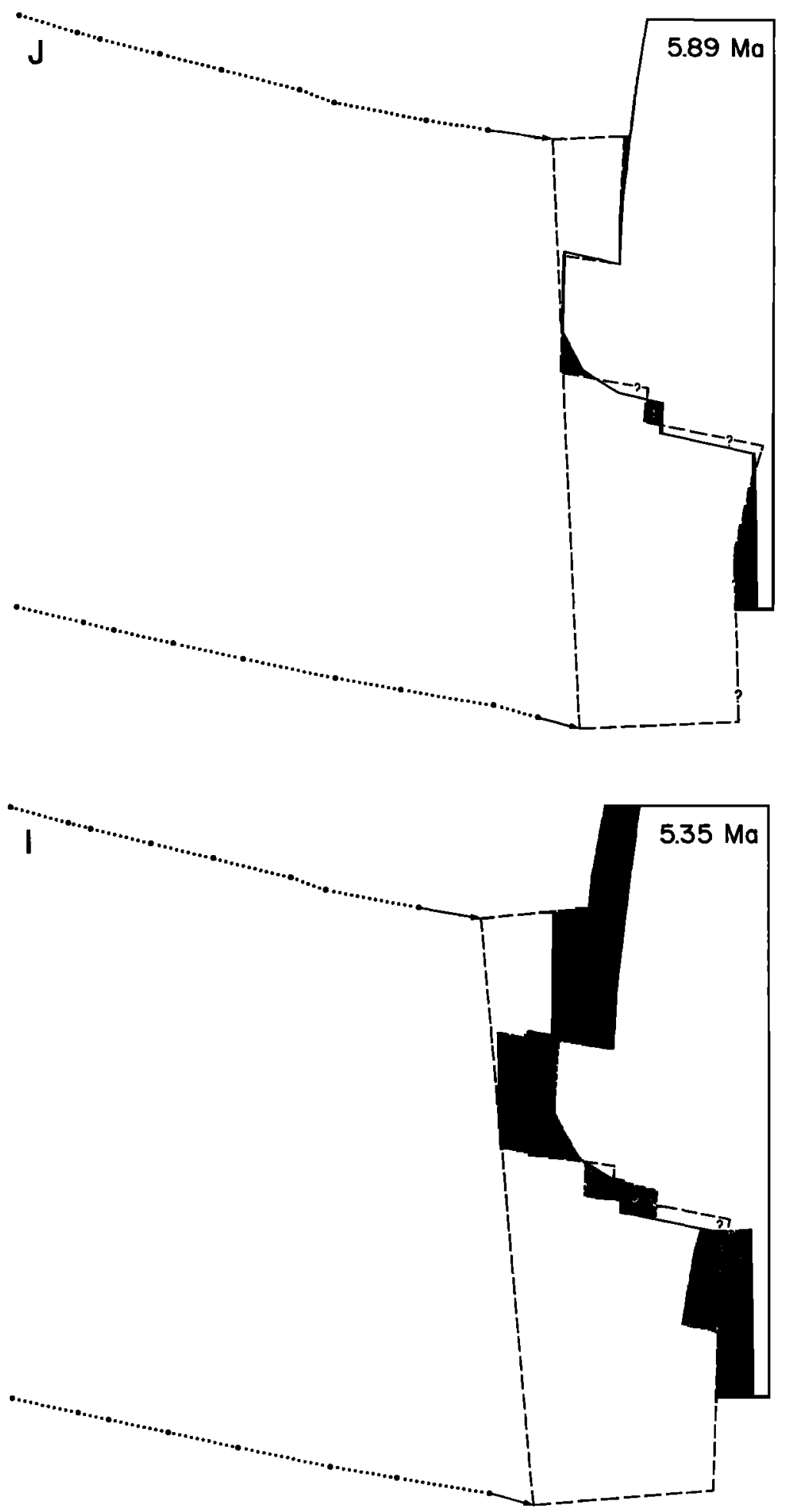

Fig. 9. (continued)

observed in the SeaMARC II side scan data. The two shallow ridges that converge toward the southem boundary (representing the pseudofaults of the Southwest Rift) have depths shallower than $1600 \mathrm{~m}$ (Figure 4) and thus this ridge is most likely tectonic as well as volcanic in origin. This interpretation is corroborated by the earthquake pattern and fault plane solutions [Engeln and Stein, 1984] in this area (Figure 3). Thus, the overlap formed in this region is difficult to evaluate because of the very complicated tectonics in this area.
The gaps and overlaps near the dotted blocks of transferred lithosphere formed by the small-offset propagating rifts around the microplate are minor except at the midportion of the West Rift near the small-offset propagating rift (see the question mark in Figure 9b). This small-offset propagating rift was suspected to exist because of two southward converging deep troughs observed in the bathymetry contours (Plate 1), a small rift-like graben centered in a symmetrical ridge (see WSW-ENE profile crossing the center of this short southward propagating rift in Figure 5), 

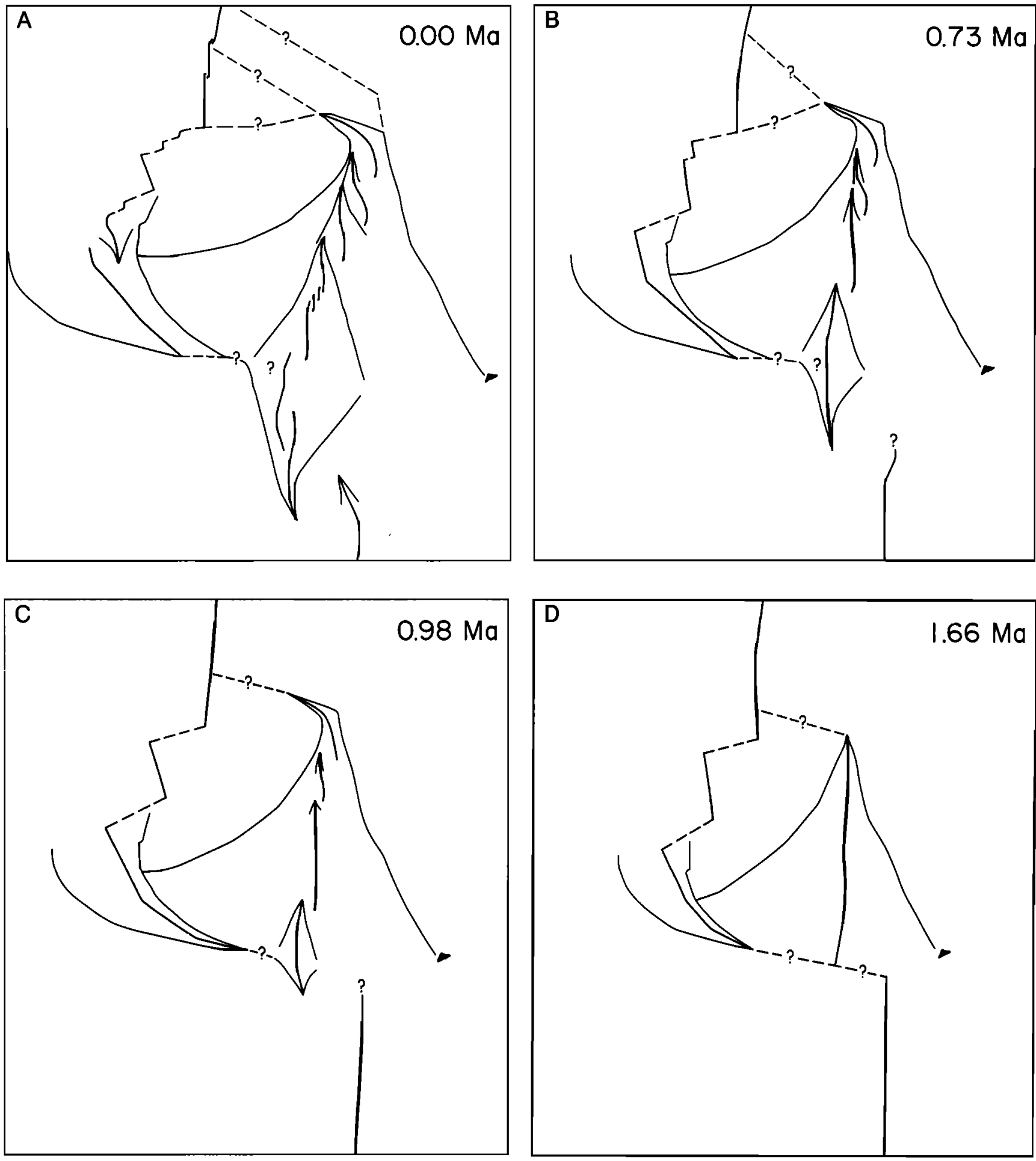

Fig. 10. Simplified tectonic history of the formation and evolution of the Easter microplate based on the detailed reconstructions of Figure 9. The spreading axes to the north and south of the microplate are held fixed so that the different time sequences (Figures $10 a-10 j$ ) can be superimposed using the edges of the figure as a reference. Solid lines represent spreading axes. Dashed lines represent an offset of the magnetic anomalies but not necessarily a transform fault, as discussed in the text. Only the outline of Easter Island is shown at 3.88 and $4.77 \mathrm{Ma}$ (Figures $10 \mathrm{~g}$ and $10 \mathrm{~h}$ ) to emphasize the uncertainty in its age. At $4.77 \mathrm{Ma}$ (Figure $10 h$ ), two dashed lines forming a V represent the possibility that the East Rift may have been already propagating prior to reaching the latitude of Easter Island. At 3.40 Ma (Figure 10f), Easter Island is solid black, indicating its probable time of formation based on the oldest subaerial sample obtained (3 Ma) [Baker et al., 1974] and the Nazca-hotspot vector from the Ahu volcanic field (Figure 3) [Naar and Hey, 1989b]. At $2.47 \mathrm{Ma}$ (Figure 10e), which is about the time the East Rift stopped propagating northward, the length to width ratio of rift overlap is about 3 . Up to this time, the average propagation rate is about $135 \mathrm{~km} / \mathrm{m}$.y. Between $2.47 \mathrm{Ma}$ and present, the propagation rate is difficult to measure. The two northern dashed lines at $0.73 \mathrm{Ma}$ (Figure $10 \mathrm{~b}$ ) represent a deforming wedge of lithosphere. At $0 \mathrm{Ma}$ (Figure 10a), a third dashed line is shown in the interior of the wedge showing the probable northernmost limit of recent deformation. The top, bottom, left, and right sides of Figure $10 \mathrm{a}$ are $21^{\circ} \mathrm{S}, 30^{\circ} \mathrm{S}, 118^{\circ} \mathrm{W}$, and $109^{\circ} \mathrm{W}$, respectively. 

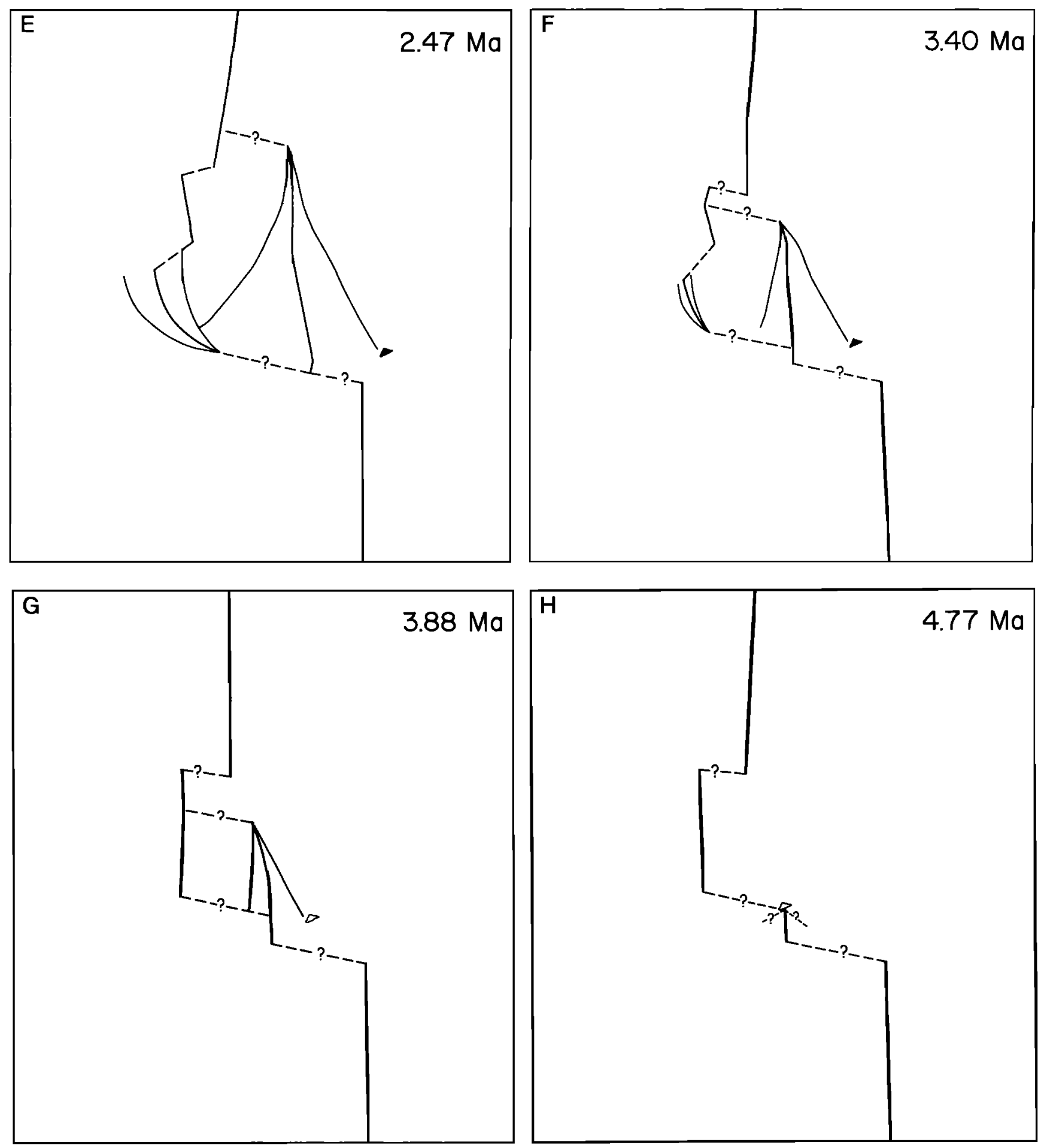

Fig. 10. (continued)

and the lack of a well-shaped Brunhes magnetic anomaly (Figure 6). GLORIA data in this area [Rusby et al., 1988; Searle et al., 1989] clearly show that there is a rift propagating southward, but even with this new corroborating data the area covered by the Brunhes Epoch is still unclear. The lack of spreading rate data from this middle portion of the West Rift has only a minor impact on our instantaneous Euler vector for the Pacific-Easter plate pair [Naar and Hey, 1989b] because the rates north and south of this area and the transform and seismic slip directions are clearly the most important data in determining the Euler vector.
The microplate has rotated about $12^{\circ}$ during this time interval, corresponding to a rotation rate of about $16 \%$ m.y., which is in very good agreement with the predicted rotation rate of $15 \% \mathrm{~m} . \mathrm{y}$. during this period [Hey et al., 1985; Naar and Hey, 1989b] considering the different data and methods used.

0.00 to $0.98 \mathrm{Ma}$. At $0.98 \mathrm{Ma}$, the misfits of the northern and southem boundaries increase. Once again, simple shear oriented in a direction parallel to the two arrows connecting the northem and southern triple junction "comers" of the Pacific and Nazca plates could accommodate the space problem. More complicated 


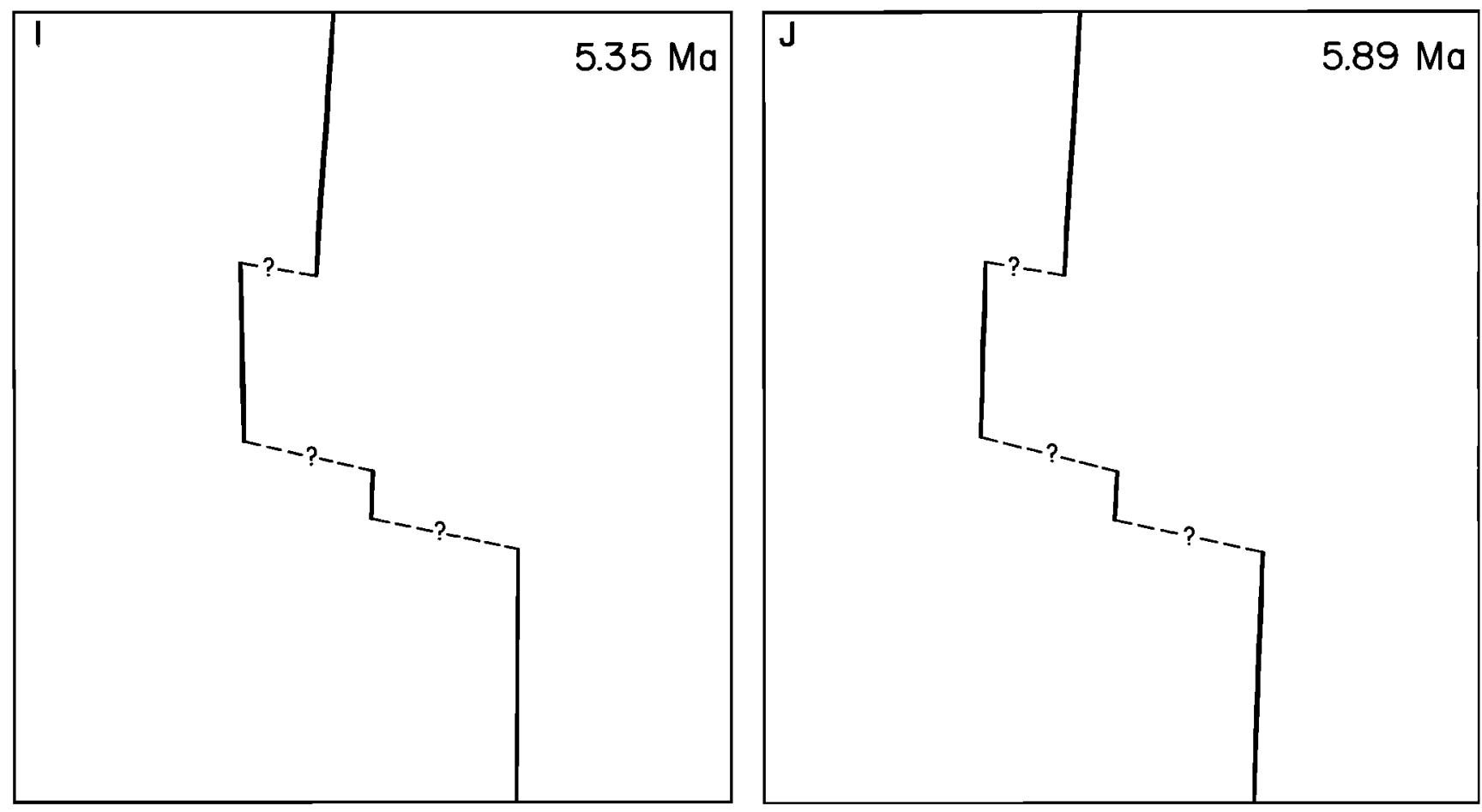

Fig. 10. (continued)

forms of deformation are more likely according to the reasons discussed earlier.

The rotation rate of the microplate is about $15 \% \mathrm{~m}$.y., which also agrees well with the rate extrapolated from the $0.00-0.73 \mathrm{Ma}$ instantaneous Euler vector [Naar and Hey, 1989b]. The location of the eastem Jaramillo anomaly is unknown along the midportion of the West Rift; hence only the western anomaly and the block of transferred lithosphere (outlined by dotted lines in Figure $9 b$ ) are removed for the reconstruction at $0.98 \mathrm{Ma}$, which creates a large gap. This was done instead of arbitrarily cutting up the block of transferred lithosphere at $0.73 \mathrm{Ma}$ to make it fit at $0.98 \mathrm{Ma}$. This has the added benefit of emphasizing when and where there are complications within the magnetic pattern.

As the reconstructions progress back into time, the amount of cumulative gaps and overlaps will increase because of the rigid method used, which means older lithosphere in the interior that had undergone any deformation over time does not "stretch" back to its original shape or size for any of the reconstructions.

0.00 to $1.66 \mathrm{Ma}$. At $1.66 \mathrm{Ma}$, the major pseudofaults of the East Rift bounding the Pito Deep area are brought together and the tip of the East Rift is farther south than it was in the previous reconstructions. Material that had been transferred to the Easter microplate is now part of the Nazca plate. A schematic northern boundary is shown connecting the East Rift tip with the northernmost transform fault of the West Rift in a nearly east-west orientation (see diagonal hachuring in Figure $9 d$ ) because the actual location of the northern boundary at $1.66 \mathrm{Ma}$ is not well known. The large gaps and overlaps in the north represent the cumulative amount of deformation that probably took place as simple shear over the past $1.66 \mathrm{Ma}$ while material was being transferred from the Nazca plate to the Easter microplate interior. This process appears to be still active today, but it is complicated because the East Rift appears to be propagating more to the west than to the north, probably in response to the rapid rotation of the microplate [Schouten et al., 1988].
There is a large gap formed along the southern portion of the East Rift and an equally large overlap along the northern portion of the East Rift. Identification of anomaly 2 surrounding the northern part of the East Rift is difficult and was mostly extrapolated northward from the midpart of the East Rift where identification was more certain. South of this midpart of the East Rift, anomaly 2 stands out clearly on the Nazca plate but less so on the microplate (Figures 6 and 7). The pattern of magnetic anomalies about the failed rift formed by the northward propagating rift at $25^{\circ} \mathrm{S}$ suggests that anomaly 2 which was on the microplate may have been transferred to the Nazca plate in the same manner as the Jaramillo (Figure 9a). However, the lineament pattem (Figure 4) and the continuous fault pattern observed in the GLORIA data [Rusby et al., 1988; Searle et al., 1989 ] are not consistent with this interpretation.

Only the tentatively identified magnetic anomalies on the Pacific plate are removed for the reconstruction of the midportion of the West Rift. The previous gap in this area at this reconstruction stage is now similar in size to other gaps around the microplate. The sheared zone south of the microplate is the last remaining manifestation of the southward propagating rift. The microplate has rotated $27^{\circ}$ since this time, corresponding to a rotation rate of about $16 \%$ m.y., which suggests a nearly constant rate of rotation for the past $1.66 \mathrm{~m} . \mathrm{y}$.

0.00 to $2.47 \mathrm{Ma}$. At $2.47 \mathrm{Ma}$, all the sheared zones associated with the small-offset propagating rifts are gone. This is probably an artifact of the coverage and resolution of the data. Hence there may have been other small-offset propagating rifts during this time. There is still a small gap along the southern portion of the East Rift. There is more overlap along the northern portion of the West Rift than there was at $1.66 \mathrm{Ma}$. There is a new gap that has formed at the westernmost edge of the microplate which appears related to the assumed orientation of the transform fault offsetting the midportion of the West Rift. The northern boundary is farther south and is still connected to the northernmost transform fault of 
the West Rift. One of the major problems in identifying magnetic anomalies 2, 2', and 3 on the Nazca plate just to the west of Easter Island is the magnetic overprinting resulting from the recent submarine volcanism throughout the Ahu volcanic field [Hagen et al., 1990] (see stipple west of Easter Island in Figure 6 and shallow bathymetry extending $190 \mathrm{~km}$ WNW from Easter Island, Plate 1).

The corresponding rotation rate of the microplate during the past $2.47 \mathrm{Ma}$ is about $17 \%$ m.y., which is slightly faster than the present-day rotation rate of the microplate. The large radius of curvature for the Southwest Rift indicates that the majority of the interior was still behaving as a rigid "ball bearing." The East Rift tip geometry does not show this curvature, yet the previous geometry of the northern East Rift is difficult to determine because the magnetics are very complicated in this area of very rough bathymetry. Thus it is possible that the East Rift geometry is oversimplified and may have had a geometry compatible with rigid rotation of the microplate.

There is a growing overlap across the southernmost EPR offset which might be related to the orientation uncertainty of the preexisting offset. The southern East Rift is located well to the east of the center of anomaly 2'. This indicates that there was a great deal of asymmetric spreading or, more likely, that there was one or more rift jumps to the east possibly related to the Easter hotspot. Between anomaly 2' and the present, the jumps along the East Rift appear to be mostly to the west, which may be related to the rotation of the microplate and is discussed further in the simplified tectonic evolution section.

0.00 to $3.40 \mathrm{Ma}$. At $3.40 \mathrm{Ma}$, a large amount of overlap north of the microplate is formed to enable matching the Pacific-Nazca magnetic isochrons north and south of the microplate simultaneously. To close only the northem isochrons would have caused a very large gap to the south of the microplate as seen from the different orientation of the northern Pacific and Nazca isochrons (Figure $9 f$ ). In addition, it must be kept in mind that all the lithosphere north of the diagonal hachuring is now on the Nazca plate and not part of the microplate. As discussed in the models section, the apparent continuous propagation between 3.40 and $2.47 \mathrm{Ma}$ implies that all this material should be deformed back to its previous position as was done for the smaller propagating offsets along the West Rift, East Rift, and the southern EPR. The curvature of the Southwest Rift is last observed at this time, but this is not well constrained because of the uncertainty of the anomaly 2 ' identification inside the Southwest Rift (Figure 4).

The rotation rate since 3.40 Ma corresponds to $19 \% \mathrm{~m}$.y., which is another slight increase from the $17 \%$ m.y. rotation rate measured at $2.47 \mathrm{Ma}$. Yet if some kind of rotational deformation such as simple shear occurred within the interior, the amount of rotation and the rotation rate would be less. The overlaps to the north and south of the microplate and the gaps to the east and west of the microplate are strong indicators that shear deformation occurred because the oblong Easter microplate needs to be shortened and broadened to fit within the area formed by closing the Pacific and Nazca plates. Rigid rotations alone cannot resolve this apparent space problem.

0.00 to $3.88 \mathrm{Ma}$. At $3.88 \mathrm{Ma}$, there are two discontinuities in the magnetic anomalies of the microplate interior which are both predicted from the sparse information on the Pacific plate (see Figure $9 a$ ). The real geometry of the magnetic isochrons in the interior is probably much more complicated. The first discontinuity is the offset of anomaly 3 which is predicted by the northem offset of magnetic anomalies on the Pacific plate. The second discontinuity is a truncation of all the anomalies that range from the Brunhes to anomaly 2 ' north of the microplate interior by the east-west oriented anomaly 3 (Figure $9 a$ ).

The first discontinuity is not visible as a discontinuity in the lineament map (Figure 4) nor is it visible in the GLORIA side scan mosaic [Rusby et al., 1988; Searle et al., 1989]. If the offset was a nontransform offset, then it would not necessarily have the distinctive crosscutting morphology associated with fracture zones and would only be visible as a subtle pattern of overlapping rift tips. Further analysis of the GLORIA data may reveal such a pattern if it is not obliterated by rotational deformation. There is, however, a slight indication of a small depth change across the predicted location of the offset. This small depth change corresponds to the $3600-\mathrm{m}$ contour oriented approximately NWSE near the northeastern corner of the microplate interior (Plate 1). The depth offset is in the opposite sense; that is, the older side is shallower than the younger side (according to the dashed isochron offset) and the shape of the $3600-\mathrm{m}$ contour is curved and at a different orientation (Plate 1) than the predicted offset (Figure 9a), suggesting that if a linear fracture zone did exist it may have undergone deformation or the plate boundaries reorganized in such a way to produce a curved fracture zone.

The second discontinuity is the unusual pattern where several north-south oriented anomalies in the northern half of the microplate are truncated by the hypothesized east-west oriented anomaly 3 (dashed in Figure 9a) near the microplate interior. This is partially due to the unidentified older magnetic anomalies about the middle and southem thirds of the West Rift and the discontinuous method of cutting away anomaly 2' and rotating the interior as a rigid body to form a best fit within the two larger plates.

This reconstruction of the core of the microplate interior is the least constrained and leaves two unresolved problems. First, where is anomaly 3 ? Second, if anomaly 3 is correctly located, how does the seafloor age progress from anomaly 2 to the eastwest orientated anomaly 3 ?

The rotation rate for the past $3.88 \mathrm{Ma}$ is about $20 \% \mathrm{~m} . \mathrm{y}$., indicating that there was rapid rotation at this early stage or, more likely, there was shear deformation as discussed for $3.40 \mathrm{Ma}$. The tip of the East Rift is now much farther south. The overlap along the southem boundary is an artifact of not knowing where the southern offset of the magnetic anomalies is located. Only the outline of Easter Island is shown as a reference location because Easter Island had not yet formed according to the oldest $\mathrm{K}-\mathrm{Ar}$ ages of the rocks sampled ( $3 \mathrm{Ma}$ ) [Baker et al., 1974] and the 3.5 Ma age prediction of the Nazca hotspot trace from the Ahu volcanic field (Figure 3) [Naar and Hey, 1989b].

Currently, the interpretations presented and the age estimates for the origin of Easter Island indicate that Easter Island was formed at least a million and a half years after the initial formation of the microplate, contradicting previous speculations that the formation of the microplate and Easter Island was contemporaneous [Naar and Hey, 1989b; Hagen et al., 1990]. However, the fact that Easter Island is one of the largest volcanic edifices along the Easter/Sala y Gomez Seamount Chain indicates the size of Easter Island may be related to the age offset across the outer pseudofault of the Easter microplate. This age offset is at least $1.5 \mathrm{~m} . y$. based on the magnetic interpretations (Figure 9a).

One of the greatest difficulties in dating Easter Island is obtaining the oldest rock samples because there has been recent volcanism on the island estimated to have occurred between 50,000 years [Clark, 1975] and 2000 years before present [Heyerdahl et al., 1961]. There have been many other radiometric 
age determinations for rocks from Easter Island, giving $\mathrm{K}$-Ar values of $0.16 \pm 0.05,0.18 \pm 0.16$, and $0.32 \pm 0.08 \mathrm{Ma}$ [Gonzalez Ferran et al., 1976]; 0.3 and 3.0 Ma [Baker et al., 1974]; 0.24, 1.0, and 2.5 $\pm 0.2 \mathrm{Ma}$ [Clark and Dymond, 1977]; and $0.24 \pm 0.04$ and $0.67 \pm 0.26 \mathrm{Ma}$ [Kaneoka and Katsui, 1985]. In addition, young submarine flows are observed west and north of Easter Island and are estimated to have erupted at $0.4 \mathrm{Ma}$ or more recently [Hagen et al., 1990]. All these young ages indicate that there has been a great deal of young volcanism covering older flows that would presumably lie underneath. Thus, the only way to date properly the origin of the island would be to drill through its flanks down to the original seafloor.

Kaneoka and Katsui [1985] estimated the maximum volume of Easter Island and calculated the extrusion rate necessary to form the volume within two time intervals, $0.0-0.6 \mathrm{Ma}$ and $0.0-3.0$ Ma. If Easter Island is only $0.6 \mathrm{~m} . \mathrm{y}$. old, then the average eruption rate would be about tens of thousands of cubic kilometers per million years, which is comparable to rates predicted for the Hawaiian islands [Barger and Jackson, 1974]. If Easter Island formed $3 \mathrm{Ma}$, the rate would be 5 times less.

The only way Easter Island could have formed with the formation of the Easter microplate is if the island is much older $(\sim 4.5 \mathrm{Ma})$ or if the magnetic anomaly next to and south of Easter Island is anomaly 2'. The former possibility has been alluded to [Searle et al., 1989], but the age dating problem of Easter Island has not been addressed. The latter possibility is appealing because the age of anomaly 2' approximately coincides with the published $\mathrm{K}$-Ar age of Easter Island, the age predicted from the Nazca hotspot trace, and the age of the most recent postulated change in the absolute motion of the Pacific plate, estimated to have occurred between 3.40 and $3.86 \mathrm{Ma}$ [Harbert and Cox, 1989]. Anomaly 2' from the southernmost portion of the Nazca plate could be extended with a slight westward curvature directly up to Easter Island (Figure 6), thereby simplifying the initial starting geometry, i.e., only two offsets of the EPR instead of three as shown at $5.89 \mathrm{Ma}$ (Figure $10 \mathrm{j}$ ). In this scenario, anomaly 2 ' would run along the length of the major outer pseudofault of the East Rift which would require anomaly 2' to also run along the major inner pseudofault, because pseudofaults mark the location of the rift tip at any given time. The sum of the two spreading half rates between anomaly 2 ' and the Brunhes anomaly would be equal to $\sim 215 \mathrm{~km} / \mathrm{m}$.y. (using the reversal ages of 2.47 $\mathrm{Ma}$ and $0.73 \mathrm{Ma}$ ), which is much faster than the $\sim 160 \mathrm{~km} / \mathrm{m} . \mathrm{y}$. Pacific-Nazca spreading rate predicted to exist during that time period (NUVEL 1) [Gordon et al., 1988; DeMets et al., 1990]. It is difficult to explain why the East Rift would be forming lithosphere faster than the large Pacific-Nazca plates were moving apart; thus this initially appealing scenario has been discarded.

One possible explanation is that a failed rift next to the inner pseudofault was formed by an eastward rift jump just after the microplate was initiated, juxtaposing the edge of anomaly 2 ' and anomaly 3 near Easter Island and the major outer pseudofault. This would leave a doubled anomaly 3 about a failed rift just to the east of the major inner pseudofault. Another possibility is that the major inner pseudofault does not curve as far toward the west as indicated and instead is more NE-SW running along the older edge of anomaly 2' [Handschumacher et al., 1981]. The lineament and bathymetric data (Figure 4 and Plate 1) and the GLORIA side scan data [Rusby et al., 1988; Searle et al., 1989] are not compatible with these two possibilities, but the possibilities are presented to emphasize that the majority of the data suggest the initial formation of Easter Island was not contemporaneous with the origin of the microplate and that the 1nitial starting configuration of the EPR was complicated prior to the formation of the microplate as previously proposed [see Figure 7 of Handschumacher et al., 1981].

0.00 to $4.77 \mathrm{Ma}$. At $4.77 \mathrm{Ma}$, our data indicate that the microplate did not exist. It was initiated at approximately $4.5 \mathrm{Ma}$ (the approximate age of where anomaly 3 is truncated by the pseudofault near Easter Island). If the microplate was actually initiated from the southernmost EPR offset, then the microplate would have originated before $4.77 \mathrm{Ma}$ and the East Rift would have crossed the present-day location of Easter Island at about 4.5 Ma. The latter possibility is physically difficult to understand because it requires that the East Rift originates from the middle of an EPR offset.

What does exist at $4.77 \mathrm{Ma}$ is lithosphere that will be transferred from the Nazca plate to the microplate interior. Spreading is only active on the West Rift, which would be the EPR (Pacific-Nazca plate boundary) at that time. The gaps remaining at this time indicate the cumulative amount of deformation and data uncertainty of the transferred microplate interior. The rotation rate is calculated by dividing $96^{\circ}$ by an age of $4.5 \mathrm{Ma}$, which gives a rotation rate of about $21 \% \mathrm{~m}$.

0.00 to $5.89 \mathrm{Ma}$. At $5.35 \mathrm{Ma}$ and $5.89 \mathrm{Ma}$, most of the misfits from the previous reconstruction ( $4.77 \mathrm{Ma})$ remain as expected. New misfits result from uncertainties in the location and orientation of the EPR offsets over the duration of the reconstruction. The misfit of the magnetic anomalies at the small spreading segment near Easter Island results from using the width of the older magnetic anomalies to the north at $4.77 \mathrm{Ma}$. The widths of the magnetic anomalies in the south of the microplate were not used because they are less constrained and do not correlate well from one long profile to another (see magnetic profiles $G$ and $H$ in Figure 6 and the corresponding models in Figure 7). The gaps that form clearly show that the identifications of the older magnetic anomalies, especially to the south of the microplate, are suspect. Most of the misfits are probably related to more complex spreading system reorganizations than shown here (e.g., dueling propagators across the EPR offsets). In the next section, simplified outlines of the detailed reconstructions illustrate the general microplate tectonic evolution (Figure 10).

\section{Simplified Tectonic Evolution}

Starting at 5.89 Ma (Figure 10j), the EPR is offset in at least two places. There are very little data to resolve whether fracture zones offset the magnetic anomalies at this early stage. Near the active spreading axes, where there are more data, transform faults are not presently observed offsetting magnetic anomalies except where spreading rates are less than $145 \mathrm{~km} / \mathrm{m} . \mathrm{y}$. [Naar and Hey, $1989 a$ ]. When the spreading rate is greater than this rate, the magnetic anomalies and rift axes are offset by nontransforms such as microplates, propagating rifts, or overlapping spreading centers. Dashed lines with question marks are drawn to show the possibility of either a linear transform fault or a broad nontransform zone, such as the pattern formed by the $20^{\circ} 40^{\prime} \mathrm{S}$ EPR offset [Rea, 1978; Macdonald et al., 1988] or at the Cobb offset in the Juan de Fuca area [Johnson et al., 1983].

A third offset is shown by the inclusion of a small spreading axis within the large southern offset. The data do not require this third spreading segment, but physically it was more desirable as discussed in the previous section to provide an initiation point for the northward propagating East Rift. On the other hand, off the west coast of California between the Mendocino and the Murray fracture zones it has been proposed that some rifts did originate 
and propagate from the middle of transform faults during the late Tertiary reorganization of the Pacific-Farallon spreading system (L. Skaer and R. N. Hey, Late Tertiary tectonic evolution of the seafloor spreading system off the Coast of California between the Mendocino and Murray fracture zones, submitted to Journal of Geophysical Research, 1990). As this issue is not resolvable with the data available at this time, this latter scenario is also shown schematically at time $4.77 \mathrm{Ma}$ as a pair of pseudofaults, dashed lines with question marks converging near the present location of Easter Island (Figure 10h).

Between 5.89 and $5.35 \mathrm{Ma}$, slight changes in the orientations and offsets of the spreading axes are shown. These changes may be related to nontransform offsets of the EPR such as dueling propagators causing changes in the geometry of the EPR. Or the changes may be related to hotspot perturbations. However, these changes are based on very few profiles and are not well constrained.

At $4.77 \mathrm{Ma}$, the short rift segment is either at or reaches the present location of Easter Island if it started from the southernmost offset of the magnetic anomalies. There is a slight indication in the Seasat altimetry map [Haxby and Weissel, 1986] that the outer pseudofault of the East Rift may actually extend southeast of Easter Island. This slight indication may be real because the strong correlation with a downward deflection of the sea surface over the Pito Rift area and the outer pseudofault of the East Rift north of Easter Island indicates that Seasat altimetry [Haxby and Weissel, 1986] is sensitive to the bathymetric effects generated by the propagation of the East Rift. In addition, there is a shallow ridge extending from Easter Island toward the southeast, but it is not certain whether it is part of the Easter Seamount Chain, a fracture zone, or the major outer pseudofault of the East Rift during a period of slow propagation.

According to the geometry of the major outer pseudofault and anomaly 3 (Figure $9 g$ ), it is estimated that at $\sim 4.5 \mathrm{Ma}$ the short rift segment starts propagating quickly to the north from the present location of Easter Island. A change in absolute Pacific plate motion has been estimated to have occurred at about $5 \mathrm{Ma}$ [Cox and Engebretson, 1985] and more recently this change has been estimated between 5 and 3.2 Ma [Pollitz, 1986]. Harbert and Cox [1989] estimate that a change in Pacific-Antarctica plate motion occurred between 3.40 and $3.86 \mathrm{Ma}$. This change of relative motion is suspected to be directly related to the above change in absolute Pacific plate motion. Changes in plate motion are an appealing mechanism for the formation of a microplate, but if the absolute Pacific plate motion change is in the range estimated by Harbert and Cox [1989] and the magnetic anomaly identifications around Easter Island are correct, then the origin of the microplate would predate the changing plate motions. If so, then the changing plate motions would only have an effect on the intermediate propagation history of the East Rift. Hotspot interactions with the EPR [Hey et al., 1985; Hagen et al., 1990; Searle et al., 1989] may be another mechanism responsible for initiating and sustaining a microplate.

At $3.88 \mathrm{Ma}$, the East Rift has rapidly propagated $\sim 210 \mathrm{~km}$ in -0.9 m.y., giving an approximate propagation rate of $230 \mathrm{~km} / \mathrm{m} . \mathrm{y}$. The rift tip is approaching the latitude of the northernmost EPR segment shown in Figure $10 \mathrm{~g}$ to the northwest. At this point the offset of the two overlapped rifts is approximately $130 \mathrm{~km}$. The overlap zone between the propagating and failing rifts may have been under pervasive shear and not behaving as a rigidly rotating body because SeaMARC II side scan, bathymetry, and seismic data suggest that pervasive shear is currently occurring at a propagating rift system near $29^{\circ} \mathrm{S}$ with a similar offset of about $120 \mathrm{~km}$ [Hey et al., 1988; Klaus et al., 1991].

At $3.40 \mathrm{Ma}$, the propagation rate of the East Rift slows down to about $70 \mathrm{~km} / \mathrm{m} . \mathrm{y}$. (since $3.88 \mathrm{Ma}$ ) and the West Rift starts propagating in a curved arc toward the southeast. This indicates that the microplate may have started rotating as a rigid body at about this time. The configuration of the Southwest Rift at this time is not well constrained because most of the older magnetic anomalies are not identified (Figure 6). Hence it is possible that the Southwest Rift may not have propagated toward the southeast until more recent times.

By $2.47 \mathrm{Ma}$, the southward propagating rift is clearly in existence. The East Rift has propagated northward at about 155 $\mathrm{km} / \mathrm{m}$.y (since $3.40 \mathrm{Ma}$ ). If the microplate was rotating as shown by the strong curvature of the Southwest Rift, the tip of the propagating East Rift should have had a similar amount of curvature toward the west [Schouten et al., 1988]. Unfortunately, the magnetic anomaly data are too sparse in this region of slow spreading and rough bathymetry to test this hypothesis.

At $1.66 \mathrm{Ma}$, the propagation rate has slowed to about 40 $\mathrm{km} / \mathrm{m}$.y. (since $2.47 \mathrm{Ma}$ ) and the offset distance between the overlapped rifts has increased. It is difficult to measure any other propagation rates, and the four rates mentioned must be taken as very rough estimates because the data are too sparse to locate accurately where the magnetic anomalies are truncated by the major pseudofaults. A more accurate propagation rate is obtained by dividing the total propagation distance by the total propagation time. From 4.77 to $1.66 \mathrm{Ma}$ the East Rift propagated about 420 $\mathrm{km}$ during $3.1 \mathrm{~m} . \mathrm{y}$. , which gives a long-term propagation rate of about $135 \mathrm{~km} / \mathrm{m}$.y. This rate and its relationship to other areas of rift propagation will be discussed later.

The northern dashed line with a question mark represents the northern boundary of the microplate. It is not clear whether the northern boundary extended to the kink in the EPR to the north or connected to the transform to the west so it is drawn in between the two. It may have a similar geometry as at $0.73 \mathrm{Ma}$ and present. The orientations of the transforms on the western rifts are becoming more east-west, but this could be partially a result of the reconstruction assumptions, i.e., extrapolation of the current transform fault orientation to older areas with less data coverage. The only way to examine the evolution of the transform faults along the West Rift is to combine the recently collected GLORIA data with new magnetics data along both sides of each fracture zone stemming from the transform faults of the West Rift.

It is difficult to constrain when and where the East Rift started to break into several small northward propagating rifts because of incomplete magnetic coverage, rough bathymetry, and recent volcanism. The complicated magnetic pattern formed by the East Rift and the variable amounts of asymmetry required to fit the magnetic anomalies strongly suggest that the East Rift went through several episodes of rift propagation since its inception, although most of these offsets were probably small. During anomaly 2', however, there were either large ridge offsets or several successive waves of propagators (each with the same direction of offset) because of the asymmetric pattern of anomaly 2' about the East Rift (Figure 9e).

At $0.98 \mathrm{Ma}$, there is a rift propagating southward away from the Easter microplate along the East Rift. It started propagating at approximately the same time and from the same location as the rift that has currently propagated northward to about $25^{\circ} \mathrm{S}$ along the East Rift [Naar and Hey, 1986; Sempere et al., 1989]. The new data analyzed here substantiates the speculation that there is a rift propagating southward from the presently shallowest portion 
of the entire EPR ( $2050 \mathrm{~m})$ [Naar and Hey, 1986]. Schilling et al. [1985] observed a first-order iron enrichment trend southward of this shallow portion of the East Rift that supports this interpretation, although there was a higher degree of data scatter than observed for the northward propagator near $25^{\circ} \mathrm{S}$. There are a few minor episodes of northward propagation of the doomed (southernmost) EPR segment during the southward journey of the $29^{\circ} \mathrm{S}$ propagator tip (see the hooks or barbs along the Brunhes/Matuyama surrounding the failed rift in Figure $9 a$ ). Dueling propagators have been observed at the Cobb offset in the Juan de Fuca area [Johnson et al., 1983] and near 20 40'S along the EPR [Macdonald et al., 1988]. The northernmost episodes of dueling propagation along the failed rift are indicated in the lineament, bathymetric, and magnetic data (Figures 4 and 6 and Plate 1) and are similar to the present geometry at $29^{\circ} \mathrm{S}$ [ Hey et al., 1988; Klaus et al., 1991]. However, if the present situation at $29^{\circ} \mathrm{S}$ is any indication of what happened in the past, then it is likely that there were more episodes of dueling propagation than indicated in Figure $9 a$. Even if the failed rift magnetic pattern has been interpolated properly, the propagating rift magnetic pattern should have corresponding discontinuities along its inner and outer pseudofaults. The rifts propagating northward along the East Rift propagate into the microplate interior and transfer lithosphere from the microplate to the Nazca plate at $0.98 \mathrm{Ma}$.

At $0.73 \mathrm{Ma}$, it is clear that the microplate is still rotating, the offset distance between the overlapped rifts has increased, and the rift tips are propagating to accommodate the rotation of the microplate instead of transferring lithosphere from the larger plates to the microplate interior. The only significant transfer of lithosphere occurring by rift propagation is the continued "shaving" of the microplate interior by the small-offset propagating rifts along the East Rift and West Rift that always propagate into the microplate interior and transfer lithosphere to one of the larger plates. This causes the overall growth rate of the microplate to be reduced [Searle et al., 1989]. Another observation about the geometry of the East Rift is that the smalloffset propagating rifts appear to be guided by the previously formed pseudofaults. This geometry becomes even more evident at present (Figures $9 a$ and $10 a$ ), suggesting that the pseudofaults act as zones of weakness along which the rift tips preferentially propagate. The Southwest Rift tip, however, appears to have been propagating in a more southerly direction and started breaking through the southern pseudofault of the Southwest Rift sometime between 0.00 and $0.73 \mathrm{Ma}$.

A wedge-shaped northern boundary is shown to indicate the diffuse broad area which probably marks the northern boundary of the microplate. The lower-dashed line of the northern wedge connects the East Rift tip to the northernmost transform of the West Rift, and the upper-dashed line of the northern wedge connects the East Rift tip to where the Pacific and Nazca plates are flush with no misfit in the detailed reconstruction of $0.73 \mathrm{Ma}$ (Figure 9b).

At present (Figure 10a), the offset between the East Rift and the West Rift has increased and the Southwest Rift has clearly propagated across its southern pseudofault (Plate 1 and Figures $9 a$ and 10a). This interpretation is corroborated by interpretations based on GLORIA data [Rusby et al., 1988; Searle et al., 1989]. The Southwest Rift is pointing toward the Pacific-Easter pole [Naar and Hey, 1989b] as expected for orthogonal seafloor spreading. The northem boundary of the microplate is delineated by three dashed lines with question marks. The top and bottom lines represent the envelope of current and previous deformation related to the propagating rift tip of the East Rift as defined by the pattern of earthquakes, disrupted bathymetry, lineaments, and magnetics. The middle-dashed line is a simplified estimate of the most active deformation within the wedge at present (Figure 8), although the earthquake pattern shows the deformation is probably more diffuse.

Near the "base" of the East Rift near $26^{\circ} 30^{\prime} S$, where two rifts have propagated away from each other, is the very shallow East Rift axis where deep mantle geochemical signals are observed from the dredged samples [Craig et al., 1983; Schilling et al., 1985; Hanan and Schilling, 1989]. The rates of propagation for both the northward and southward rifts are grossly the same. This observation supports the idea that rifts propagate away from shallow areas [Hey et al., 1980; Naar and Hey, 1986] and that the propagation driving force for these two rifts is related to the shallow ridge depth [Phipps Morgan and Parmentier, 1985]. The tip of the apparently southward propagating segment is shown to be still propagating southward, and the failing rift segment is shown to be recently propagating northward based on analyses of SeaMARC II bathymetry and side scan data and Sea Beam bathymetry data, although the details of volcanic activity of the southward propagating rift can only be guessed at because of the incomplete data coverage [Hey et al., 1988; Klaus et al., 1991].

The question mark at the East Rift shallow summit is to emphasize the uncertainty of how the Pacific-Easter transform boundary connects to the East Rift. Zukin and Francheteau [1990] suggest that the curvature of the shallow bathymetry in this area (Plate 1) is very near to the predicted recent Easter-Pacific transform motion direction and that it may accommodate transform slip motion. If this is correct, it would indicate that the southern triple junction is much farther south, closer to the theoretical triple junction calculated from the intersection of equal spreading rates predicted by the poles of rotation as described in the data description section. However, the farther south the triple junction is located, the more the microplate shape would become obstructive for the predicted $15 \% \mathrm{~m}$.y. microplate rotation. On the other hand, this curving ridge to the west may be an old or recent overlapping EPR axis that curves toward the Southwest Rift.

\section{DisCUSSION}

The average rotation rates for the different ages, assuming the microplate rotated as a rigid body, range from 15 to $20 \%$ m.y. Although there is a general slowing down of the microplate rotation rate since its origin, the change of rate appears to be slow and gradual. The faster rotation rates occur during the early formation of the microplate. In the older plate reconstructions, gaps formed east and west of the microplate and overlaps formed north and south of the microplate indicate that the interior of the microplate underwent rotational deformation possibly in the form of simple shear and in a direction subparallel to the Pacific-Nazca spreading direction during the time of lithospheric transfer from the Nazca plate to the Easter plate.

The ratio of overlap length to offset width changes from about 1:1 at $3.88 \mathrm{Ma}$ to about $2: 1$ at $3.40 \mathrm{Ma}$ and to about $3: 1$ at 2.47 Ma. Macdonald et al. [1987] show that a ratio of 3:1 is generally observed at most overlapping spreading centers along the EPR. They show that the crack propagation force decreases to very small values when the length to width ratio $(L / W)$ is greater than 3. They propose that propagation of small-scale offsets $(<30 \mathrm{~km})$ will tend to stall when $L / W$ approaches three. This prediction for small-scale offsets is surprisingly similar to that observed at the Easter microplate, because after $2.47 \mathrm{Ma}$ (when $L / W=3$ ) the northward growth of the East Rift has virtually stopped and 
continued evolution of the microplate shows that the offset distance between the East Rift tip and the EPR to the west increases (see difference between times 2.47 and $1.66 \mathrm{Ma}$ in Figure 10 ). This similarity suggests the crack propagation force may play an important role even at a scale which is two orders of magnitude greater than overlapping spreading centers along the EPR. This is not a surprising result considering the examples discussed by Pollard et al. [1982] and Pollard and Aydin [1984], which have similar overlapping rift geometries with $L / W$ ratios equal to or less than 3 for three examples spanning eight orders of magnitude. Specifically, Pollard and Aydin [1984] discuss overlapped cracks in glass at a scale of about $25 \mu \mathrm{m}$, overlapped quartz-feldspar veins in granitic rock at a scale of about $25 \mathrm{~cm}$, a minette dike in the Mancos Shale at a scale of about $250 \mathrm{~m}$, and an overlapping spreading center at a scale of about $2.5 \mathrm{~km}$.

The growth of the offset distance between the East Rift tip and the EPR and the lack of northward propagation cause $L / W$ to decrease to 2.5 which might start the East Rift to propagate northward again after $1.66 \mathrm{Ma}$. The East Rift does appear to propagate northward between 1.66 Ma and 0.98 Ma (Figure 10), but at that point the East Rift is clearly broken into several spreading segments and this change in geometry may complicate the analogy to smaller offsets. Furthermore, the strong westward curvature of the northern East Rift tip shown at this time indicates that the microplate is predominantly behaving as a rigid rotating body which might reduce the analogy to overlapping cracks. It is not clear whether the slowing down of the northward propagation of the East Rift is a result of the microplate rotation or vice versa. Another factor that may complicate the analogy to propagating cracks is that the distance from the possible channeling of the Easter hotspot [Schilling et al., 1985; Hanan and Schilling, 1989] may play an important role on the propagation forces in terms of elevated topography, excess heat, and partial melt [Hey et al., 1980; Phipps Morgan and Parmentier, 1985].

Propagation rates from other parts of the microplate have been discussed elsewhere [Naar and Hey, 1986; Sempere et al., 1989] or else they have not been calculated because they are not well constrained. The long-term propagation rate of $135 \mathrm{~km} / \mathrm{m} . \mathrm{y}$. for the initial growth of the East Rift is about double the $-65 \mathrm{~km} / \mathrm{m}$.y. propagation rate calculated for the northward propagating EPR that formed the Mathematician paleoplate [Mammerickx et al., 1988]. The Pacific-Nazca spreading rate near the Easter microplate is also about double the Pacific-Cocos spreading rate at the approximate latitude of the Mathematician paleoplate. This gives support that the propagation rates are related to spreading rates [Hey and Wilson, 1982; Wilson, 1988]. Mutter et al. [1988] claim that spreading center jumps occur almost instantaneously. This may be true in some locations or circumstances as mentioned below, but it is not true for the long-term formations of the Easter and Mathematician microplates.

More recent studies [Shoberg et al., 1991] suggest that there have been short-lived episodes of propagation at rates of about $400-900 \mathrm{~km} / \mathrm{m}$.y. based on numerical modeling of tectonic fabric. How this relates to long-term propagation velocities is unclear because the distances traveled by these fast propagators is usually less than $50 \mathrm{~km}$, and the velocities appear related to the interaction of dueling propagators. Caress et al. [1988] document propagation rates in the range of $100-300 \mathrm{~km} / \mathrm{m} . \mathrm{y}$. and possibly in excess of this range for the Eocene reorganization of the PacificFarallon spreading system north of the Mendocino fracture zone. L. Skaer and R. N. Hey [submitted manuscript, 1990] show similar propagation rates with one possible outlier at about 1000 $\mathrm{km} / \mathrm{m}$.y. for the late Tertiary reorganization of the Pacific-Farallon spreading center south of the Mendocino fracture zone. Thus the long-term propagation rate for the Easter microplate is within the range of other long-term propagation rates.

The Southwest Rift does not have to be in the curved orientation prior to the initial formation of the microplate as suggested in the schematic tectonic evolution shown in Figure 12 of Engeln et al. [1988] because this curved fabric appears to form later due to rotation of the microplate (Figures 9 and 10). More importantly, the Southwest Rift pseudofaults do not appear to have formed from a previously existing transform fault or fracture zone because a fracture zone is not observed in Plate 1 at the same distance to the east of the EPR (within the limits of the data coverage shown in Figure 4). The magnetic anomalies (Figure 6) do indicate an offset, but there is no evidence of a linear fracture zone within the data coverage (Figure 4), as discussed in the magnetic modeling section.

The counterclockwise rotation of the spreading segments of the West Rift, previously discussed by Engeln and Stein [1984], has also been observed at the Mathematician failed rift [Mammerickx et al., 1988] and at small-offset propagating rift systems, such as the Galapagos failing rift at $95.5^{\circ} \mathrm{W}$, except that at the Galapagos failing rift, the rotated spreading segments are not connected by transform faults. Instead, they are in an en echelon overlapping pattern [Hey et al., 1986; Kleinrock et al., 1989].

An instability arises in the Schouten et al. [1988] instantaneous "ball bearing" model over time because lithosphere is accreted to the interior of the microplate, causing the microplate to lose its circular shape and slowly become lopsided. Eventually, the microplate will not fit within its northern and southern boundaries as it continues to rotate $(H$. Schouten, personal communication, 1988). Recall that the surface area of microplates can grow in two ways. First, it can grow by seafloor spreading. This will always cause the microplate to grow unless there was $100 \%$ asymmetric seafloor spreading, which has never been observed anywhere on earth on a geological time scale and has only been observed at a lava lake [Duffield, 1972] and during wax modeling experiments [Oldenburg and Brune, 1972, 1975; Macdonald et al., 1984; Naar et al., 1986]. These plate tectonic models do not scale properly in all regards, and thus it is assumed that oceanic microplates along a divergent boundary must grow by some amount of seafloor spreading. Theoretically, if a microplate did have $100 \%$ asymmetric spreading or if all the material accreted on the interior of the microplate was transferred back to the larger plates by other propagating rifts (the "shaving" mechanism), then the microplate could behave as a true "ball bearing." As previously discussed, these two options are not observed. However, the reconstructions suggest that the northern and southern boundaries of the microplate have moved farther apart, the rift offset grew, and part of the microplate was "shaved" by small-offset propagators, which together would tend to cause the microplate to retain a roughly equidimensional shape. However, these three mechanisms do not always appear to be synchronous; for example, the distance between the northern and southern boundaries of the microplate appears to have increased early on, whereas rigid plate rotation and the growth of the rift offset appears to have occurred more recently (Figure 10).

The abyssal hill fabric in the northern part of the microplate has an average orientation of $-72^{\circ}$. This orientation corresponds to a $59^{\circ}$ clockwise rotation from the current predicted orientation of the EPR (NUVEL 1), and a $67^{\circ}$ clockwise rotation from the abyssal hill fabric to the northeast and east of the microplate. In addition, the reconstructions indicate that this lithosphere would have had to rotate for $\sim 3.40 \mathrm{Ma}$ (to obtain this change of 
orientation), which is older than the predicted age of lithospheric transfer $(\sim 1 \mathrm{Ma})$ of the oblique lithosphere just to the west of the Pito Rift area. This indicates that shear deformation (most likely related to the continuous process of lithospheric transfer from the Nazca plate to the Easter microplate) must have occurred in the past. This interpretation is corroborated by the generally continuous change in orientation of the abyssal hill fabric just to the north and northwest of the Pito Deep area observed in Figure 4 and in the SeaMARC II side scan mosaic from this area [D. F.
Naar et al., submitted manuscript, 1991]. Thus, a rigid rotation explanation [Engeln and Stein, 1984; Engeln et al., 1988; Schouten et al., 1988] cannot explain the entire lineament pattem of the Easter microplate interior, especially the northeastern part of the interior.

The age of the core of the microplate interior is not well constrained; thus it is difficult to remove effects of rotational deformation because age control is needed to do this. It can only be speculated that there has been rotational deformation probably

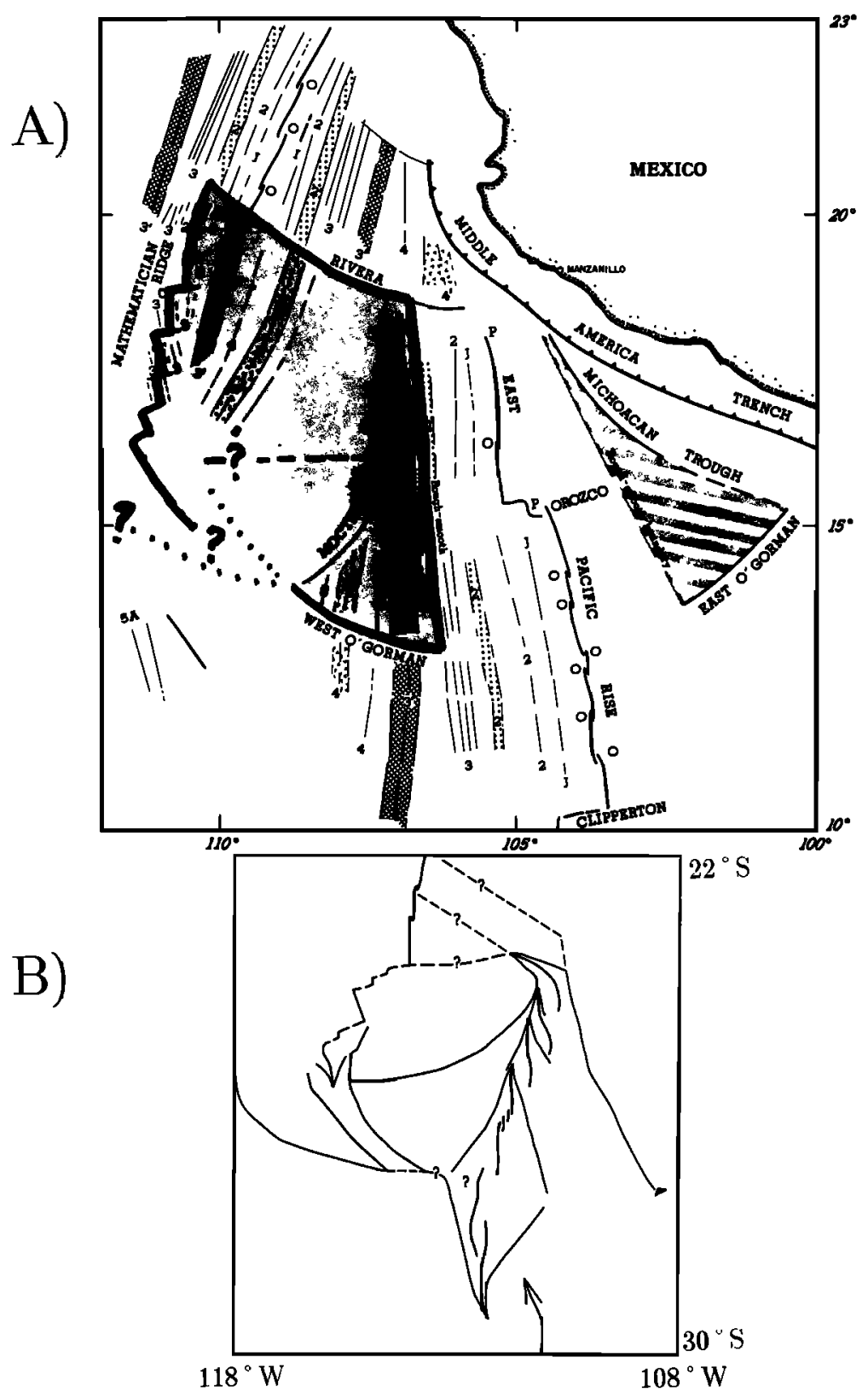

Fig. 11. Comparison of an inactive and active microplate at approximately the same map scale. (a) The Mathematician paleoplate extends from the Mathematician Ridge to the rough-smooth boundary at $\sim 106^{\circ} \mathrm{W}$ and is outlined with a thick line. The thick line surrounded by a V-shaped pair of dotted lines represents a hypothesized tectonic geometry predicted from the Easter microplate. The dashed line oriented east-west represents a ridge partially mapped with Sea Beam that has a variable relief ranging from 500 to $1500 \mathrm{~m}$ [Mammerickx et al., 1988]. This ridge appears similar to the east-west ridge at the northern boundary of the Easter microplate. The Moctezuma Trough and the Michoacan Trough represent the inner and outer pseudofaults of the EPR that had previously propagated north. Circles along the EPR represent overlapping spreading centers from Macdonald et al. [1984]. Figure modified from Mammerickx et al. [1988]. (b) The simplified present-day tectonic configuration of the Easter microplate (see Figure 10 for description), which has many similarities with the southern portion of the Mathematician paleoplate, as discussed in the text. 
in the form of pervasive simple shear as the East Rift propagated northward until at least $3.40 \mathrm{Ma}$, at which time the rift offset distance grew and the microplate slowly started rotating as a rigid body (Figure 10). Beyond this time, most of the plate deformation appears to be related to the microplate's rotation and, to a lesser extent, the transfer of the Nazca plate to the microplate (Figure 9). This more recent deformation appears to have been concentrated at the microplate boundaries (Figure 3 and Plate 1).

Apparently, a failed rift was never formed during the the early part of the microplate's evolution, although the sparse magnetic data at this time and area do not rule out the possibility of a previously formed failed rift. If there was a failed rift for a short while, it is possible that it was rejuvenated when the microplate started rotating or has been left to the west of the Southwest Rift.

The current lineament pattern of the inactive Magellan microplate has many similarities with that of the Easter microplate [Tamaki and Larson, 1988]. The overlapped rift remains active during the time of activity of the microplate. There is a fanning of magnetic anomalies indicating a nearby pole of rotation along the propagating rift. On the core of the interior, there are a few oblique trending anomalies that have been proposed to have been formed by rigid rotation of the microplate [Tamaki and Larson, 1988]. It appears that these few oblique trends are discontinuous with respect to the fanned trends on the interior of the microplate and may have been reoriented nonrigidly by rift propagation. This is difficult to test because of incomplete magnetic coverage and the thick sediment cover in the area which masks the underlying seafloor basement structure.

The southern portion of the Mathematician paleoplate [Mammerickx et al., 1988] is very similar to the present-day geometry of the Easter microplate (Figure 11). There is a multiple trough making up the inner pseudofault of the Mathematician paleoplate to the north also known as the Moctezuma Trough (Figure 11), which is very similar to the present-day ridge and valley structure of the Pito Deep region (Plate 1). There is a curving pseudofault, from $14^{\circ} \mathrm{N}$ to $16^{\circ} \mathrm{N}$ (Figure $11 a$ ), which has a similar orientation to the major inner pseudofault of the East Rift. It extends into an east-west ridge that stands $500 \mathrm{~m}$ or more above the seafloor near $16^{\circ} \mathrm{N}$ (Figure $11 a$ ). There are not many data in the southwestern portion of the Mathematician paleoplate, but the analogy with the Easter microplate predicts that the southwestem part of the Mathematician paleoplate has a similar orientation to the Southwest Rift and probably connects somehow with the O'Gorman fracture zone (Figure 11a). Furthermore, using the analogy with the Mathematician paleoplate and wax modeling observations [Naar et al., 1986], it is expected that when the deformation resulting from the rigid rotation of the microplate reaches a maximum, the microplate will momentarily or completely stop rotating, the stress field at the Pito Rift area will change, and the direction of the propagating East Rift will change from northwest to a more northerly direction, thereby causing the zone of deformation to be moved northward into an area of mostly undeformed seafloor. Eventually, the West Rift of the Easter microplate will most likely cease activity when the East Rift propagates far enough north to cause the nearly round shape of the microplate to become so oblong in shape that it can no longer rotate between the quickly separating Pacific and Nazca plates. However, the interaction with a long-lived deep mantle plume may prolong spreading activity along the microplate boundaries, especially along the very shallow portions of the East Rift and Southwest Rift (Plate 1). The slight increase of La/Sm ratios [Schilling et al., 1985] and He 3/4 ratios [Poreda et al., 1988] along the Southwest Rift is consistent with this idea.

\section{CONCLUSIONS}

Sparse magnetic, bathymetry, and satellite altimetry data indicate that the Easter microplate initially formed at or southeast of Easter Island near a left-lateral offset of the EPR sometime between anomaly 3 and 3'. The East Rift started propagating north from the present location of Easter Island at $\sim 4.5 \mathrm{Ma}$, which is $-1.5 \mathrm{~m}$.y. earlier than previously proposed. However, the magnetic data that support this interpretation are sparse and complicated by recent volcanic flows and associated rough bathymetry west of Easter Island.

The geometry of the microplate changes very rapidly during its evolution. At the initial stages of development, the microplate resembles a large propagating rift system, suggesting deformation may have been occurring throughout most of its interior up to about $2.47 \mathrm{Ma}$. At this time, the length to width (of overlap) ratio of the two rifts reaches a value of 3 , the northward propagation slows down, the curved opening of the Southwest Rift becomes well established, and rigid rotation of the predeformed transferred lithosphere probably starts and predominates. At this time, the offset distance between the two overlapped rifts starts to increase. Some time after $2.47 \mathrm{Ma}$ and before $1 \mathrm{Ma}$, the East Rift starts propagating northwestward, probably in response to the microplate rotation, and continues up until present. Also during this time period, the East Rift breaks into a series of rifts propagating northward toward the pole of opening with each rift propagating inside the preceding rift, thereby transferring lithosphere from the microplate to the Nazca plate and reducing the total growth rate of the microplate.

Rigid plate motions are insufficient to explain the complete tectonic evolution of the Easter microplate. The patterns of lineaments and bathymetric structures suggest that rotational deformation of the Nazca plate is the general mechanism that accommodates the space problems arising from transfer of the Nazca plate to the microplate and rapid rotation of the microplate against the Nazca plate. Similar but less deformation is predicted along the southern boundary of the microplate. "Bookshelf faulting" appears to be occurring in the eastern part of the northern transform wedge but is not evident in the western part, indicating that the mechanism of deformation is much more complex.

Acknowledgments. Funding was provided by grants from the National Science Foundation (OCE82-15396, OCE84-10196, and OCE86-10412) and the Office of Naval Research (wax modeling experiments). D.F.N. also received financial assistance from the University of South Florida. We thank R. Searle, H. Schouten, J. Zukin, and T. Shoberg for advanced copies of their manuscripts prior to publication. We also thank J. Francheteau, J. Fox, and K. Macdonald for use of unpublished Sea Beam data. We thank R. Parker for the use of some computer programs. We thank R. Searle, J. Francheteau, P. Patriat, J. Engeln, S. Stein, J. Sinton, B. Taylor, F. Duennebier, K. Macdonald, M. Kleinrock, D. Caress, F. Martinez, J. Karsten, N. Sleep, R. Hagen, A. Klaus, B. Mallonee, and M. Wilke for discussions about the area. For technical assistance we thank $D$. Myhre, S. Stahl, S. McClintock, T. Duennebier, M. Simpson, B. Cunningham, E. Strickland, J. Teo, J. Lee, M. Tugaoen, C. Yoshinaga, S. Dang, N. Hulbirt, B. Bays, L. Peterson, and the SeaMARC II group. We thank W. Bartlett and $K$. Chainey for the real-time processing of the SeaMARC II data. We thank J. Francheteau for use of unpublished lineament data from the Sea Rise expedition and a few unpublished magnetic profiles along transits of the Rapa Nui expedition. We thank Captain Hayes, the crew of the R/V Moana Wave, and D. Johnson, D. Vonderhaar, S. Davis, and G. Costa. We give a special thanks to Lisandro Rojas and Ricardo Gonzales from the University of Santiago whose dedication and effort were an inspiration to us. We are indebted to the inhabitants of Rapa Nui for their warm hospitality and thank the government of Chile for permission to work in the area. We thank Seth Stein for his review of an earlier version of this manuscript, and we thank 
Joe Engeln, Roger Searle, and Ruth Rusby for their detailed and careful reviews. The majority of the work for this manuscript was done in Hawaii at SOEST. SOEST contribution number 2391.

\section{REFERENCES}

Acton, G., S. Stein, and J. Engeln, Formation of curved seafloor fabric by changes in rift propagation velocity and spreading rate: Application to the $95.5^{\circ} \mathrm{W}$ Galapagos propagator, J. Geophys. Res., 93, 11,845-11,861, 1988.

Anderson, R. N., D. W. Forsyth, P. Molnar, and J. Mammerickx, Fault plane solutions of earthquakes on the Nazca plate boundaries and the Easter plate, Earth Planet. Sci. Lett., 24, 188-202, 1974.

Anderson-Fontana, S., J. F. Engeln, P. Lundgren, R. L. Larson, and S. Stein, Tectonics and evolution of the Juan Fernandez microplate at the Pacific-Nazca-Antarctic triple junction, J. Geophys. Res., 91, 2005-2018, 1986.

Baker, P. E., F. Buckley, and J. G. Holland, Petrology and geochemistry of Easter Island, Contr. Mineral. Petrol., 44, 85-100, 1974.

Barger, K. E., and E. D. Jackson, Calculated volumes of individual shield volcanoes along the Hawaii-Emperor chain, J. Res. U.S. Geol. Surv., 2, 545-550, 1974.

Blackington, J. G., D. M. Hussong, and J. G. Kosalos, First results from a combination side-scan sonar and sea-floor mapping system (SeaMARC II), Proc. Annu. Offshore Technol. Conf., 15, 307-311, 1983.

Bullard, E. C., J. E. Everett, and A. G. Smith, The fit of the continents around the Atlantic, Symposium on Continental Drift, Philos. Trans. $R$. Soc. London, 258, 41-51, 1965.

Caress, D. W., H. W. Menard, and R. N. Hey, Eocene reorganization of the Pacific-Farallon spreading center north of the Mendocino fracture zone, J. Geophys. Res., 93, 2813-2838, 1988.

Champion, D. E., G. B. Dalrymple, and M. A. Kuntz, Radiometric and paleomagnetic evidence for the Emperor reversed polarity event at 0.46 \pm 0.05 m.y. in basalt lava flows from the eastem Snake River Plain, Idaho, Geophys. Res. Lett., 8, 1055-1058, 1981.

Clark, J. G., Age, chemistry, and tectonic significance of Easter and Sala y Gomez Islands, M.S. thesis, Oreg. State Univ., Corvallis, 1975.

Clark, J. G., and J. Dymond, Geochronology and petrochemistry of Easter and Sala y Gomez Islands: Implications for the origin of the Sala y Gomez Ridge, J. Volcanol. Geotherm. Res., 2, 29-48, 1977.

Cox, A., and D. Engebretson, Change in motion of Pacific plate at $5 \mathrm{Myr}$ BP, Nature, 313, 472-474, 1985.

Craig, H., K. R. Kim, and J. Francheteau, Active ridge crest mapping on the Juan Fernandez microplate: The use of Seabeam-controlled hydrothermal plume surveys, Eos Trans. AGU, 64, 856, 1983.

Craig, H., K. R. Kim, and W. Rison, Easter Island hotspot, I, Bathymetry, helium isotopes, and hydrothermal methane and helium, Eos Trans. $A G U, 65,1140,1984$.

Creager, K. C., and T. H. Jordan, Aspherical structure of the core-mantle boundary from PKP travel times, Geophys. Res. Lett., 13, 1497-1500, 1986.

DeMets, C., R. G. Gordon, D. F. Argus, and S. Stein, Current plate motions, Geophys. J. Int., 101, 425-478, 1990.

Duffield, W. A., A naturally occurring model of global plate tectonics, $J$. Geophys. Res., 77, 2543-2555, 1972.

Engeln, J. F., and S. Stein, Tectonics of the Easter plate, Earth Planet. Sci. Lett., 68, 259-270, 1984.

Engeln, J. F., S. Stein, J. Wemer, and R. G. Gordon, Microplate and shear zone models for oceanic spreading center reorganizations, J. Geophys. Res., 93, 2839-2856, 1988.

Fontignie, D., B. B. Hanan, and J.-G. Schilling, Easter microplate: $\mathrm{Sr}$ and $\mathrm{Pb}$ isotope variations, Eos Trans. AGU, 67, 410, $1986 a$.

Fontignie, D., B. B. Hanan, and J.-G. Schilling, $\mathrm{Sr}$ and $\mathrm{Pb}$ isotope evolution along the Easter microplate, Terra Cognita, 6, 189, $1986 b$.

Forsyth, D. W., Mechanisms of earthquakes and plate motions in the East Pacific, Earth Planet. Sci. Lett., 17, 189-193, 1972.

Francheteau, J., A. Yelles-Chaouche, and H. Craig, The Juan Fernandez microplate north of the Pacific-Nazca-Antarctic plate junction at $35^{\circ} \mathrm{S}$, Earth Planet. Sci. Lett., 86, 253-268, 1987.

Francheteau, J., P. Patriat, J. Segoufin, R. Armijo, M. Doucoure, A. Yelles-Chaouche, J. Zukin, S. Calmant, D. F. Naar, and R. C. Searle, Pito and Orongo fracture zones: The northern and southem boundaries of the Easter microplate (Southeast Pacific), Earth Planet. Sci. Lett., 89, 363-374, 1988.

Gonzalez Ferran, O., U. G. Cordani, and M. Halpern, Potassium-argon ages and $\mathrm{Sr} 87 / 86$ ratios of volcanic rocks from Easter Island, in Proceedings of the symposium on Andean and Antarctic volcanology problems, Monogr., meeting held September 1974, in Santiago, Chile, edited by $\mathrm{O}$. Gonzalez Ferran, p. 28, Int. Assoc. of Volcanol. and Chem. of the Earth's Inter. (IAVCEI), Rome, Italy, 1976.

Gordon, R. G., C. DeMets, D. F. Argus, and S. Stein, Current plate motions, Eos Trans. AGU, 69, 1416, 1988.

Hagen, R. A., N. A. Baker, D. F. Naar, and R. N. Hey, A SeaMARC II survey of recent submarine volcanism near Easter Island, Mar. Geophys. Res., 12, 297-315, 1990.

Hanan, B. B., and J.-G. Schilling, Easter microplate evolution: Pb isotope evidence, J. Geophys. Res., 94, 7432-7448, 1989.

Handschumacher, D. W., R. H. Pilger, J. A. Foreman, and J. R. Campbell, Structure and evolution of the Easter plate, Mem. Geol. Soc. Am., 154, 63-76, 1981.

Harbert, W., and A. Cox, Late Neogene motion of the Pacific plate, $J$. Geophys. Res., 94, 3052-3064, 1989.

Haxby, W. F., and J. K. Weissel, Evidence for small-scale mantle convection from Seasat altimetry data, J. Geophys. Res., 91, 3507-3520, 1986.

Herron, E. M., Two small crustal plates in the South Pacific near Easter Island, Nature Phys. Sci., 240, 35-37, $1972 a$.

Herron, E. M., Sea-floor spreading and the Cenozoic history of the eastcentral Pacific, Geol. Soc. Am. Bull., 83, 1671-1692, 1972b.

Hey, R. N., A new class of pseudofaults and their bearing on plate tectonics: A propagating rift model, Earth Planet. Sci. Lett., 37, 321-325, 1977

Hey, R. N., and D. F. Naar, Cruise Report, R/V Moana Wave, Leg 8711, Hawaii Institute of Geophysics, University of Hawaii, Honolulu, pp. $1-23,1987$

Hey, R. N., and D. S. Wilson, Propagating rift explanation for the tectonic evolution of the northeast Pacific - The pseudomovie, Earth Planet. Sci. Lett., 58, 167-182, 1982

Hey, R. N., F. K. Duennebier, and W. J. Morgan, Propagating rifts on mid-ocean ridges, J. Geophys. Res., 85, 3647-3658, 1980.

Hey, R. N., D. F. Naar, M. C. Kleinrock, W. J. Phipps Morgan, E. Morales, and J.-G. Schilling, Microplate tectonics along a superfast seafloor spreading system near Easter Island, Nature, 317, 320-325, 1985.

Hey, R. N., M. C. Kleinrock, S. P. Miller, T. M. Atwater, and R. C. Searle, Sea Beam/Deep-Tow investigation of an oceanic propagating rift system, J. Geophys. Res., 91, 3369-3393, 1986.

Hey, R. N., A. Klaus, W. Icay, and D. F. Naar, SeaMARC II survey of the propagating limb of a large non-transform offset along the fastest spreading EPR segment, Eos Trans. AGU, 69, 1429, 1988.

Heyerdahl, T., E. N. Feindon, W. Mulloy, A. Skjolsvold, and C. S. Smith, Reports of the Norwegian archaeological expedition to Easter Island and the East Pacific, vol. 1, Archaeology of Easter Island, Monogr. 24, pp. 537-546, School of American Research and the Museum of New Mexico, edited by T. Heyerdahl and E. N. Feindon, Forum Pub. House, Stockholm, Sweden, (U.S. distributors: Rand McNally, Chicago), 1961.

Hilde, T. W. C., S. Uyeda, and L. Kroenke, Evolution of the western Pacific and its margin, Tectonophys., 38, 145-165, 1977.

Hussong, D. M., and P. Fryer, Back-arc seamounts and the SeaMARC II seafloor mapping system, Eos Trans. AGU, 64, 627-632, 1983.

Johnson, H. P., J. L. Karsten, J. R. Delaney, E. E. Davis, R. G. Currie, and R. L. Chase, A detailed study of the Cobb offset of the Juan de Fuca Ridge: Evolution of a propagating rift, J. Geophys. Res., 88, $2297-2315,1983$

Kaneoka, I., and Y. Katsui, K-Ar ages of volcanic rocks from Easter Island, Bull. Volcanol. Soc. Jpn., 30(1), 33-36, 1985.

Kent, D. V., and F. M. Gradstein, A Jurassic to recent chronology, in The Geology of North America, vol. M, The Western North Atlantic Region, edited by P. R. Vogt and B. E. Tucholke, pp. 45-50, Geological Society of America, Boulder, Colo., 1986.

Klaus, A., W. Icay, D. F. Naar, and R. N. Hey, SeaMARC II survey of a propagating limb of a large non-transform offset along the fastest spreading East Pacific Rise segment, J. Geophys. Res., in press, 1991.

Kleinrock, M. C., Detailed structural studies of the propagator system near $95.5^{\circ} \mathrm{W}$ along the Galapagos spreading axis, Ph.D. thesis, Univ. of Calif., San Diego, 1988.

Kleinrock, M. C., and R. N. Hey, Detailed tectonics near the tip of the Galapagos $95.5^{\circ} \mathrm{W}$ propagator: How the lithosphere tears and a spreading axis develops, J. Geophys. Res., 94, 13,801-13,838, 1989 a.

Kleinrock, M. C., and R. N. Hey, Migrating transform zone and lithospheric transfer at the Galapagos $95.5^{\circ} \mathrm{W}$ propagator, J. Geophys. Res., $94,13,859-13,878,1989 b$. 
Kleinrock, M. C., R. C. Searle, and R. N. Hey, Tectonics of the failing spreading system associated with the $95.5^{\circ} \mathrm{W}$ Galapagos propagator, $J$. Geophys. Res., 94, 13,839-13,857, 1989.

Klitgord, K. D., and J. Mammerickx, Northern East Pacific Rise: Magnetic anomaly and bathymetric framework, J. Geophys. Res., 87, $6725-6750,1982$.

LaBrecque, J. C., and D. E. Hayes, Seafloor spreading history of the Agulhas Basin, Earth Planet. Sci. Lett., 45, 411-428, 1979.

Lonsdale, P. F., Structural pattern of the Galapagos microplate and evolution of the Galapagos triple junctions, J. Geophys. Res., 93 , $13,551-13,574,1988$

Macdonald, K. C., J.-C. Sempere, and P. J. Fox, East Pacific Rise from Siqueiros to Orozco fracture zones: Along strike continuity of axial neovolcanic zone and structure and evolution of overlapping spreading centers, J. Geophys. Res., 89, 6049-6069, 1984.

Macdonald, K. C., J.-C. Sempere, P. J. Fox, and R. Tyce, Tectonic evolution of ridge-axis discontinuities by the meeting, linking, or selfdecapitation of neighboring ridge segments, Geology, 15, 993-997, 1987.

Macdonald, K. C., R. M. Haymon, S. P. Miller, J.-C. Sempere, and P. J. Fox, Deep-Tow and Sea Beam studies of dueling propagating ridges on the East Pacific Rise near 20 40 'S, J. Geophys. Res., 93, 2875-2898, 1988.

Macdougall, J. D., and M. O. Tanzer, Easter Island hotspot, II, Isotopic and chemical evidence of its influence on EPR basalts, Eos Trans. AGU, $65,1140,1984$

Madsen, J. A., P. J. Fox, and K. C. Macdonald, Morphotectonic fabric of the Orozco transform fault: Results from a Sea Beam investigation, $J$. Geophys. Res., 91, 3439-3454, 1986.

Mammerickx, J., and D. Sandwell, Rifting of old oceanic lithosphere, $J$. Geophys. Res., 91, 1975-1988, 1986.

Mammerickx, J., and G. F. Sharman, Tectonic evolution of the north Pacific during the Cretaceous quiet period, J. Geophys. Res., 93, 3009-3024, 1988.

Mammerickx, J., E. Herron, and L. Dorman, Evidence for two fossil spreading ridges in the southeast Pacific, Geol. Soc. Am. Bull., 91 , 263-271, 1980 .

Mammerickx, J., D. F. Naar, and R. L. Tyce, The Mathematician paleoplate, J. Geophys. Res., 93, 3025-3040, 1988.

Marchig, V., H. Gundlach, and Ship Board Scientific Party, Results of cruise Geometep 4, Circ. 4, pp. 3-22, Bundesantstalt fur Geowissenschaften und Rohstoffe, Hannover, Germany, 1987.

Martinez, F., D. F. Naar, T. B. Reed, and R. N. Hey, Isostasy of the Pito Deep area: The terminus of a large-offset propagating rift of the Easter microplate, Eos Trans. AGU, 70, 1318, 1989.

McKenzie, D. P., The geometry of propagating rifts, Earth Planet. Sci. Lett., 77, 176-186, 1986.

Means, W. D., Stress and Strain: Basic Concepts of Continuum Mechanics for Geologists, 339 pp., Springer-Verlag, New York, 1976.

Menard, H. W., Sea-floor spreading, topography, and the second layer, Science, 157, 923-924, 1967.

Minster, J. B., and T. H. Jordan, Present-day plate motions, J. Geophys. Res., 83, 5331-5354, 1978.

Mutter, J. C., W. R. Buck, and C. M. Zehnder, Convective partial melting, 1 , a model for the formation of thick basaltic sequences during the initiation of spreading, J. Geophys. Res., 93, 1031-1048, 1988.

Naar, D. F., and R. N. Hey, Fast rift propagation along the East Pacific Rise near Easter Island, J. Geophys. Res., 91, 3425-3438, 1986.

Naar, D. F., and R. N. Hey, Speed limit for oceanic transform faults, Geology, 17, 420-422, 1989a.

Naar, D. F., and R. N. Hey, Recent Pacific-Easter-Nazca plate motions, in Evolution of Mid Ocean Ridges, Geophys. Monogr. Ser., vol. 57, edited by J. M. Sinton, pp. 9-30, AGU, Washington, D.C., $1989 b$.

Naar, D. F., M. C. Kleinrock, R. N. Hey, D. W. Caress, K. Raeder, and D. Sandwell, Hot wax seafloor spreading experiments on video, Eos Trans. $A G U, 67,1228,1986$.

Oldenburg, D. W., and J. N. Brune, Ridge transform fault spreading pattern in freezing wax, Science, 178, 301-304, 1972

Oldenburg, D. W., and J. N. Brune, An explanation for the orthogonality of ocean ridges and transform faults, J. Geophys. Res., 80, 2575-2585, 1975.

Phipps Morgan, J. W., and E. M. Parmentier, Causes and rate-limiting mechanisms of ridge propagation: A fracture mechanics model, $J$ Geophys. Res., 90, 8603-8612, 1985.

Pollard, D. D., and A. Aydin, Propagation and linkage of oceanic ridge segments, J. Geophys. Res., 89, 10,017-10,028, 1984.
Pollard, D. D., P. Segall, and P. T. Delany, Formation and interpretation of dilatant en echelon cracks, Geol. Soc. Am. Bull., 93, 1291-1303, 1982.

Pollitz, F. F., Pliocene change in Pacific-plate motion, Nature, 320, 738-741, 1986.

Poreda, R. J., H. Craig, B. B. Hanan, and J.-G. Schilling, Helium isotope ratios in Easter microplate basalts, Eos Trans. AGU, 69, 1473, 1988.

Purdy, G. M., The eastern end of the Azores-Gibraltar plate boundary, Geophys. J. R. Astron: Soc., 43, 973-1000, 1975.

Rea, D. K., Asymmetric sea-floor spreading and a non-transform axis offset: The East Pacific Rise $20^{\circ}$ S survey area, Geol. Soc. Am. Bull., 89, 836-844, 1978.

Rea, D. K., Tectonics of the Nazca-Pacific divergent plate boundary, Mem. Geol. Soc. Am., 154, 27-62, 1981.

Rea, D. K., and R. J. Blakely, Short-wavelength magnetic anomalies in a region of rapid seafloor spreading, Nature, 255, 126-128, 1975.

Rea, D. K., and J. M. Dixon, Late Cretaceous and Paleogene tectonic evolution of the North Pacific Ocean, Earth Planet. Sci. Lett., 65, 145-166, 1983.

Rusby, R. I., R. C. Searle, J. Engeln, R. N. Hey, D. Naar, and J. Zukin, GLORIA and other surveys of the Easter and Juan Fernandez microplates, Eos Trans. AGU. 69, 1428, 1988.

Ryan, W. B. F., Stratigraphy of late Quatemary sediments in the eastem Mediterranean, in The Mediterranean Sea: A Natural Sedimentation Laboratory, edited by D. J. Stanley, Dowden, Hutchinson and Ross, Stroudsburg, Pa., 1972.

Sager, W. W., D. W. Handschumacher, T. W. C. Hilde, and D. R. Bracey, Evidence from magnetic lineations of a late Jurassic microplate between the Pacific, Farallon, and Izanagi plates, Eos Trans. AGU, 68, 1476, 1988.

Schilling, J.-G., H. Sigurdsson, A. N. Davis, and R. N. Hey, Easter microplate evolution, Nature, 317, 325-331, 1985.

Schouten, H., K. D. Klitgord, and D. G. Gallo, Microplate kinematics of the second order, Eos Trans. AGU, 69, 488, 1988.

Searle, R. C., R. I. Rusby, J. Engeln, R. N. Hey, J. Zukin, P. M. Hunter, T. P. LeBas, H.-J. Hoffman, and R. Livermore, Comprehensive sonar imaging of the Easter microplate, Nature. 341, 701-705, 1989.

Sempere, J.-C., J. Gee, D. F. Naar, and R. N. Hey, Three-dimensional inversion of the magnetic field over the Easter-Nazca propagating rift near $25^{\circ}$ S, $112^{\circ} 25^{\prime} \mathrm{W}, J$. Geophys. Res., 94, 17,409-17,420, 1989.

Shoberg, T., S. Stein, and J. Karsten, Constraints on rift propagation history of the Cobb offset, Juan de Fuca Ridge, from numerical modeling of tectonic fabric, Tectonophys., in press, 1991.

Strong, R., and J. F. Engein, The Eureka plate: An alternative hypothesis for the Western Cordillera, Eos Trans. AGU, 67, 1199, 1986.

Tamaki, K., and R. L. Larson, The Mesozoic tectonic history of the Magellan microplate in the westem central Pacific, J. Geophys. Res., 93, 2857-2874, 1988.

Taylor, B., R. Mallonee, K. Crook, and J. Sinton, The Manus microplate, Eos Trans. AGU, 68, 1476, 1987.

Walker, D. A., Seismicity of the East Pacific Rise: Correlations with the Southem Oscillation Index?, Eos Trans. AGU, 69, 857-867, 1988.

Weissel, J. K., and R. N. Anderson, Is there a Caroline plate?, Earth Planet. Sci. Lett., 41, 143-158, 1978.

White, W. M., A. W. Hofmann, and H. Puchelt, Isotope geochemistry of Pacific mid-ocean ridge basalts, J. Geophys. Res., 92, 4881-4893, 1987.

Wilson, D. S., Tectonic history of the Juan de Fuca ridge over the last $\mathbf{4 0}$ million years, J. Geophys. Res., 93, 11,863-11,876, 1988.

Wilson, D. S., and R. N. Hey, The Galapagos axial magnetic anomaly: Evidence for the Emperor event within the Brunhes and for a two-layer magnetic source, Geophys. Res. Lett., 8, 1051-1054, 1981.

Woodhouse, J. H., and A. M. Dziewonski, Mapping the upper mantle: Three-dimensional modeling of Earth structure by inversion of seismic waveforms, J. Geophys. Res., 89, 5953-5986, 1984.

Zukin, J., and J. Francheteau, A tectonic test of instantaneous kinematics of the Easter microplate, Oceanologica Acta, vol. spec. 10, 183-198, 1990.

R. N. Hey, School of Ocean and Earth Science and Technology, University of Hawaii, 2525 Correa Road, Honolulu, HI 96822.

D. F. Naar, Department of Marine Science, University of South Florida, 140 Seventh Avenue South, St. Petersburg, FL 33701.

(Received January 8, 1990; revised October 24, 1990; accepted October 30, 1990.) 